
QK21

. $\mathrm{F} 7$

L415

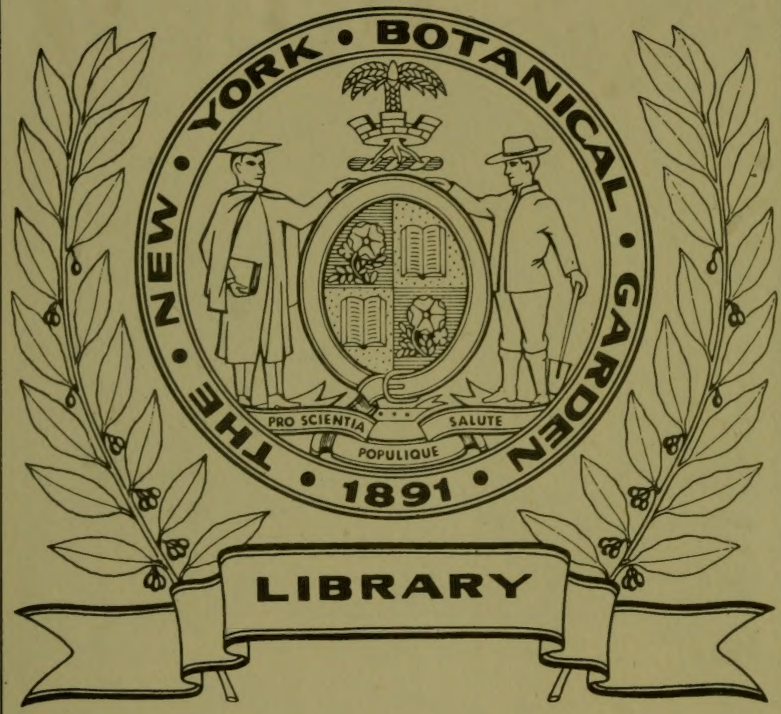






\section{LUDOVIC LEGRE}

LA BOTANIQUE EN PROVENCE AU XVI ${ }^{e}$ SIÈCLE

Aloyo LOUIS ANGUILLARA

\section{PIERRE BELON}

\section{GHARLES DE L'ESGLUSE}

\section{ANTOINE CONSTANTIN}

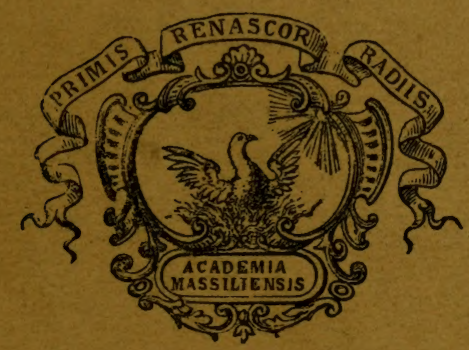

\section{MARSEILLE}

H. AUBERTIN \& G. ROLLE

$$
\text { LIBRAIRES - ÉDITEURS }
$$

Rue Paradis, 34, et rue de la Darse, $41-43$ 

tedi.

otus a

hommag anmen ther antaur Ludovie Leqré 



\section{LA BOTANIQUE EN PROVENCE}

AU $\mathrm{XVI}^{\circ}$ SIÈGLE 



\section{LUDOVIC LEGRÉ}

LA BOTANIQUE EN PROVENCE AU XVIe SIÈCLE

\section{LOUIS ANGUILLARA}

\section{PIERRE BELON}

\section{GHARLES DE L'ESGLUSE}

\section{ANTOINE CONSTANTIN}

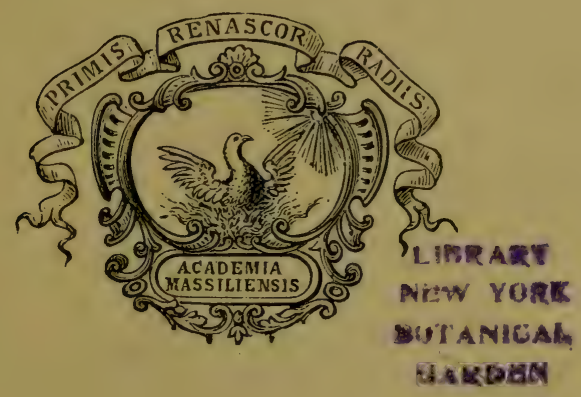

MARSEILLE

H. AUBERTIN \& G. ROLLE LIBRAIRES - ÉDITEURS

Rue Paradis, 34, et rue de la Darse, 41-43 


$$
\begin{aligned}
& Q K 21 \\
& . F 7 \\
& L 415
\end{aligned}
$$




\section{LOUIS ANGUILLARA}





\section{LOUIS ANGUILLARA}

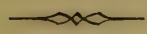

En un siècle où la Botanique, alors dans toute l'exubérance de sa jeune vitalité, prenait le plus large essor, - et tandis que la plupart des phytographes, pour enregistrer et commenter leurs découvertes, ne procédaient que par d'épais in-folio qu'ils agrémentaient de nombreuses plantes gravées sur bois, - le botaniste italien dont nous allons étudier les rapports avec la Provence se contenta de léguer à la postérité un mince vólume de format petit inoctavo, orné seulement de deux modestes figures (1).

Cet opuscule, qui ne semblait pas avoir été écrit en vue de l'impression, et qui fut livré à la publicité non point par l'auteur, mais par un ami de celui-ci, a suffi néanmoins pour assurer à Louis Anguillara une place glorieuse dans le panthéon des rénovateurs de la Res herbaria au xvi ${ }^{\mathrm{e}}$ siècle.

Les origines de ce botanographe illustre sont demeurées obscures. Nous ne savons même pas com-

(1) Ce volume, dont les plats ont quinze centimètres et demi de haut et dix centimètres de large, contient 304 pages de texte et un index non paginé remplissant 16 feuillets. Nous dommerons plus loin les autres indications bibliographiques. 
ment il se nommait. Car Anguillara n'était point son nom. C'était celui d'une bourgade des États de l'Église (1) où il naquit à une date inconnue, probablement vers les premières années du siècle (2).

On n'a guère, pour reconstituer l'histoire de sa vie, que les renseignements qu'il consigna, d'une façon incidente et discrète, dans le livre dont nous venons de parler.

Ce qui, - en quelque sorte à première rue, ressort avec éclat de cet ouvrage, c'est le haut degré de science et d'autorité auquel avait atteint Louis Anguillara, d'abord par une étude approfondie du texte des auteurs anciens, et ensuite par une série d'herborisations persévérantes qui le conduisirent dans toutes les provinces de l'Italie, des Alpes à la Calabre, et lui firent parcourir une raste étendue de pays étrangers.

Presque tous les biographes d'Anguillara ont loué sa modestie. On ne peut, effectivement, méconnaître chez lui cette aimable vertu, quand on a lu le récit de ses herborisations (3). Il se met en scène le moins possible. Il tient que le moi est haïssable : aussi n'emploie-t-il que bien rarement la première personne du singulier. Au lieu de dire qu'il a trouvé telle plante en Grèce ou en Syrie, il préfère cette formule : "On trouve en Morée..., on voit à Alep... )

(1) " Anguillara, bourg de la province, circondario, et à 30 kil. N.-O. de Rome (anciens Etats de l'Eglise, Italie centrale) sur le bord méridional du lac de Bracciano, au point où l'Arrone, affluent de la Méditerranée, s'en écoule. 880 habitants. On y voit des restes de monuments romains. "Vivien de SAIntMartis, Nouveau Dictionnaire de Géographie universelle).

(2) Tiraboschi, Storia della letteratura italiana (édition de Florence, 1810 , tome VII, $2^{\circ}$ partie).

(3) En dédiant un de ses Parères « al molto magnifico signor Pietro-Antonio Nichiele », Anguillara lui disait : " En quelle manière puis-je, moi, pauvre Rhizotome, si petit à côté des autres, espérer qu'aucun de mes Parères puisse être jugé bon par votre haute science?'D 
Nous sommes forcé de regretter qu'il se soit ainsi attaché à effacer sa personnalité. Nous aurions été heureux de rencontrer dans ses écrits un plus grand nombre de détails personnels qui eussent permis à la biographie de dresser avec certitude la liste de toutes les localités qu'il visita en dehors de l'Italie continentale.

Mais il est hors de doute qu'Anguillara entreprit de longues et pénibles pérégrinations. En écrivant, le 25 octobre 1560, à un médecin de Venise, Messer Nicolò da San Michiele Comasco, il parlait du très grand désir, qu'il avait toujours éprouvé, de se rendre utile autant qu'il dépendait de lui, et il ajoutait: “ C'est ce désir qui m'a induit maintes fois à entre" prendre de lointains et périlleux voyages où je " mettais ma vie au pouvoir des 'Turcs et autres bar" bares, sans avoir jamais, pour cela, reçu ni mème " espéré aucune récompense; j'y ai, au contraire, " très largement dépensé mon bien. ")

Nous avons pris une comnaissance minutieuse des écrits d'Anguillara, et d'après les détails qu'il y a donnés, voici quels sont, à notre avis, les itinéraires que dut suivre le voyageur.

En herborisant dans le nord de l'Italie, il franchit les Alpes et s'avança en Suisse, dans le canton des Grisons, jusqu'à Coire.

Puis, lorsqu'il prit la mer, il visita l'Istrie, la Dalmatie (Zara, Sebenico et quelques-unes des iles de l'Archipel illyrien, entre autres Lesina), l'Albanie, les grandes îles Ioniennes, Corfou, Céphalonie et Zante, la Morée, plusieurs des Cyclades et des Sporades, l'ile de Chio. Nous croyons qu'il poussa jusqu'à Constantinople (1). Il vit les îles de Chypre

(1) La ville de Constantinople est nommée deux fois dans le livre d'Anguillara. Il dit du Reupontico : "A Constantinople, on en voit moins qu'en d'autres lieux "; et de la Réglisse : ( On la trouve sur le chemin de Constantinople, vers la 
et de Crète (1), où il parait aroir fait un séjour d'une certaine durée. Il aborda en Syrie, où il a nommé Alep et Damas. Il relâcha très probablement à Alexandrie d'Égypte. De là, faisant voile vers l'ouest, il s'arrêta en Sicile, en Sardaigne, en Corse, et finalement il gagna le port de Marseille où il mit pied à terre et d'où il partit pour aller explorer une partic de la Provence.

Ces longs et difficiles voyages qui, chez Anguillara, n'avaient pas eu d'autre mobile que l'ambition de s'instruire (2), lui procurèrent, quand il fut de retour en Italie, une grande renommée.

Aussi, la République de Venise s'empressa-t-elle de lui confier, en 1546, la direction du Jardin botanique de Padoue, dont un décret du Sénat, rendu le 30 juin de l'année précédente, avait décidé la création. Le titre officiel que lui conférait l'acte de nomination était celui de Gran Semplicista dell' Illustrissima Signoria di Vinegia nel studio di Padova (3).

Thrace \%. Il nous semble que cette double affirmation de faits précis procède d'une constatation de visu. Et, du reste, sa présence, en beaucoup d'autres endroits, est certifiée uniquement par de menus détails que, seul, peut avoir rapportés un témoin oculaire.

(1) En Crète, Anguillara s'était lié avec un speziale (pharmacien) originaire de Rhodes, qu'il appelle Constantino Rhodioto et dont il paraît avoir fait le plus grand cas. Il le proclame ( son ami très cher, très célèbre en l'art pharmaceutique, nella sua (urte molto celebre et mio carissimo amico ». Comme en un autre passage il lui donne le nom de maestio, on s'est demandé s'il ne s'était pas constitué l'élève du savant speziale. Que ce fût en qualité d'ami ou à titre d'élève, il avait certainement essayé, pendant son séjour à Candie, de mettre à profit le savoir et l'expérience de Constantin le Rhodiote.

(2) Dans une lettre adressée à un de ceux qui lui avaient écrit pour le consulter, il disait : "J'ai fait de nombreux voyages étant seul, et j'en ai obtenu profit et consolation non petite $\gg$.

(3) Gaspard Bauhin, en inscrivant sur une liste d'auteurs qu'il a insérée en tête du Pinax le nom de Louis Anguillara, Iui 
Le goùt de la botanique était, en ce temps-là, fort répandu dans toute l'Italie. Non seulement les médecins et les speziali étudiaient, recherchaient et cultivaient les plantes, sur lesquelles l'art de guérir fondait alors de si belles espérances, mais il y arait aussi, parmi l'aristocratie et jusque dans le haut clergé, des botanophiles passionnés qui herborisaient avec zèle et livraient leurs jardins à la culture des simples. Au nombre des compagnons qui le suivirent dans ses herborisations d'Italie, Anguillara cite,- outre Cesare Odoni, « médecin et philosophe », professeur à l'université de Bologne(1), et l'Allemand Jean Prinster, médecin à Nuremberg, - l'évêque de Cesena, Monsignor Reverendo Vescovo di Cesena, qu’il

donne le titre de troisième directeur du Jardin de Padoue, " horti Patavini tertius in ordine prefectus ". Le prédécesseur d'Anguillara à Padoue, au dire du même G. Bauhin, aurait été Louis Nundella, auteur d'un recueil de lettres De natura Stirpium au sujet desquelles Tournefort a dit dans l'Isagoge de ses Instituliones: "Aloysius Mundella scripsit Epistolas de Stirpium natura eximias quidem et elegantes, sed ad rem Herbariam parum conducentes ". - Mais Tiraboschi, - qui affirme avoir eu communication des documents officiels a ce relatifs. - déclare formellement que la fondation du jardin botanique de Padoue avait été décrétée par le Sénat de Venise à la date indiquée plus haut, et que la charge de l'organiser et de l'administrer fut, dès le principe, attribucée, avec d'honorables appointements, à Louis Anguillara : a Il Senato veneto a' 30 di giugno del 1545 saggiamente ordinó che a pubbliche spese si formasse un orto botanico. Questa è la vera epoca del principio dell'orto de' simplici in Padova... Alla formazione e alla custodia di esso, fu chiamato con onorevole stipendio nel 1546 l'Anguillara, il qual n'ebbe la cura fino al $1561 \%$. (Tiraboschi, Storia della letteratura italiana).

(1) César Odon publia, en 1561, à Bologne, un volume intitulé Theophrasti sparse de plantis sententice in continuam seriem ad propria capita nominaque secundum literarum ordinem disposila. (Seguier, Bibl. bot.) - Il fut en rapport avec les autcurs du Stirpium Adversaria, où son nom est mentionné. - Le titre qu'Anguillara donnait à César Odon était celui de Lettore clignissimo di praticea nello studio di Bologna. 
nomme plusieurs fois ; puis deux gentilshommes, l'un Pisan, Odoardo Gualandi, et Fabricio Candiano, de Milan.

La haute autorité que Louis Anguillara devait à ses études, à ses recherches, à ses royages, à son titre de " grand Simpliciste de la Seigneurie de Venise " était cause que de tous còtés ces professeurs, ces médecins, ces grands seigneurs pris d'un beau zèle pour la botanique avaient l'idée de recourir à lui et de le consulter au sujet des espèces critiqucs. Pour les botanistes de cette époque, l'importante question était de pouvoir reconnaitre, parmi les plantes qui s'épanouissaient sous leurs yeux, celles qu'avait prônées l'antiquité médicale.

Louis Anguillara, arec cette bonhomie qui était un des traits de sa nature, déférait volontiers aux désirs de ses correspondants : il leur fournissait sur les cas difficiles des avis que sa grande expérience rendait infiniment précieux. Il donnait à ces réponses le nom de parere, "avis, opinion, consultation » (1).

Un de ces consultants, il magnifico et eccellente Messer Giovanni Marinello, conçut le projet de réunir au parère dont il avait été lui-même gratifié ceux que d'autres correspondants avaient reçus (2), et

(1) Le mot français parère serait l'exacte traduction de litalien parere, si en français cette expression n'avait pas un sens plus restreint qu'en italien. Chez nous le mot parère n'est guère usité que dans la langue des affaires. "PARìne, dit Littré. sentiment, avis de négociants sur des questions de commerce. "Ces avis de négociants sont le plus souvent rédigés, pour être produits, sous forme dattestation, devant la juridiction compétente, quand il s'agit, par exemple, d'établir l'existence d'un usage commercial actuellement en vigueur.

(2) Tous les Parères d'Anguillara furent adressés à des personnages italiens, à l'exception du premier, qui eut pour destinataire un Français, Ludovic Demoulins de Rochefort, " médecin de Madame Marguerite de France, duchesse de Berry, sœur unique du Roi Très Chrétien Henri II ». La lettre de Ludovic Demoulins, à laquelle Anguillara répondit de 
de les publier en un volume. Il demanda et obtint l'autorisation d'Anguillara, et ce recueil fut imprimé à Venise, en 1561, par Vincenzo Valgrisi (1). Il parut sous le titre de Semplicr DELL' ECCELlente M. Luigi Axgulllara, liquali in piu Pareri à diversi nobili huomini scritti appaiono, et nuovamente da M. Giovanni Marinello mandati in luce (2).

Padoue le 10 avril 1558, lui avait été écrite de Marseille. Le médecin de la duchesse de Berry se disposait à faire un voyage dans le Levant, et il aurait bien voulu décider le botaniste de Padoue à l'y accompagner. Niais celui-ci, pour s'en dispenser, allègue dans sa réponse qu'il est retenu par la charge que lui a confiée le Sénat de Venise et quelques affaires particulières, " le cure publiche del giardino, e qualch" altro mio negocio privato, che mal mio grado mi ritengono."

(1) Seguier (Bibliotheca botanica) a prétendu que Valgrisi aurait successivement imprimé, en 1561. deux éditions du livre d'Anguillara : la première du format in- $t^{\circ}$ et dépourvue des deux gravures qui se trouvent dans l'édition in-8॰ (Seguier dit in-12). - Pritzel (Thesaurus literature botanic(e) n'a pas mentionné cette prétendue première édition. - Tournefort (Inst., Isagoge) invocuant une énonciation de Schenck, en sa Bibliothéque iatrique, a signalé l'existence d'une traduction latine du recueil des Parères faite par Gaspard Bauhin ; laquelle, d'après Seguier, aurait été imprimée à Bâle en 1593. L'article AxgunLara de la Biographie universelle (signé par Dupetit-Thouars) affirme, après recherches, que si cette traduction a été faite, elle n'a jamais été imprimée. Cependant Pritzel donne, à ce sujet, les indications suivantes : "Latinè, cum notis Casparis Bauhini, Basileæ ap. Henric. Petrum. 1593. 8. Liber perrarus exstat in Bibl. regia Berolinensi, in bibl. civ. Hamburgensis, in Marciana Yeneta, in Horto Patavino, nec non in Palatina Vindobonensi, ubi Tournefortii exemplum servatur. »

(2) Au risque d'offenser, par un jugement téméraire, la mémoire de Jean Marinello, nous croyons qu'en se faisant l'éditeur de ce recueil il obéissait à un sentiment de vanité personnelle. Il était riche, comme le démontre, - en même temps que son offre de payer l'impression du livre, - l'épithète de magnifico que lui avait appliquée Anguillara. Mais il n'était pas noble puisqu'on lui donnait seulement le titre de .resser et non point celui de Signor réservé à des gentilliommes, tels que Contarini ou Loredano, figurant en majorité 
Ce livre, devenu aux yeux de la postérité le titre de gloire d'Anguillara, lui suscita tout d'abord de vifs désagréments.

Au cours de ses consultations, Anguillara fut plus d'une fois amené à contredire des affirmations formulées par Matthiole en ses Commentaires sur Dioscoride. Il le faisait toujours avec une irréprochable courtoisie et de façon à ménager les susceptibilités du botaniste de Sienne. D'ailleurs, dans ses Parères, il le louait encore plus souvent qu'il ne le critiquait, et jamais il ne le citait sans l'appeler " l'eccellentissimo e dottissimo Messer Pietro-Andrea Matthioli."

Mais on rencontre quelquefois des botanistes devenus irritables autant que peuvent l'être les poètes. Quand on leur démontre qu'en tel endroit ils ont commis une erreur, leur orgueil se cabre, et dans leurs colères il ne gardent plus aucune mesure.

Ainsi fit le commentateur de Dioscoride. Il conçut pour Anguillara une violente inimitié. Il rechercha toutes les occasions de lui nuire. Il parvint même à faire partager sa haine par Aldrovande.

Tiraboschi a cité divers passages des lettres que Matthiole écrivit à ce dernier, et dans lesquelles, aveuglé par sa fureur, il ne craignit pas de descendre jusqu'aux pires injures.

parmi les clients auxquels l'auteur des Parères avait répondı. Cette dernière circonstance permettait à Marinello d'indiquer sur le frontispice du volume que les Parères étaient adressés à des nobles, à diversi nobili huomini scritti; et de cette façon il trouvait le moyen de s'affilier à la noblesse, et de laisser croire qu'il était gentilhomme, lui aussi. - Nous supposons que c'est le même Jean Marinello qui composa un traité relatif à la toilette des dames, intitulé : Gli ornamenti delle donne scritti per Giovanni Marinello et divisi in qualtro libri, imprimé à Venise chez Valgrisi en 1562 , et traduit en français par S. Liebault (Paris, 1582). 
"J'ai lu avec le plus grand plaisir, disail-il, ce " que vous m'écrivez au sujet de ce làche fripon de "Louis Anguillara ; je suis charmé que vous l'ayez (" recomnu tout d'abord pour très ignorant, puis pour " très méchant et très envieux (1). "

L'historien ilalien a supposé que ees inexcusables attaques portient une grave atteinte à la réputation d'Anguillara. Allèrent elles jusqu’à influencer le gouvernement de Yenise? Toujour's est-il que le directeur du jardin de Padoue fut en butte à des tracasseries administratives. Son traitement fut suspendu, et quatre esattori (2) eurent mission de vérifier, si, sous son autorilé, les intérêts du jardin n'avaient pas eu à souffrir.

Le résultat de l'enquète ful entièrement favorable a notre botaniste (3). Mais tous ces emuis finirent par le décourager. Brusquement, en 1561, il se démit de ses fonclions, et partit aussitòt pour Ferrare.

On a prélendu que, reliré dans celle ville, il résolut d'y enseigner publiquement la médecine. Nais ce fail est contesté par Tiraboschi. En réalité Anguillara oceupa ses loisirs et mil toule son application à composer de la thériaque, aidé par un moine augustin, Frate Evangelista Quadramio. que

(1) «Con grandissimo piacere veramente ho poi letto tutto a quello che mi serivete di quel vigliace mariolo d'Aluigsi An" guillara, e molto me piace che lo abbiate conosciuto prima "per ignorantissimo, e poi per malignissimo et invidiosissimo." - Dans une autre lettre Matthiole, jouant sur le nom d'Anguillara, l'appelle scortica anguilla, anguille écorchée.

(2) Littéralement " percepteur's », mais ici il conviendrait de traduire par " inspecteurs des finances ».

(3) Tiraboschi nous apprend, d'aprés Faccioli Fasti Gymnnusii Palavini), que l'Université de Padoue prit parti pour Anguillara et fit justice des calomnies dont il était victime : "nella qual occasione peró l'Universita stessa rendette all Anguillara onorevole testimonianza, e ribattè le calunnic appostegli. , 
protégeait le duc de Ferrare (1). D'un voyage dans la Pouille, entrepris en compagnie du religieux pour aller y cueillir des simples, Anguillara rapporta une fièvre pestilentielle dont il ne put se guérir (2): il s'éteignit à Ferrare au mois d'octobre 1570.

$\mathrm{Si}$, pendant cette retraite de dix années, il n'enseigna point, comme professeur attitré, la médecine et la botanique, du moins continua-t-il à ètre recherché et consulté par des étudiants ou des botanistes, désireux de s'instruire en recourant à ses lumières et à son expérience:

Cette circonstance nous est révélée dans le grand ouvrage que publièrent en 1571 Pierre Pena et Mathias de Lobel, le Stirpium Adversaria.

Des relations familières et suivies s'établirent entre Anguillara et les deux signataires de ce livre célèbre, ou tout au moins celui des deux qui en fut le principal rédacteur, - le Provençal Pierre Pena (3).

Pena qui, en 1561, était déjà arrivé en Italie, y demeura jusqu'en 1565 , où il alla continuer ses études à Montpellier.

Nous derons admettre qu'entre ces deux dates il vint plusieurs fois à Ferrare, ou qu'il y prolongea son séjour, car il eut avec Anguillara de fréquents entretiens.

(1) Haller ,Bibl. bot.) indique que le frère Evangelista Quadramio fit paraitre à Ferrare, en 1597 , un traité ayant pour titre: Degli ingredienti della theriaca e mithridatio.

(2) Tiraboschi ajoute que cette "febre pestilenziale " lui avait été occasionnée " per molti suoi disordini ».

(3) Voir à ce sujet ce que nous avons exposé dans l'ouvrage qui a pour titre : La Bolanique en Provence all XrIe siecle ; Picrre Pena el Mathias de Lobel (Marseille, 1899). - Mathias de Lobel était certainement venu étudier en Italie. Dans le Stirpium Observationes, œuvre qui lui est propre, il cite divers personnages italiens avec lesquels il avait été en rapport. Mais il n’a pas nommé Anguillara, ce qui fait supposer qu'il n'était pas allé à Ferrare. 
L'illustre botaniste est cité quinze fois dans le Stirpium Adversaria et presque toujours avec des épithètes amicales et flatteuses qui montrent combien l'étudiant provençal avait conçu pour lui d'atlachement et d'estime : " doctissimus, sedulus, materia medica callentissimus, non vulgaris amicus " (1). Deux fois le superlatif modestissimus vient témoigner de cette modestie qui avait été chez Anguillara une vertu si manifeste, et l'adjectif candidus exprimait, pensons-nous, l'aimable franchise avec laquelle le vétéran consulté répondait à ses jeunes interlocuteurs.

Ceux-ci mettaient parfois à l'interroger une certaine insistance : " negabat Anguillara, nobis anxie sciscitantibus ") ; mais ses réponses étaient toujours affables : " cùm multa alia doctè et amicè nos moneret ", ajoute le texte. C'était à propos d'un " Tragium " qu’il avait rencontré jadis dans les collines de Pise ; et comme Pierre Pena montrait un vif désir de connaitre la station de cette plante, Anguillara eut l'obligeance d'écrire à un pharmacien de Lucques pour le prier d'y conduire son jeune ami (2).

On sait que Matthiole est fort maltraité dans l'ouvrage auquel Pena et Lobel ont attaché leur nom. Le rédacteur du Stirpitum Adversaria ne laisse échapper aucune occasion de lui reprocher ses bévues, de le tourner en ridicule, de témoigner à son égard une animosité, une aversion des plus ardentes. Il

(1) Dans son Rariorum aliquot stirpium per Hispanias observalarum, Charles de lEscluse fait plusieurs fois mention d'Anguillara, en lui appliquant les qualificatifs de peritissimus et diligentissimus.

(2) Mais ils ne retrouvèrent pas le Tragium ; "Nobis literas dedit [Anguillara] ad quendam perbonum et industrium Lucensem pharmacoprum : qui tamen plantam neque ipse potuit, neque quisquam alius, illic quo loco esset, indicare. " (Stirp. Adv. p. 360.) 
est permis de supposer que ces colères furent suscitées ou avivées par le souvenir des invectives grossières dont le Commentaleur (1) avait si injustement accablé le doux Anguillara.

Dans les quatorzes Parères dont se compose le recueil édité par Jean Marinello, Anguillara a étudié environ quinze cents espèces. Ce livre demeure, pour l'histoire tant de la fiore italienne que de celle du Levant, un document du plus haut intérêt.

Quand Anguillara parcourut la Provence, il y revit beaucoup de plantes (qu'il avait déjà rencontrées en Italie et dans les autres pays où il s'était transporté.

Aussi ne devons-nous pas nous étonner s'il n'a mentionné qu'un petit nombre des espèces indigènes en Provence.

Avant de passer en revue celles dont il a parlé, nous avons à dire quclques mols de l'ilinéraire quil suivit dans ses excursions à travers le terriloire provençal.

Nous avons supposé, suivant toute probabilité, qu'il arriva par mer à Marseille. Il s'arrêta sans doute pendant un certain temps dans cette grande ville, aux environs de laquelle il herborisa tout d'abord : Marscille est citée trois fois dans les Parères.

Puis il traversa toute la partie nord-ouest de la province pour atteindre Avignon et de là Carpentras. Ces deux villes appartenaient alors au Saint-Siège. Mais on les considérait toujours comme faisant partie de la Provence.

Les autres localités dont Anguillara a fait mention sont :

(1) Cest presque toujours par ectte expression que Itatthiole est désigné dians les diatribes du Slirpium adversuria. 
Les Pennes et Lançon (1), qui dépendent actuellement du département des Bouches-du-Rhône ;

Roussillon, Mazan et l'Isle, qui appartiennent au département de Vaucluse.

C'est chose fort regrettable, nous l'avons dit, que dans ses notices Anguillara ait toujours été si sobre de détails personnels. Il n'a pas même fait connaitre l'année de sa venue en Prorence (2). Les diverses plantes dont il a signalé l'habitat provençal sont mentionnées en cinc de ses Parères : le plus ancien des cinq est daté du 18 férrier 1559. C'est done antérieurement à cette annéc 155'? qu'il avait effectué son voyage de Provence.

Nous pensons qu'il fit en ce pays un séjour assez. long. Nous en arons pour preure cette circonstance qu'il avait eu le temps de se familiariser avec la langue provençale. Il a, en effet, indiqué le nom provencal d'un Buplère. Et comme le mot avait, dans la langue populaire, une signification spéciale, il en donnait, au cours du chapitre relatif à cette Ombellifère, une exacte explication (3).

Voici maintenant quelles sont, arec leurs noms modernes, les espèces que, dans le recueil des Sem-

(1) Au temps où Anguillara vint à Lançon, ce villagge était protégé par une enceinte flanquée de tours dont quelques-unes subsistent et ont encore grand air.

(2) Pour les nombreuses herborisations quil fit en Italie, Anguillara, dans les Semplici, cite fréquemment des dates: ainsi nous savons qu'en 1539 il explora les alentours de Bologne : en $15+2$, le Monte-Nero de Livourne ; en 1544 et 1545 , le MonteNero de Pise ; en 1546, le Vicentin ; en $15 \frac{1}{1} \mathrm{~S}$ et 1549 , l'Abruzze. Sans que l'on puisse expliquer cette anomalie, lorsquil rient a parler de ses royages hors de litalie, il n inserit plus aucun mullésime ; et nous n'avons à ce sujet pas d'autre renseignement que celui fourni par Tiraboschi, d'après lequel Anguillara était jeune cyuand il se mit en route: "Avea l'Anguillara negli anni snoi giovanili corse molte provincie straniere. ")

(3) Pour ne point exagérer la portée de cet argument, nous devons reconnaître qu'étant Italien, Anguillara avait eu beaucoup de facilité à s'initier au provençal. 
plici, Anguillara déclarait avoir rencontrées sur le . territoire de la Provence :

Cistus albidus L., C. Salviaffolius L., C. nonspeliensis L., Cytinus Hypocistis L. - Il est question de ces quatre espèces dans le chapitre qui est intitulé Del Cisto e Ladano (1) : "Il existe, écrivait Anguillara, deux espèces de Ciste, ainsi que l'enseigne Dioscoride : le Ciste màle et le Ciste femelle ". Le premier est notre Cistus albidus L. et le second, $C$. salvicefolius L. Puis, après avoir indiqué des stations de l'une et l'autre espèce en diver's pays, notre auteur ajoutait : "Le même Ciste se voit encore en Provence et les deux espèces y produisent l'Hipocisto(2).) - Par le nom de Ladano, il désignait le Cistus monspeliensis L. Il constatait que celui-ci donnait aussi naissance à l'Hypociste, et pour l'habitat il répétait : "Si puo vedere... in Provenza (3) ".

Cytrisus sessilifolius L. - Anguillara le nomme Citiso. Il énonce qu'on le trouve en Corse et en Prorence (4), et il en donne une description dont les détails se rapportent bien au Cytise à feuilles sessiles. "C'est, dit-il, un arbrisseau de quatre coudées,

(1) Semplici, p. 61.

(2) Cytinus Hypocislis.

(3) Dans le Pinax, Gaspard Bauhin a fait du Cisto maschio d'Anguillara un synonyme de son "Cistus mas folio rolundiore hirsutissimo n, auquel Linné a donné le nom de Cistus villosus. Mais il y a ici une erreur évidente. Anguillara n'avait pas pu voir en Provence le C. villosus $\mathrm{L}$. qui ne s'y trouve point. Nous devons done admettre qu'il entendait par Cisle mâle le C. albidus actuel, comme le firent d'autres floristes du xvro siècle, Gesner, Pena et Lobel, Camerarius, Charles de l'Escluse, etc. - Pour le Cisto femina et le Ladano, notre interprétation concorde avec celle de Gaspard Bauhin.

(4) Semplici, p. 83: "Questo tale si trova in Corsica e per la Provenza, p 
à écorce lisse, avec des feuilles petites et semblables à celle du Fénugrec [c'est-à-dire trifoliolées], un peu charnues, et de petites flcurs de couleur jaune comme celles du Genêt (Spartium junceum L. )... n (1).

Ulex parviflorus Pourr. - Dans la plupart des cas, Anguillara se contente de donner aux plantes qu'il étudie leur nom italien. Ici, et par exception, il applique à l'Ulex les noms latins de Scorpio et Nepa (2). "Bien que cette plante, dit-il, soit très abondante en Grèce, néanmoins on la trouve aussi en Provence, entre Lançon et les Pennes, et en beaucoup d'autres endroits près de Marseille (3). " Puis il la décrit et après avoir noté que la floraison commence dès le mois de septembre, il termine son article par cetle singulière observation : "Les fleurs tombent ensuite sans produire aucun fruit, selon ce que je puis affirmer ; sauf certaines petites capsules

(1) Ibid. : " La pianta è di quattro gombitti... con corteccia liscia... Sono tutti [i suoi rami] carichi di foglie picciole simili à quelle del Fienugreco, di sostanza carnose, e da esse escono alcuni surcoli piccioli che producono i fiori piccioli simili à quelli della Genestra di color giallo. ») Gaspard Bauhin, dans le Pinax, et Jean Bauhin, dans l'Historia plantarum universalis, n'ont proposé que sous forme interrogative l'assimilation du Citiso d'Anguillara avec l'espèce que plus tard Linné nomma Citisus sessilifolius. Nous ne trouvons pas dans la flore de la Provence d'autre arbrisseau à feuilles trifoliolées et à fleurs papilionacées jaunes auquel puisse se mieux appliquer la description d'Anguillara.

(2) En latin ces deux mots signifient scorpion. Les Adversaria (p. 353) expliquaient ainsi la dénomination appliquée à l'L'lex : (Nepa vocatur cognomine ab animalculo caudæe ictu metuendo. ) La langue italienne a conservé, avec le même sens, celui de scorpio.

(3) Semplici, p. 143: "Anchor che in Grecia questa pianta si trovi copiossima, nientedimento si trova anchora in Provenza tra Lansone e le Penne, e in molti luoghi apprezzo ì Marsiglia. „) 
de forme ovale ì l'intérieur desquelles il n'y a rien (1). »

CNices Bexedictes L. - L'autcur des Parères appelait cette Curduacée Atrattile, mot qui traduisait le latin Atractylis. Il l'arait rencontrée " nella Provenza, tra Masan e Lilla (2). ”

Bupleurum fruticosum L. - Suivant les errements de la plupart des bolanographes du xvi siecle, qui royaient en celle grande Ombellifère le Seseli celhiopicum de Dioscoride, Anguillara l'appelait Seseli ethiopico. Voici textuellement ce qu'il en dit : a On le trouve entre Roussillon et Marseille en Provence, où les paysans le nomment Tacobugada. Ce mol na pas d'autre signification que celle de Tachelessive; il rien! de ce que la plante, quand on la brûle, donne des cendres qui laissent des taches aux endroits qu’elles touchent. Le Séséli éthiopique est un arbrisseau pareil au Verbasco salvatico (Phlomis fruticosa L.). Ses feuilles imitent celle du Chèrrefeuille, mais elles sont un peu plus allongées. Cet arbrisseau produit de grandes ombelles, comme la Férule. La semence a la mème formie que celle du Séséli de Marseille (Seseli tortuosum L.), mais elle est dure, de couleur noire. La plante, qui conserve ses feuilles toute lannée, est entièrement odorante, mais la graine l'est plus que tout le reste. C'est une orleur qui rajpelle celle du Térébinthe (3). "

(1) Ibid. : « I fiori cascano poi senza lasciarne frutto alcuno, secondo cle pote io avvertir: eccetto certi vasetti di figura olivari, dentro de qual non vi è cosa alcuna. ”

(2) Semplici, p. 149. - Mazan et l'Isle font partic aujourd'hui du département de Vaucluse, ainsi que nous l'avons dit plus haut.

(3) Semplici p. 212 : "Si trova fra Riossiglione e Marsiglia nella 
$9^{\circ}$ Quercus coccifera L. - Le long chapitre dans lequel Anguillara a décrit le Chêne-nain porte pour titre Cocco. Le mot de Cocco, ou Cocco baphico (en latin Coccus baphicus), désignait, ainsi que celui de Grana (graine), l'insecte parasite, - sur la nature duquel on n'avait alors que des notions très confuses, - qui procurait la couleur écarlate. Le phytographe italien s'exprimait à ce sujet de la façon que roici : "La Grana ou Cocco baphico est produite par deux sortes de plantes : par l'Ilex (Quercus coccifera L.) et par une plante particulière. La Grana de l'Ilex se trouve encore aujourd'hui en diverses parties de la Provence et dans l'Esclavonie où elle est appelée Cervach, ce qui signifie teinture. Elle existe aussi en Macédoine et là elle se nomme pareillement Cervach, mais avec une aspiration à la première syllabe. La même plante fournit la liqueur que Théophraste nommait ús.s. laquelle est de couleur rouge et de la nature du miel. Les dames du pays s'en servent pour se rougir et se rendre belles. Les Provençaux l'appellent Chermes... (1). » - Anguillara parle en-

Provenza, e da paesani chiamasi hoggi Tacobugada, laqual parola altro non vuole significare, che Macchia bucada ; perche la cenere di questa pianta abbruciata dove tocca, lascia le macchie. La pianta $\dot{e}$ un frutice simile al Verbasco salvatico, legnoso piu del detto Yerbasco. Le foglie paiono quelle del Periclimeno, ma alquanto piu lunghe. Produce ombelle grandi simili à quelle della Ferula. Il seme mostra il Seseli di líarsiglia, ma duro, di color nero. É pianta, che sempre è vestita delle sue foglie, e tutta odorata : ma piu il seme, chell resto; l'odore del quale rassembra quello del Terebintho. »)

(1) Semplici, p. 260 : " La Grana, over Cocco Baphico, è prodotto da due maniere di piante : dall' llice, e della pianta propria. Quello dell' Ilice si trova ancora hoggidli nelle parti della Provenza, e in Schiavonia, ove è chiamato Cervach, che significa tintura. Ne $\dot{e}$ anco per la Macedonia, e ivi medesimamente si chiama Cliervach, ma con l'aspiratione nella prima sillaha. Questa medesima pianta produce quel liquore, che Theofrasto chiama ự̇́s, il qual è rosso di colore, e di sostanza di mele. Le donne del paese l'usano per farsi rosse, e belle. I Provenzali il chiamano Chermes. ") 
suite de l'autre espèce, pianta propria, et il entre en beaucoup de détails au sujet de la substance tinctoriale extraite de cette plante qu'il considérait comme une Pimprenelle. Il est tombé ici dans une confusion manifeste (1). Mais comme, d'après ses indications, ce n'est pas la Provence qui nourrissait cette prétendue Pimprenelle, nous n'avons pas à le suivre dans les longues explications qu'il a données à ce propos.

Pour les neuf espèces que nous venons d'énumérer, nous ne pensons pas qu'il puisse y avoir doute, et nous croyons exacte l'application que nous leur avons faite des noms actuellement en usage dans nos flores.

A l'égard de cinq autres plantes, attribuées par Anguillara à la Provence, la tàche du traducteur devient plus ardue. Nous allons examiner ces espèces critiques, en les présentant sous le nom que leur donnait en italien l'auteur des Parères :

Eringio di Archigene. - Aussitôt après arnir traité de l'Atrattile (Cnicus benedictus L.), Anguillara décrivait en ces termes un Eringio dont Aetius, dit-il, a fait mention d'après Archigène (2) :

(1) Confusion que Jean Bauhin a relevée dans l'Hisloria plantarum universalis (t. I, $2^{\mathrm{e}}$ part., p. 109): "Singularis et plane

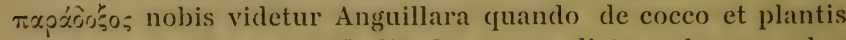
cocciferis scribens ait: Italis la grana dicta, vel coccus baphica, nascitur in duabus plantis distinctis : Ilice, et in planta propria. Coccus Ilicis adhuc hodie reperitur in Provincia... Provinciales Cinermes nuncupant. » - Et Bauhin déclare expressément que, pour lui, la prétendue pianta propria décrite par Anguillara ne diffère pas de l'Ilex coccifera que le botaniste voyageur avait vu en Provence: a Planta igitur quam Anguillara propriè cocciferam appellitat ac describit, eadem nobis est cum Hlice coccifera Provincia. 》)

(2) Archigène, médecin gree né en Syrie, vint s'établir à 
( Les feuilles ressemblent à celles de l'Atrattile, mais elles sont d'une consistance plus dure et d'une teinte plus claire; tirant sur le blanc. Une racine unique produit plusieurs rameaux (tiges) qui s'élèvent à la hauteur d'une coudée. Les fleurs sont semblables à celles de l'GEil de bœuf, c'est-à-dire du Buphthalme, mais il y pousse au milieu quelques étamines qui altèrent la ressemblance avec un œeil. Cette plante est très abondante dans toute la Provence. Mais je n'en connais pas le nom vulgaire(1). "

Gaspard Bauhin, toutes les fois qu'il peut les déterminer, a grand soin de faire figurer les plantes d'Anguillara parmi les synonymes des espèces pour lesquelles il a lui-même, dans le Pinax, établi une dénomination nouvelle. Il a identifié (p. 379) l' "Eryngium Archigenis Anguil.") avec la plante qu'il nommait "Acarna flore luteo patulo", et dont Linné, dans le Species, a fait le Carlina racemosa. Mais cette Carline ne se trouve point sur le territoire de la Provence. Dans leur Flore de France (t. II, p. 283) Grenier et Godron, sous la rubrique "Espéces exclues », s'expriment ainsi : "Carlina racemosa L. (C. sulphurea Desf.). - Indiqué par Gouan à Montpellier et par De Candolle en Corse, nous n'avons pu constater sa présence ni dans l'une ni dans l'autre de ces deux localités. De Candolle ne la possède pas de Corse dans son herbicr. Il existe en Sardaigne ".

Il est infiniment probable qu'Anguillara appliquait le nom d'Eringio di Archigene à notre Carlina corym-

Rome et $y$ acquit une grande réputation sous Domitien, Nerva et Trajan.

(1) Semplici, p. 150: "Aetio di sententia di Archigene descrive un' Eringio, il quale fa le foglie simili all Atrattile, ma sono di sostanze piu dure, e il color è piu chiaro che trahe al pallido. Fa molti rami à una radice, i quali si inalzano alla grandezza d'un gombito. I fiori sono simili à quelli dell' occhio di bue, ciò è Buphthalmo, ma crescendo poi alcune stamine in mezo,guastano la forma del occhio. È questa pianta copiosissima per tuta la Provenza, Ma non vi so nome volgare. $)^{\circ}$ 
bosa L., qui est bien, comme il le constatait, « très abondant dans toute la Provence ". Il comparait, on l'a vu, la fleur de l'Eringio à celle du Buphlhalmo: or, dans le chapitre qu'il consacrait à cette dernière espèce, il indiquait le caractère suivant: «fleurs entièrement jaunes et non point, comme quelques-uns l'ont prétendu, jaunes au milieu et blanches autour (1). ") Justement les fleurs du Carlina corymbosa sont toutes jaunes.

Polirizo di Plinio. - " Cette plante, écrit Anguillara, naît en Provence entre Mazan et Roussillon (2). Elle est semblable au Rusco (Ruscus aculeatus L.), mais elle n'est pas piquante. Elle a de nombreuses racines qui ressemblent à celles de l'Hellébore noir, tout en étant quelque peu plus minces et sans aucune odeur. La saveur est astringente (3) ».

Pline, au sujet du Polyrrhizon (XXVII, 103), s'élait contenté de dire : "Le Polyrrhizon a les feuilles du Myrte et des racines nombreuses. " - Dans la traduction qu'il a donnée de l'Histoire naturelle, Littré

(1) Semplici, p. 239 : "Fiore tutto giallo, e non, come vogliano alcuni, bianco attorno, e in mezo giallo $)$.

(2) Nous arons lieu d'être quelque peu surpris qu'Anguillara. qui n'a nommé qu'un très petit nombre des localités de la Provence, ait cité deux fois des endroits d'aussi minime importance que Mazan et Roussillon. Lorsquil veut marquer les limites du vaste périmètre dans leciuel croit le Buplère ligneux, n'est-ce pas singulier que de le voir, en désignant Marseille pour l'une des extrénités, choisir comme terme opposé l'humble village de Roussillon? P'eut-être avait-il lié connaissance avec quelque botanophile provençal qui, ayant des intérêts en ce pays, l'y conduisit et l'y retint pendant un certain laps de temps.

(3) Semplici, p. 213 : "Questa pianta nasce in Provenza fra Masan e Rossiglione, è simile al Ruseo, ma non punge. Le sue radici sono molte. Somigliano quelle dello Helleboro nero, ma aliquanto piu sottili, e di niun' odore. Il sapore ̀̀ astringente $)$. 
a pris soin d'adapter un nom linnéen à toutes les plantes décrites ou mentionnées par Pline. Mais il n'en a point indiqué pour le Polyrrhizon et dans une note spéciale il s'est exprimé ainsi : «Le Polyrrhizon a été rapporté à l'Aristolochia Pistolochia L. parce que Pline (dans un autre passage, XXV, 54), donne le nom de Polyrrhizos à une espèce d'Aristoloche. Mais cette Aristoloche n'a pas les feuilles du Myrte que Pline attribue ici à son Polyrrhizon. Il ne paraît done pas possible de déterminer celui-ci (1).»

Odontide di Plinio. - Dans le chapitre qui est ainsi intitulé, Anguillara commence par indiquer avec précision la station de la plante: “ Nasce la Odontide nella Provenza verso Carpentras, e nel contado d'Arignone. ) Puis il formule la description suivante: "Les racines donnent naissance à plusicurs petits rameaux (tiges) triangulaires, pleins de nouds, scmblables aux tiges du Polygonum màle. Les feuilles, étroites et allongées, sont placées près des nœuds : il y en a trois à chaque noeud. Au som. met des rameaux (ou tiges) surgit en son temps un petit épi chargé de petites fleurs roses; après celles-ci apparaît un fruit semblable à l'orge, mais plus petit. Les racines, assez épaisses, sont de nul usage. Cette plante vient dans les prés (2). »

(1) Histoire naturelle de Pline, avec la traduclion en françuis, par M. E. Littré. (Paris, Firmin Didot et Cie, 1877), t. II, p 245.

(2) Semplici, p. $220:$ «... Fa molti rametti triangolari dalle radici, piene di nodi, simili à quelli del Poligono maschio, appresso i quali sono le foglie strette e lunghette tre per ciascun geniculo. In cima de rami sorge al suo tempo una spighetta piena di fiori rossetti piccioli, e doppo quelli esce un frutto simile allorzo, ma piu piccolo. Le radice sono grossette di niun'uso. Nasce ne'prati, ) 
Cette description est empruntée presque littéralement au texte de Pline (1). Littré, dans sa traduction, a identifié l'Odontites du naturaliste romain avec l'Euphrasia Odontites de Linné. Si cette assimilation est fondée, et rien dans la diagnose n'y répugne absolument, Anguillara aurait ru à Carpentras et aux environs d'Avignon une des deux espèces qui ont remplacé, chez les floristes modernes, l'espèce linnéenne primitive : Odontites rubra Pers. ou une espèce affine, $O$. serotina Richb.

Poligala. - Voici exactement ce que, sous ce titre, Anguillara a écrit :

(" En Provence, la Poligala se sème et se donne aux bestiaux. Elle naît aussi en Italie, dans les montagnes de Bologne, et dans l'A bruzze, mais je ne connais pas son nom vulgaire. C'est une plante semblable à la Lentille, mais plus charnue; elle fait une fleur jaune avec une silique mince (2). »)

Il s'agit évidemment d'une Légumineuse, mais laquelle?

Matthiole, l'HisloriaLugdunensis et Tabernæmontanus ont appelé (Polygala », et Charles de l'Escluse a nommé "Polygala Valentina secunda» une plante à laquelle Gaspard Bauhin a plus tard conféré le nom de " Polygala major Massiliotica » et qui est présentement Coronilla juncea L.

(1) Pline avait dit (XXVII, 84) : "LOdontitis est une espèce de foin. Il jette d'une seule racine plusieurs petites tiges serrées, pleines de noxuds, triangulaires, noirâtres. Les nocuds sont garnis de petites feuilles, plus longues cependant que celles du Polygonon. La graine, semblable à l'orge, est dans les aisselles des feuilles. La fleur est pourpre, petite. Il croît dans les prés.” (Traduction Littré.)

(2) Semplici, p. 290: "La Poligala si semina nella Provenza, e dassi alle bestie. Nasce ancora in Italia per gli monti di Bollogna et nell' Abruzzo. É pianta simile alla Lente, ma piu grassetta, e fa un fior giallo con una siliqua sottile. ) 
Le même G. Bauhin nomma "Polygala altera " une autre espèce qui était antérieurement le «Polygala Valentina prima " de Clusius ; et lorsqu'il en établit la synonymie il se demanda d'une façon dubitative s'il ne devait pas identifier son espèce arec le Polygala d'Anguillara. Linné a fait, du «Polygala altera ») du Pinax, son Coronilla Valentina.

Mais il nous parait de toute évidence que ce n'est ni le Coronilla juncea ni le $C$. Valentina que les Provençaux semaient pour en nourrir leurs bestiaux. Et d'ailleurs, quioique trop courte, la description donnée par Anguillara de son Polygala énonce des caractères qui nous semblent inapplicables à ces deux Coronilles (1).

Titmalo Petreo. - Ici encore il convient tout d'abord de traduire fidèlement le texte du Semplici :

( Le Titimalo Petreo ou Dendroide se trouve au Saut-de-la-Biche en Toscane, dans la Ligurie entre

(1) M. le docteur Saint-Lager ayant publié, dans les Annales de la Société botanique de Lyon (1898), une note sur les Acceptions diverses du nom de "Polygala ", nous lui avons soumis, en le priant de nous faire connaitre son sentiment, le passage du Semplici relatif à la plante qu'Anguillara appelait de ce nom. Notre éminent confrère de Lyon, dont la compétence en ces matières est si grande, a bien voulu nous répondre qu'à son avis le Polygala d'Anguillara devait être notre Coronilla minima L., var. australis Godr. "Anguillara, nous écrit M. Saint-Lager, compare la foliaison de son Polygala à celle de la Lentille, mais cette comparaison, déjà faite par les botanistes de l'Antiquité, doit s'entendre dans un sens large; on a voulu seulement indiquer que les rameaux portent plusieurs paires de folioles, et non des feuilles trifoliollées. Le Polygala, dit encore Anguillara, a une silique mince. Cette expression convient mieux aux Coronilles qu’à aucun autre genre de Papilionacées. "

La variété australis du C. minima est, en effet, très commune sur toutes les collines calcaires de la Provence méridionale. Les cultivateurs provençaux du XVIe sieccle propageaient-ils 
Nice et Sarone, et aux alentours de Marscille. Celte plante croît à la manière d'un arbre, atteignant la hauteur d'un homme de stature élevée, avec un tronc dépourvu de feuilles, très ligneux. Au sommet se voit une tête pleine de rameaux minces, chargés de feuilles semblables à celles du Myrte, mais un peu plus étroites. Les fleurs sont jaunes et les graines telles que les ont les autres Tithymales. Elle nait dans les rochers. Je n'en comnais pas le nom vulgaire (1). "

En dressant la liste des synonymes de son " Tithymalus myrtifolius arboreus ", dont Linné a fait ensuite Euphorbia dendroides, Gaspard Bauhin y a inséré, mais arec l'expression d'un doute (an), le Tithymalus petræus d'Anguillara.

L'Euphorbia dendroides L. croissait-il, au Xv' ${ }^{e}$ sic̀cle, dans les environs de Marseille? Nous sommes porté à répondre affirmativement. L'allestation d'Anguillara est précise, et c'est celle d'un lémoin digne de foi.

On ne saurait mettre en doute qu'il ail vu près de Marseille, sur des rochers, une plante ligneuse ayant véritablement les caractères rapportés plus haut. Peut-être dans l'indication de la taille y a-t-il eu quelque exagération. Et encore se pourrait-il qu'il y eût alors sur le territoire de Marseille de

dans leurs champs, par des semis, cette plante frutescente? C'est là un problème quauront ì résoudre ceux qui entreprendront d'écrire une histoire de l'agriculture en Provence.

(1) Semplici, p. 294: "Il Titimalo Petreo, over Dendreide, si trova al Salto della Cerva in Toscana, e per Liguria tra Nizza e Savona, e nel contorno di Marsiglia. Cresee questa pianta à guisa di albero, all'altezza di un'huomo, che sia ben grande, con un tronco nudo di frondi, legnosissimo. Nella eui cima si vede una chioma piena di surcoli sottili, carichi di foglie simili à quello del Mirto, ma alquanto piu strelte : i fiori soro gialli, e' l seme tale qual è quello degli altri Titimali, e nasee ne gli sassi. Non vi so nome volgare, ”) 
vieux pieds de cette Euphorbe ayant atteint les proportions énoncées par l'auteur du Semplici.

L'Euphorbia dendroides se rencontre actuellement près de Toulon, au milieu des rochers qui avoisinent le fort de Sainte-Marguerite. Pourquoi la même plante n'aurait-elle pas végété aussi dans une station identique aux environs de Marseille?

Mais, dira-t-on, si l' $E$. dendroides habitait, au $\mathrm{xvI}^{\circ}$ siècle, le terroir de Marseille, pourquoi ne l'y voiton plus aujourd'hui?

L'expression employée par Anguillara, " nel contorno di Marsiglia ", marque (qu'il avait découvert le Titimalo Petreo dans les alentours immédials de la ville. Or depuis le xvie siècle ces alentours, singulièrement remaniés, ont changé d'aspect el de destination. La station marseillaise d' $E$. dendroides devait ètre unique, comme l'est présentement celle de Toulon. La grande ville s'étendant toujours davantagge, cette unique station fut ainsi détruite, et roilà comment on peut expliquer que l'Euphorbe arborescente ait cessé d'appartenir à la florule des en rirons de Marseille.

Quelles sont, parmi les plantes qu’Anguillara déclare avoir vues en Provence el dont l'identité peut être reconnue avec cerlitude, celles qu'il a été le premier à y signaler?

Avant lui, dans un ouvrage publié en 1549 (les Scholies sur Aetius), Hugues de Solier avait noté la présence sur le territoire provençal de quatre des espèces mentionnées ensuite par les Parères: Cistus albidus, C. salvixfolius, Bupleurum fruticosum, Quercus coccifera (1).

En ne tenant aucun compte de celles dont la détermination demeure hypothétique, Anguillara con-

(1) Ludovic Legré, La Bolanique en Provenee an XVIe siècle : Hugues de Solier (Marseille, Aubertin et Rolle, éditeurs, 18!9. 
serve incontestablement la primauté pour cinq espèces qui sont les suivantes: Cistus monspeliensis, Ulex parviflorus, Cytisus sessilifolius, Cnicus benedictus, Cytinus Hypocistis.

"Les botanistes désireux de compléter leur instruction, - a dit le docteur Saint-Lager, - ont certainement grand profit à étudier l'histoire des acquisitions successives de notre science, et, en ce qui concerne plus particulièrement la phytostatique, à constater combien il a fallu de temps et d'efforts pour acquérir la somme de connaissances que nous possédons aciuellement. " Et il ajoute avec beaucoup de raison : “ Toutefois cette étude historique, lorsqu'elle s'applique à un grand pays comme la France, doit être fractionnée par régions. »

Nous croyons nous-même que rien ne serait plus intéressant qu'une hisioire des plantes de France qui ferait connaître le nom du premier inventeur de toutes les espèces indigènes en chacune de nos provinces.

Dans une ouvre de cette nature, entreprise pour la Provence, il y aurait à inscrire au moins cinq fois lc nom de Louis Anguillara (1).

(1) Au début de ce travail, nous avons dit, d'après Tiraboschi, que l'on ne savait pas quel fut le nom patronymique de Louis Anguillara. Nous devons ajouter, pour être tout à fait exact, que גi. le professeur Saccardo lui a, - mais avec doute, - attribué le nom de Squalermo. Dans un ourrage intitulé La Botanica in Italia (Venezia, 1895), il s'exprime ainsi : "Anguillara (meglio forse Luigi Squalermo detto Anguillara) nat. Anguillara presso Bracciano intorno 1512, m. Ferrara $1570 \ldots$ " Cette question est, à notre avis, dénuée de tout intérêt. Le botaniste avait lui-même adoptí le nom d'Anguillara, puisqu'il a signé ainsi le recucil de ses Parères. Ce nom lui est donc irrévocablement acquis, et quel avantage y aurait-il à le remplacer aujourd'hui par un autre, quand mème il serait établi que le nom de Squctlermo lui appartenait véritablement? 


\section{PIERRE HBLUN}





\section{PIERRE BELON}

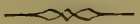

Pierre Belon fut un naturaliste de large envergure et de haute valeur : la postérité ne saurait, sans grande injustice, lui refuser ce témoignage.

Rien de ce qui dépend du domaine de l'histoire naturelle ne lui fut indifférent. Il manifesta de remarquables qualités d'observateur aussi bien en botanique qu'en zoologie, et quand, en ouvrant son Histoire de la nature des oyseaux, on tombe sur la page où il a représenté en regard l'une de l'autre, pour en accuser les analogies, la charpente osseuse de l'homme et celle de l'oiseau, il faut bien que l'on salue en lui le fondateur de l'anatomie comparée.

Né en 1517, aux environs du Mans (1), il eut pour premier protecteur René du Bellay, évèque de cette

(1) Dans un de ses ouvrages (Les Observations de plusicurs singularitez), Belon a indiqué d'une façon précise l'endroit où il naçuit. A propos d'un Ciste qu'il vit en Orient, il écrivait : " Il y a une espece de Cistus, croissant sauvage par les landes de Oise [Oizé] au pays du Maine, et principalement joignant le bourg de Fouletourte pres de la Soulletiere (qui est le lieu de nostre naissance). " 
ville (1). Il commença ses études à Paris et les poursuivit en Allemagne, où il devint l'élève, l'ami et le compagnon de voyage d'un botaniste de rare mérite, Valerius Cordus (2).

Sous le patronage du célèbre cardinal de Tournon, avec des subsides fournis par celui-ci (3), il entreprit, en 1546, un long voyage en Orient. Il vit la

(1) Parlant dans un autre de ses livres (Les Remonstrances), de ceux qui furent ses protecteurs, il disait de René du Bellay : "Aussi estoit de feu monsieur René du Bellay evesque du Jans, et duquel autresfois avons receu bienfaicts des nostre jeune aage, et non que pour luy avoir communiqué des semences de plusieurs plantes apportées d'Italie et Almaigne et Flandres, et desquelles encore en durent aucunes, embellissans le jardin de Touvoie qu'il a edifié pres la ville du Mans. ") - René du Bellay était un ardent botanophile. Belon, dans son traité des Conifères, en a encore témoigné par ces mots : "Renatus Bellayus episcopus Cenomanensis, qui unicè rei herbaria stuclebat... " Le prélat avait accumulé dans son jardin de Touvoie les végétaux les plus rares, et Conrard Gesner déclarait que ce jardin était le plus riche de lEurope. (Horti Germanice).

(2) Valerius Cordus (son véritable nom était Eberwein), né en 1515 a Siemershausen, n'était que de deux ans l'aîné de Pierre Belon. Il avait, par ses études et ses voyarges, acquis de très bonne heure une grande réputation. Aprés avoir parcouru l'Allemagne et l'Italie, il mourut à Rome en 1544 , avant d'avoir accompli sa trentième année. Belon l'accompagna dans ses voyages. A propos de l'un des arbres dont il s'est occupé dans les Remonstrances, il a écrit : "Ducquel en devoss raporter la cognoissance prinse du deffunct V'alerius Cordus, Almand, tres expert en ceste matiere, graticux personnage et modeste, qui d'une grande gaieté et franche bonté. qui est commune à tous Almans, nous l'a autresfois monstré, et en Pomeranie et Saxoine. "Il le suivit aussi en Italie, ainsi qu'il l'a rappelé dans ce passage du De arboribus coniferis où il dit au sujet du Genévrier de Phénicie: "Cum aliquando V'alerium Cordum comitarer, et Lyciam quam jam nuper descripsi non procul ab arce ad mare Mediterraneum quem vulgus Ligornum [Livourne] nominat... enatam offendissemus, ille ut erat ingenii acerrimi Thuiam esse conjecit, atcue cum ramos amicis impertiretur, Lyciam offerre asserebat. "

(3) En dédiant au cardinal de Tournon l'ouvrage dans lequel il raconta son royage, Belon sexprimait en ces termes: "Apres 
Grèce, Constantinople, l'Asie Mineure, la Syric, l'Égypte. Cette expédition, dont il publia le récit en un volume intitulé : Les Observations de plusieurs singularitez et choses memorables, tronvées en Grèce, Asic, Judée, Egypte, Arabie et autres pays estranges (1), lui valut une éclatante renommée : il eut même l'honneur insigne d'être chanté par Ronsard :

Or si Jason a tant receu

De gloire pour avoir deceu

Une jeune infante amoureuse,

Et pour n'avoir passé sinon

Qu'un fleuve de petit renom,

Combien Belon, au prix de luy,

Doibt avoir en France aujourd'huy

D'honneur, de faveur et de gloire

Qui a veu ce grand univers

Et de longueur et de travers

Et la gent blanche et la gent noire ? (2)

qu'custes cogneu le desir que j'avoye de parvenir à l'intelligence des choses concernantes la matiere des medicaments et des plantes laquelle je ne pouroye bonnement acquerir sinon par une loingtaine peregrination), il vous pleut me commander les aller veoir es regions loingtaines, et les chercher jusques aux lieux de leurs naissances, chose que je n'eusse peu ny osé entreprendre sans vostre aide, sachant que la difficulté eust esté es frais et despens. "

(1) Paris, 1553 " chez Guillaume Cavellat, à l'enseigne de la Poulle grasse, devant le College de Cambray. " - Cet ouvrage eut plusieurs éditions ct fut traduit en latin par Charles de l'Escluse.

(2) Notre profond respect pour la vérité nous obligge à déclarer que ce ne sont point les exploits de Belon qui avaient d'abord inspiré la muse de Ronsard. L'ode dont nous venons de citeı quelques vers fut composée pour célébrer la gloire d'André Thevet, d'Angoulême, moine cordelier qui fit un long voyage en Orient (1549-1554). Dans l'édition des Odes de P. de Ronsard que nous avons sous les yeux (Paris, 1567), cette piece a pour titre 
Pierre Belon fut aussi l'objet des faveurs royales. Il obtint du roi Henri II une pension et Charles IX lui accorda le droit de loger au chàteau de Madrid près Paris, grâce qui devait être fatale au naturaliste-royageur, car il fut tué dans le bois de Boulogne, probablement par un voleur, mais en tout cas au milieu de circonstances demeurées mystérieuses. C'était en arril 1564 ; Belon avait alors quarantesept ans.

Au cours de sa carrière scientifique, il ne s'était pas contenté de visiter l'Orient. Il avait accompli de nombreux royages en Allemagne, dans les Flandres, en Italie, en France. Il explora plusieurs de nos provinces, entre autres l'Auvergne et le Dauphiné. Il parcourut aussi la Provence; et c'est le relevé des observations botaniques faites par lui sur le territoire provençal qui va faire le sujet de ce travail.

En compulsant les œuvres de Belon, nous fìmes une remarque qu'araient déjà provoquéc plus d'une fois les écrils des botanographes du xvi" siècle, notamment ceux de Louis Anguillara. La plupart de leurs observations sont consignées dans leurs livres sous une forme impersonnelle ; on dirait qu'appré-

la dédicace même A André Thevel Angonmoyssin, et le vers où le poète rabaisse le mérite de Jason :

Combien Belon, au prix de luy,

y porte :

Combien Theret.....

Le nom de Belon fut, dans les éditions postérieures, substitué à celui de Thevet. Quelle circonstance motiva ce changement? Sans doute lamitié qui s'était formée entre Ronsard et Belon. Celui-ci, revenant dillemagne et se dirigeant vers Met\%, avait été arrêté près de Thionville par les soldats espagnols qui oceupaient le pays. Il raconte, dans les Remonstrances, qu il dut, pour sortir de prison, payer une forte somme dont une partie fut eomptée par " un gentilhomme nommé de Hammes qui, en faveur du sçavoir de mon de Ronsard, fournit ce qui restoit pour parachever ma rançon. ») 
ciant outre mesure le mérite de la modestie, ils éludent le plus souvent les occasions de se mettre en scène et de se citer eux-mèmes.

C'est ainsi que dans les nombreux ouvrages de Pierre Belon, nous n'avons pas trouvé une seule phrase où il dise expressément qu'il est venu en Provence. Mais il donne sur ce pays une multitude de menus détails qui, manifestement, ont été constatés de visu. Quand, par exemple, il nous apprend qu'à Ramatuelle croît le pin maritime, et qu'à Salon de Crau on voyait, en dehors des remparts, à côté d'une fontaine, deux superbes micocouliers, nous sommes bien obligés d'admettre que ce sont là des faits qu'il avait personnellement remarqués et notés.

Indépendamment de la relation de son voyage d'Orient, en laquelle il a fait une assez large place aux végétaux observés, Pierre Belon écrivit deux ouvrages spécialement consacrés à la res herbaria.

Le premier, qui parut en 1553 (1), est intitulé : De arboribus coniferis, resiniferis, aliis quoque nonnullis sempiterna fronde virentibus. Ce titre indique suffisamment de quelle catégorie d'arbres l'auteur s'est occupé dans ce livre.

L'autre, publié cinq ans plus tard, a pour titre: Les remonstrances sur le default du labour et culture des plantes et de la cognoissance d'icelles, contenant la maniere d'affranchir et apprivoiser les arbres saivages (2).

(1) Voici le titre complet : P. Bellonii Cenomani de arboribus coniferis, resiniferis, aliis quoque nonnullis sempiterna fronde virentibus cum earundem iconibus ad vivum expressis. - Parisiis, apud Gulielmum Cavellat, in pingui Gallina, ex adverso Collegii Cameracensis, 1553. - Ce livre est dédié " ad illnstrissimum dominum Franciscum Olivarium, Francice Cancellarium, virum amplissimum ». François Ollivier, chancelier de France, fut un des bienfaiteurs de Pierre Belon.

(2) «A Paris, chez Guillaume Cavellat, à l'enseigne de la Poulle grasse devant le College de Cambrai, 1558. „ - Charles de l'Escluse a aussi donné de cette ceuvre de Belon une traduction latine sous le titre de De neglecta cultura. 
Une supplique présentée au roi Henri II et dont le texte est reproduit dans l'ouvrage, fait comnaître, mieux que la bizarre phraséologsie du frontispice, quel était l'objet de ces " remonstrances ".

Une pension de six cents livres avait élé précédemment accordée à Pierre Belon. Mais le brevet royal était resté lettre-morte, et le bénéficiaire n'avait jamais rien touché. Il s'en plaint et promet, s'il obtient satisfaction, d'employer les fonds à se procurer les graines d'une grande quantité d'arbres qui ne croissent pas dans les forêts " des plaines de France ", et qui cependant pourraient fort bien y être introduits et acclimatés. La proposition est ainsi formulée dans cette curieuse requête :

Sire, depuis le temps qu'il vous pleut accorder que ceux à qui vous donneriez bienfaicts de valeur feroient obtenir six cens livres de pension annuelle à Pierre Belon du Mans, plusieurs ayants depuis esté pourreuz par rous s'en sont exemptez. Et iceluy sachant qu'on ne donne le bien à personnes inutiles, a cherché le moyen de s'employer à vous faire service : c'est qu'il vous pourra recouvrer les semences de maintes especes d'arbres qu'on ne veit one, ne en roz jardins, ne en ceux des autres, ne es forests des plaines de France. Et se confiant de les avoir fraiches et en grande quantité, il se faict fort d'en eslever tel nombre que voudrez, telle part où bon rous semblera. Par cuoy, Sire, vostre bon plaisir soit commander aux Secretaires de voz finances que, sans rien excepter, ils mettent en execution suivant le contenu des brevets que de vostre grace vous a pleu luy signer de vostre propre main : à fin que Iorsque l'oceasion se presentera, il soit jouyssant du don que luy avez ottroié et en depeschent lettres où besoing sera : et il se soubmet donner moyen de vous faire naistre les arbres dont les noms s'ensuivent :

La requête est en effet suivie d'une longue liste d'arbres et d'arbustes qu'il a remarqués en ses 
voyages. Les divers chapitres de l'ouvrage ont pour but d'indiquer en quels lieux ils croissent, par quels procéciés, d'un emploi généralement facile et peu coûleux, on en pourrait acquérir les semences, et quels seraient les moyens à prendre pour les " apprivoiser " et en doter les forêts françaises.

Nous avons classé suivant l'ordre méthodique les diverses espèces végétales mentionnées par Pierre Belon, avec indication d'habitat provençal, dans les trois ouvrages dont nous arons cité les titres et fait connaître le contenu ; et pour chacune de ces espèces nous reproduisons texiuellement les détails que l'auteur a donnés.

Paliurus australis Rœm. et Schult. - Pierre Belon appliquait à cet arbuste épineux le nom de Rhamnus (1). Il l'a mentionné deux fois dans les Remonstrances. En premier lieu, au chapitre où il examine quelles sont les espèces dont on peut se servir pour former des haies autour des champs cultivés : "Aucuns sont propres pour enclorre les labourages et faire haies, dont les uns sont espineux, les autres non. Voyez Halimus sur le terrouer de Jerusalem et en Crete, les Tamarisques en Egypte..., estre propres à faire haies, toutes fois sans estre espineux: car icy faire les haies aux champs de Bourgespine, d'Aubespine, et d'Espine noire et d'Espine vinette, en Provence de Rhamnus..., et ailleurs de Ronees, est chose accommodant chacune region, par l'usage de ce qu'elle a. " Et dans la " remonstrance " suivante, où il insère " les noms des arbres sauvages propres pour les faire eslever et apprivoiser en tous endroicts"), il

(1) $\Delta$ insi que le firent la plupart des floristes clu xrie sicele. Linné lui-même considéra le Paliure comme une espéce dụ genre Rhamnus, Rh. Paliurus, 
écrit : « A peine trouveroit on arbres autour d'Antibe et de Farjus (1), et quasi par toute la Provence, plus frequents que sont ceux de Rhamnus. "

Rhannes Alaternus L. - C'est encore dans les Remonstrances qu'il est question de ce Nerprun. Belon l'appelle Phylica, se conformant ainsi à la nomenclature de l'époque. "Les Philicæ; dit-il, ont nom au port de Lespecie (2) Soudre ou Sondre, et autour de Rome Salvestrille, et dont y a si grande quantité que dernicrement les facines des rempars pour la fortification de la ville contre les Espagnols n'estoient d'autre arbre pour la plus part que de Salvestrille. Aucuns en Provence le nomment Pincerfi, et à Rochabruna (3) pres Lespecie, Pincervin. » - Pincerfi ou Pincervin est une déformation des mots Spina Cervina, nom populaire que certains botanographes du xvíe siècle avaient adopté pour l'appliquer à l'Alaterne.

Pistacia Lentiscus L. - Dans les Observations de plusieur's singularitez, Belon écrit: " Les Lentisques qui croissent par le Languedoc, Provence et Italie sont tels que ceux de Chio, toutes fois ne rendent point de mastic. »)

Rhus Coriaria L. - « Sumac ont leurs semences vulgairement vendues es boutiques des Apoticaires, cueillies des guarrigues d'autour Montalimar et

(1) Fréjus, actuellement chef-lieu de canton du département du Var, et siège d'un évêché.

(2) La Spezzia.

(3) Roquebrune, bourg du département des Alpes-Mraritimes, arrondissement de Nice. - Roquebrune, qui faisait partie de la principauté de Monaco, s'en sépara en 1848, comme Menton, et se donna à la France en $186^{\prime}$ ): 
Orenge pres du Rhosne. ) Dans la traduction latine qu'il a donnée des Remonstrances, Charles de l'Escluse a joint ici une note pour dire que luimême, faisant route à travers la même contrée, n'y avait pas aperçu le Sumac, mais y avait trouvé en grande quantité le Fustet, non moins utile que le Sumac pour corroyer les peaux : "Carolo Clusio istac iter facienti nullum Rhus conspectum, sed Coccigrya plurima, non minus Rhoë ad densanda coria utilis. "

Cneorum tricoccun L. - Ce in'est qu'incidemment que dans les Remonstrances Belon a parlé de cette Térébinthacée. Nous avons déjà dit, - et nous citerons le texte un peu plus loin, - qu'il signalait la présence du Pin maritime à Ramatuelle. Il ajoutait : « là où la Chamælea en provençal est nommée Garoupe ». - Les botanistes du $\mathrm{xvr}^{\mathrm{e}}$ siècle donnaient en effet le nom de Chamalea à l'espèce devenue depuis Linné Cneorum tricoccum. L'appellation provençale Garoupo n'est point tombée en désuétude et s'applique toujours à la même plante (1).

Cenatonia Siligua L. - Le Caroubier croit spontanément et n'est point rare dans cette région des Alpes-Maritimes où la Provence confine à la Ligurie (2). Le fait se trouve indiqué dans les ouvrages

(1) V. le Trésor du Félibrige, dictionnaire provençal-français, de Frédéric Mistral. - Le Cneorum Tricoccum est rare en Provence. D'après le Catalogue des plantes de Provence, d'Honoré Roux, on ne le trouve aujourd'hui que dans le département des Alpes-Maritimes. Le village de Ramatuelle, eité par Belon, appartient au département du Var, mais n'est pas très éloigné de la partic du département des Alpes-araritimes ou croît le Cneorum.

(2) "Le Caroubier peut être observé dans de nombreuses localités, surtout près des rives de la mer, entre les environs 
de divers auteurs du xvr siècle (1), et c'est Pierre Belon qui le premier l'a divulgué.

Dans le mémoire adressé au roi, et dont nous arons plus haut reproduit le début, il préroyait une objection qui certainement lui serait faite : à savoir, que certains arbres, qu'il conseillait de propager en France, n'y supporteraient pas la rigueur du climat. A quoi il répondait en invoquant l'exemple du Caroubier " qui endure vivre au jardin de Touroie pres le Mans, dont grands arbres y sont presentement en essence (2). )

Mais comment sera-t-il possible d'amasser des graines de Caroubier en quantité suffisante pour assurer de nombreux semis?

Il réfule cette nouvelle objection au moyen des détails suivants :

( Le fruict de ce Caroubier, qui est proposé le premier, est nommé des Grecs Keration; sa semense, pesant six grains, a faict dire Karats au poix de l'or. Il n'est de moindre revenu aux habilants des orées de Gennes, Savonne et Villefranche, que les Noyers sont par les plaines de France. Ce sont arbres qui aiment à naistre sur les pendans pierreux, au pied des montaignes, et aux rivages de la mer, et aussi en terre ferme, ayans si grande affluence de grandes gousses ou siliques, qui sont leurs fruicts, qu'en faulte d'Orge, Foin et Aroine, ils nourrissent leurs Anes, Mulets et Chevaux d'elles. Mais iceux, en les mangeant, laissent les graines es mangeoires, et qui n'avoient accoustumé estre amassées avant que les

d'Albenga et le golfe de la Napoule ». (Emile Burnat, Flore des Alpes Maritimes, t. 11, p. 226).

(1) Notamment par les auteurs du Stirpium Adversaria. V. les clétails donnés au sujet du Caroubier dans notre ouvrage intitulé : La Botanique en Provence all xv1e siècle : Pierre Pcna el Mathias de Lobel (Marseille, 1899).

(2) Nous rappelons quil s'agit ici du beau jardin botanique créé par René du Bellay, évêque du Mans. 
eussions advertiz de les serrer. Voyla pourquoy faisant mention des Caroubes, qui est le premicr arbre proposé, ne sera difficile de recouvrer leur semence, d'autant qu'il y a asseurance des personnes du pays qui en délirreront plus de vingt lirres pour chacun escu. )

Anygdalus persica L. - On trouve mentionnés dans les Remonstrances certains végétaux pour lesquels Pierre Belon n'a pas indiqué d'habitat en Provence, mais qu'il a désignés par leur nom provençal ; preuve manifeste qu'étant venu en Provence, il y avait séjourné assez longtemps pour s'y familiariser avec la langue du pays (1); preuve non moins évidente qu'il avait vu là les espèces auxquelles nous faisons allusion : quelles raisons aurait-il eues d'appliquer une dénomination provençale à des plantes observées en d'autres contrées?

Le Pêcher est une de ces espèces. Belon n'a donné, au sujet de cet arbre fruitier, aucun détail qui mérite d'être rapporté ; mais il l'a mentionné plusieurs fois sous le nom provençal de Perseguier (2).

(1) Le fait que Pierre Belon fit en Provence un séjour prolongé se trouvera confirmé jusqu'à la dernière évidence au moyen des détails que nous donnerons plus loin sur les observations icthyologiques fitites a Marseille par le naturaliste manceau.

(2) Le mot perseguié est toujours employé dans certains cantons de la Provence et du Languedoc; mais, en beaucoup d'autres endroits, l'usage, de par la loi de l'euphonie, en a adouci la prononciation, et la forme la plus usitée est actuellement pesseguié. - Hugues de Solier, dont l'ouvrage (Scholies sur Actius) vit le jour en 1549, et par conséçuent neuf ans avant les Remonstrances de Belon, avait indiqué que le nom provençal de la pêche était persegue. (Ludovic Legré, La Botanique c'n Provence au XVIe siècle : Hugues de Solier, Marseille, 1899.) 
Myrtus communis L.- Même observation pour le Myrte. Les Provençaux appellent cet arbuste Nerto. Le mot, sans doute, avait plu à Pierre Belon, car il semble l'employer de préférence toutes les fois qu'il a l'occasion de parler du Myrte. "Voiez, dit-il dans les Remonstrances, les Romains mesmes, encor failloit-il qu'ils defendissent les Nertes dans leurs jardins contre le froid, disants :

Dum teneras defendo à frigore Myrtos. »)

Et plus loin, à propos d'un parasite qui vit sur le Myrte, il écrit : “C'est une excrescence rouge et platte qu'on trouve au commencement de l'esté sur les Nertes, de la grandeur d'une lentille, et qui est presque de mesme nature que le Vermillon (1). ».

Phillyrea Angustifolia L.- Le mot Dalader (2) est encore, à l'heure qu'il est, employé par les Provençux qui l'appliquent généralement au Filaria à feuilles étroites. "Qui vouldra, déclare Belon, observer le bois dont il se chauffera au Sainct Esprit (3) apporté des prochaines forests, n'en trouvera de plus frequent qu'est le Dalader ».

(1) Le Kermès ou Cochenille du Chêne-nain (Coccus Ilicis L. i. V. plus loin les détails que nous donnons à ce sujet.

(2) On dit aussi Alader, et cette forme serait plus correcte si, comme c'est probable, le mot provençal dérive du latin Alaternus. La plupart des floristes du xvie siècle donnaient ce nom au Nerprun Alaterne (Rhamnus Alaternus L.). Pourtant quelques-uns, notamment les rédacteurs de l'Historia Lugdunensis, avaient appelé Alaternus le Filaria.- Hugues de Solier qui, dans ses Scholies, a fait connaitre le nom provençal de beaucoup de plantes, écrivait Alaverd, dont l'étymologie, croyait-il, aurait été Olea viridis. Nous n'avons pas besoin de rappeler que les genres Phillyrea et Olea sont très voisins, et appartiennent, non seulement à la même famille, mais aussi à la même tribu.

(3) Le Pont-Saint-Esprit, chef-lieu de canton de l'arrondissement d'Uzès (Gard). 
Chose curieuse à noter : en se servant de ces divers noms provençaux, Pierre Belon les admettait comme des expressions appartenant à la langue française. Il dit expressément en un autre endroit des Remonstrances : "Alaterni, en François Daladers, et autrement Sanguins blancs. ». Il considérait sans doute comme francais tous les mots usités dans des provinces qui faisaient partie intégrante du royaume de France (1).

Bupleurum fruticoscin L. - Dans le mème ouvrage, Belon s'exprime ainsi au sujet de cette Ombellifère: «La Cachebugade, que les Latins nomment Seseli athyopicum, est toujours vert, croissant sauvage près d'Orgon (2), vers Salon de Craux (3). ") - Cachebugade est une expression provençale que notre auteur ici défigure (4). Cette appellation, en

(1) Les rénovateurs de la littérature provençale au $\mathrm{x} r \mathrm{x}^{\circ}$ siècle ont pu dire avec raison du provençal qu'il est une langue française; c'était déji, au Xvı siècle, lavis de Pierre Belon. Il se croyait en droit d'adopter tous les mots provençaux qu'il trouvait à sa convenance. Nous lavons vu, à propos du Sumac, employer le mot garrigue. On sait que cette expression, essenticllement provençale, désigne les collines ou les plaines incultes et arides, si communes dans le Midi de la France, oú domine le le Chêne ì Kermès, Quercus coccifera L. Garrigo dérive de Garric (on dit aussi Garrus ou Agarrus), nom provençal de ce Chêne.- Il est à remarquer que Belon, en insérant dans son texte ces divers mots provençaux, n’indiquait pas leur origine: il les considérait donc bien comme des mots français. Il a cependant fait exception pour Garoupo, nom provençal du Cneorum tricoccum.

(2) Orgon, qu'en un autre endroit Belon appelle Ourgon, est actuellement chef-lieu de canton de l'arrondissement d'Arles (Bouches-du-Rhône).

(3) Salon, chef-lieu de canton de l'arrondissement d'Aix (Bouches-du-Rhône).

(4) Il y a tres probablement ici une faute d'impression. Belon, voulant traduire en français la première partie de ce mot 
usage che\% les Provençaux du xvr" siècle pour désigner le Buplevre ligneux, est aujourd'hui abandonnée. Louis Anguillara nous a fait connaître la forme correcte, qui était Tacobugado. "(On le troure, disait de ee Buplèrre le bolaniste italien, - entre lioussillon (1) el Marseille en Provence, où les paysans le nomment Tacobugalo. Ce mol n'a pas d'autre signification que celle de Tache-lessive; il vient de ce que la plante, quand on la brule, donne des cendres qui laissent des laches aux endroits qu'elles touchent (2). »)

Anbetes Lxino L. - En parcourant la Provence, comme il le fil d'une extrémité à l'aulre, Pierre Belon ne pouvait pas manquer de rencontrer l'Arbousier, espèce ligneuse très répandue dans le pays (3). C'est d'une facon implicite qu'il l'a signalé sur le terriloire provencal. Il lavail dabord apereu dans le Vivarais el aux environs de Pont-Saini-Espril; et dans le chapitre où il examine comment on peut linire provision de graines pour les semis d'arbres dont il voudrail que le gouvernement royal prescrivit laculture, il écril : "Lion peult donner ordre de faire secher les Arlouses, tant en Vivarais el au Sainct

composé (le verbe Laca, tacher), avait dû éerire Tache-bugade; et ce sont les typographes qui auront substitue fuutivement un C au T du manuscrit.

(1) Village du département de Vaucluse.

(2) Voir plus haut notre travail sur Louis Angrtillara.

(3) Le nom d'Arbousier a pris place maintenant dans les lexiques français; mais, désignant un arbre qui croît principalement dans une région oa lon ne parlait autrefois que la langue provençale, le mol a été provenȩal longtemps avant de devenir francais. Le récent Diclionnaire général de lu langue franegraise de MiN. Hatzleld, Darmesteter et Thomas reconnail, après Littré. que le mot Arbouse (nom français du fruit de l'Arbulus Unedo, d'où a été formé le mot Arbousier), dérive de l'ancien provencial Arbossu. 
Esprit, comme aussi en diverses autres contrées assises le long du Rosne. " - Ces contrées, assises le long du Rhone en aval du Pont-Saint-Esprit, faisaient évidemment partie de la Provence.

Thymus vulgaris L. - Celte Labiée, une de celles qui contribuent le plus à parfumer les gatrigues de la Provence, est nommée dans les Observations de plusients singularitez, à propos d'une autre plante aromatique que Belon avait rencontrée en Grèce, et qu’il considérait comme le vérilab)le Thym des anciens auteurs. "... Si les choses que nous nommons par noms propres ne conviennent avec la description des dictz anciens, il fault conclure que ce ne sont celles qu'ils ont entendu. Nostre Thym en soit exemple, duquel l'appellation est si commune à tous, qu'il ne le sache appeler et nommer du nom de Thym, et neantmoins ce nom luy est faussement donné. Car l'herbe que nous appellons Thym n'est pas celle a qui ce nom puisse convenir, ains à une autre qui croist communement par le pays de Grèce, c'est à sçavoir duquel les avettes recueillent l'excellent miel pres d'Athenes, au mont Hymetlus, et en Sicile, au mont Hybla... Pour semblable raison, combien que l'herbe fue nous nommons vulgairement le Thym eroisse copieusement sauvage es guarigues de Provence et de Languedoc, sans estre cultivée, ressemblant ì celle de nos jardins : toutes fois n'ayant les merques dessus dictes, ne peut estre le vray Thym (1) n.

(1) Pierre Belon tenait, autant que les autres botanistes du xví siecle, a faire aux plantes une exacte application des noms employés par les auteurs de l'antiquité. Il regardait comme "le vary " Thym eclui que Dioscoride avait ainsi appelé : ce'est la Labiée que Linné a nommée Salurcia capilala. 
Vitex Agnus castus L. - Le Gattilier Agneauchaste, que l'on troure actuellement sur le littoral de la Provence orientale, - Alpes-Maritimes, Var et confins du Var et des Bouches-du-Rhône, croissait, au xvic siècle, à l'extrême limite occidentale de ce dernier département, près des embouchures du Rhône. La formule dont se sert Belon dans les Remonstrances nous autorise à croire que c'était là une constatation qu'il avait faite, comme toutes les autres, personnellement : “ Des Agneaux chastes, dit-il, trouverez le long du Rhosne, vers l'entrée de la mer, el dont encores sont vendues ses semences es boutiques ». - Le dernier membre de phrase fait supposer que les apothicaires allaient en cet endroit récoller les sraines pour en alimenter leurs officines.

Ceitis australis L. - L'auteur des Remonstrances y parle plusieurs fois de cet arbre dont il fait connaitre les noms français, Fregolier (1) et Mifcacoulicr, ct le nom latin, Lotus (2). Pour les divers arbres qu'il recommandait de propager, il s'évertuait ì démontrer que l'on pourrait aisément et à peu de frais s'en procurer les scmences. Il dit de celles du Micocoulier : "D'autant moindre est la difficulté de les recouvrer qu'en pourrons avoir à charge de chevaux des environs de Tournon, là où il y en a quantité, sans qu'il couste que le port. C'est luy dont l'on voit moult grands arbres ì la

(1) Cet ancien nom français, - ou prétendu tel par Pierre Belon, et qui, en tout cas, ne figure plus dans les lexiques moderine:s, - est is rapprocher de Fabregoulié, liune des formes du nom provençal du Celtis australis.

(2) Les floristes du xvmo siecle domnaient le nom de Lolats à divers végétaux. Quand il s'agissait du Micocoulier, ils disaient Lotus arbor. 
Zuëque de Venise, qu'ils nomment Bagolaro. Aussi y en a deux grands arbres joignant la fontaine de Salon de Craux, hors la porte, et memorables, pour leur aage et haulteur, possible tels que ceux dont Pline a faict si grand cas, parlant des riclosses romaines. "

Quercus Ilex L., Q. coccifera L. - Nous inscrivons ces deux Chênes sur notre liste parce qu'ils sont au nombre des arbres que Pierre Belon a mentionnés en indiquant leur nom prorençal. - Le Quercus Ilex est ainsi désigné dans les Remonstrances : "Chesne verd ou Eouse. " Cette dernière forme, exclusivement provençale, n'a pas cessé d'être appliquée par les Provençaux au Chênevert (1). - Quant au (. coccifera, Belon en parle plusieurs fois et l'appelle toujours Arbre de Vermillon. Vermillon est un mot provençal qui signifie " petit ver ") : c'est un diminutif de verme, ver (2). Les Provençaux prenaient pour un petit ver, à raison de son apparence, la femelle du Kermès (Coccus Ilicis L.), insecte producteur de la couleur d'écarlate. Pendant tout le moyen-âge, la récolte et la vente du Kermès constituèrent pour les populations rurales de la Provence une source d'importants profits (3). Très recherché à cause de sa qualité, le

(1) Belon a écrit ce mot en notant exactement la façon dont les Provençaux le prononçaient et le prononcent encore. Mais en vertu de la réforme orthographique opérée par F. Mistral (d'après laquelle la voyelle $u$, placée à la suite d'une autre voyelle, prend le son oul, la graphie actuelle est Étuse. Le mot Yeuse est en français l'équivalent de l'appellation provençale du Chêne-vert.

(2) La langue provençale possẻde, pour désigner le Coccus Ilicis, d'autres expressions, toujours dérivées de la racine verme: vermet, vermèu, vermiho, vermeiado. V. le Dictionnaire provençal-français de F. Mistral.

(3) De nombreux documents conservés aux archives des 
Kermès de ce pays faisait l'objet d'un actif commerce d'exportation. Il était done naturel que la couleur extraite de cette matière prît le nom qu'on donnait à celle-ci clans la contrée d'où elle était originaire.

Pines halepensis Mill., P. Pinea Is., P. maritma Lamk. - Les diverses espèces du genre Pinus ont donné lieu, che\% les anciens botanistes, à de nombreuses confusions. Nous avons la certitude que Pierre Belon distingua parfaitement les trois espèces énoncées ci-dessus.

Ne füt-ce que par la nature de ses fruits, le Pin Pignon a loujours été le plus facile à discerner. Dans le De arboribus coniferis, Belon déclare qu'on le trouve cultivé ou spontané, mais toujours idenlique ì lui-mème, produisant en l'un et l'autre cas des cònes de grandeur égale, et procurant, aux gens du payss, un important revenu, à raison de ses pignons qui sont le remède le plus efficace que l'on ait jamais employé contre la toux (1). Il ajoute qu'on le rencontre à l'élat spontané dans une multitude d'endroits, même en plaine, sur le territoire de la Gaule Narbonaise (Provence et Languedoc), aux environs de Marseille, et dans beaucoup de localités d'Italie, telles que Ravenne, où cet arbre peuple des forêts très étendues. Les marchands vendent indifféremment les noyaux de ceux qui ont été plantés dans les licux cultivés et de ceux qui sont nés sauvages.

Bouches-du-lahone montrent que la cueillette du Kermès, sur laquelle les comtes de Provence avaient établi un impôt, donnait lieu à un grand mouvement d'affaires.

(1) Déjil, au xvie siècle, les pharmaciens du Languedoc confectionnatient avec les pignons des dragées ou pastilles appelées pignolats et dont le Stirpium Adversaria de Pena et Lobel donne la recette. 
Les Remonstrances nous apprennent ([u'il existait aussi de véritable forèts de Pinus Pinea aux alentours d'Aigues-Mortes, circonstance parfaitement exacte, puisque cette régétation s'est perpétuée là jusqu ì nos jours; les pignons en provenant étaient ì Marseille l'objet d'un assez grand commerce.

Toujours préoccupé de justifier du bon marché des graines à acequérir pour la diffusion des arbres, il écrit: "Un temps fut (que voyant les noyaux des pignons desja triez, casse\% el frais, n'estre vendu\% chez les drogueurs que cing ou six sols la livre, donnoit merveille. Mais considerants les forests, et autour d'Aigues-Mortes en estre loutes, et aussi aulour de Ravenne ì deux journées es environs $y$ en avoir en si grande abondance, cessa, ains pensa que c estoit trop. Qui seroit à Marseille, el en vouldroit avoir à charges de chevaulx, les trouvera pour les plus chers à quatre tournois la livre, ou pour le plus six deniers, èest le boul du monde: mais entendez de ceux (fui ne sont easse\%. Done en cela, qu'en doit on estimer que le port?"

C'est it Ramatuelle, - nous arons eu plus haut l'occasion de le dire, - que Belon, dans les Remonstrances, a signalé la présence du l'in maritime, auquel il domne le nom de Piceastre. Il le distingue du Pin Pignon d'après la forme des conces: "l'iceastres, dit-il, sont tels que ceulx (qu'on roit porter pommes, moindres que les franes Pins ") et il ajoule aussilot: " dont y en a forests pres Ramataucle en Provence où la Chamelea en proveneal est nommée Craroupe $n$.

Il n'a pas davantage confondu le P'in marilime avec le Pin d'Alep; et dans le mème chapilre des Remonstrances, il poursuit ainsi :

"Encore y a autre espece de ces Piceastres, moult frequente autour de Marseille et d'Aix en Provence et it Gule, faisants forests es endroicts sur le lerriloire là où mons. le president Destrets est seigneur. " 
Cette " autre espèce " de "Piceastre ", que Belon juge différente du Pin maritime, est manifestement le Pin d'Alep, toujours très commun et seul spontané aux alentours de Marseille et d'Aix.

Quel était.le personnage que Belon appelait " le president Destrets »?

A cet égard, aucun doute n'est possible. Il s'agit de Jean-Augustin de Foresta, baron de Trets,qui fut reçu en 1554 président à mortier au Parlement d'Aix, et qui devint premier président en 1558 (1).

Les hauts protecteur's qui encourageaient les études, les recherches et les voyages de Pierre Belon, non seulement lui procuraient des subsides, mais en outre se faisaient un devoir de l'aceréditer auprès de certaines notabilités des pays qu'il se proposait de visiter. Assurément l'auteur des Remonstrances n'aurait pas parlé du président de Foresta, s'il n'était pas entré en relation avec ce magistrat et n'avait pas été à même de parcourir le fief qu'il a cité sous le nom de Gule.

Où se trouvait cette localité ? Ici nous sommes complètement dérouté. Gule est un mot qui a été dénaturé lors de l'impression du livre, et nous n’avons pas pu décourrir quel est celui que devait porter le manuscrit original.

Juniperus Oxycedrus L., J. phinicea L. - Ces deux espèces sont aussi répandues l'une que l'autre dans toute la Provence méridionale. Leur foliaison bien différente empêche qui que ce soit de les confondre. Aussi ne ferons-nous pas un mérite à Pierre Belon de les avoir distinguées.

Dans son iraité des Conifères, il a donné à l'Oxycèdre la dénomination de Cedrus Phenica sive Punica;

(1) Artefeuil, Histoire héroïque et universelle de la Yoblesse de Provence (Avignon, 1757), t, Ier, p. 414, 
et celle de Cedrus Lyycia sive Retusa, à noire Genévrier de Phénicie (1).

Dans les Remonslrances, il adopte pour le premier le nom provençal de Cade, et il indique, comme habitat de Provence, les environs d'Orgon : "Cades, dit-il, se trouvent autour d'Ourgon, dont ils font de l'huille de Cade. C'est le premier lieu où s'est peu voir du charbon blane, qui est faict des souches d'icelles. ")

Pour le Genérrier de Phénicie, il en signale la présence aux environs de Marseille, ct il fait connaitre l'appellation provençale de Mourven. C'est dans le De arboribus coniferis qu'il écrit: "Circa Massiliam Lycia hace Cedrus affatim nascitur, vulgus Morveinc vocat. "Il ajoute que ce même Genévrier est appelé Cade Serbin par les gens d'Avignon : " quemadmodum et Avignionenses, apud quos frequentissima est, duabus appellationibus, Cade Serbin appellant (2). "

Nous venons de voir que dans le passage des Remonstrances relatif à l'Oxycèdre, il est question de l'huile de cade. Il résulte d'une énonciation contenue

(1) Voici en quels termes Belon indique les différences qui distinguent les deux espèces, et comment il justifie les noms qu'il leur donne: "Phenica autem, ab aculeorum rigentium in extremis mucrone, Oxycedros à Græecis dicta est, Lyciam verò a foliorum tenuitate obtusorum, Retusam ad difierentiam alterius vocare malui. Hac à Lycia provincia nomen habet. "

(2) Cade, Mourven, Serbin sont des noms provençaux encore usités aujourd'hui. Belon a écrit dans les Remonstrances: "Serbin est comme Cade, ou Genevrier rouge, tous trois noms françois, ainsi les nomment en Avignon : mais ceux de Ragouse [Raguse] le prennent pour Savinier, qui est erreur. » Le fait que notre auteur déclarait français des mots provençaux en usage à Avignon confirme une observation que nous avons déja formulée (note 1 de la page 49). Il semble résulter de cette déclaration que Belon considérait Avignon comme dépendant du territoire français, quoique étant alors au pouvoir du Saint-Siège. Le second membre de phrase nous montre (qu'il ne confondait nullement le Juniperus phonicea avec le $J$, Sabina. 
dans le De arboribus coniferis que ce produit, obtenu indifféremment des deux Genévriers, portait aussi, tant en Provence qu'en Languedoc, le nom de Cade Serbin.

Il y a, dans ce même traité des Conifères, un chapitre consacré à la Cedria ou poix liquide que, d'après les anciens auteurs, les Egyptiens employaient à l'embaumement des cadarres. Nous traduisons ainsi qu’il suit le passage qui termine ce chapitre :

" En France, le populaire est en possession de quelque chose qui répond parfaitement à la Cedria ou poix liquide. Il appelle cela de deux noms, dont l'un est: Huile de Cade, et l'autre: du Tac (1). Mais de même que cette substance porte des noms différents, elle s'obtient aussi de matières diverses. Il y a, en effet, des paysans qui, du bois de Genévrier (2), de Frêne, de Sabine, de Cèdre, et de n'importe quel autre, pourru quil soit fraîchement coupé, parviennent à extraire une liqueur semblable à la Cedria ou poix liquide. Les habitants d'Arignon, de la Provence et du Languedoc se servent surtout d'une huile qui provient du Cedrus Phenica et du Lycia, et à laquelle ils donnent pour nom les deux mots de Cade Serbin. Celle qu'emploient nos compatriotes de la Gaule Celtique, et qu'ils nomment dı Tac, parait véritablement être extraile du bois de Genérricr : elle a pris le nom de la maladie qu'clle est apte à guérir (3). C'est un mal contagicux, qui se propage parmi les troupeaux et tue les brebis. Lorsque, pour le combattre, les paysans, qui en cela sont nos maîtres, ont besoin de cette huile, ils ront chez les phar-

(1) Les mots que nous soulignons sont écrits en français dans le texte.

(2) Belon entend ici notre Juniperus communis L.

(3) Phlegmasie éruptive de la peau, contagieuse chez le mouton, le chien et le cheval; 
maciens et leur demandent du Tac et, dans la France méridionale, du Cade Serbin, nom vulgaire que les Juifs auraient mis en usage chez le peuple (1). »

S'il faut en croire Belon, notre Genévrier de Phénicie, en un certain endroit de la Provence, aurait été pourvu d'un autre nom, d'origine arabe, dit-il.

Le passage du De arboribus coniferis cité plus haut, et dans lequel il nous apprend que son Cedrus Lycia vel Retusa, vulgairement appelé Morveinc, est très abondant autour de Marseille, se termine par cette phrase : “ Sed qui apud Sirpontem versus Massiliam agunt, arbusculam ipsa Cotranum voce Arabica dicunt. )

Le mot provençal cotran, catran ou quitran désigne le goudron : ćtait-ce parce que le Genérrier de Phénicie pouvait aussi fournir du goudron, que les habitants d'une localité voisine de Marseille lui donnaient le nom de cotran (2)?

(1) Vulgus Galliarum habet aliquid quod Cedria aut Pici liquidae prorsus respondeat. Duobus autem nominibus id appellare solet. Uno modo, Huile de Cade, alio veró, du Tac. Sed quemadmodum variam sortitur nomenclaturam, sic ex variis materiebus fieri consuevit. Sunt enim artifices, sed alioqui rustici, qui ex quibusvis materiebus veluti Juniperi, Fraxini, Sabinæ, Cedri, et ejusmodi lignis adhuc virentibus, liquorem pici licuida aut Cedrix similem exsudare cogant : nam indigenæe Avignionenses, Provinciales et Linguoscitones eo maxime oleo utuntur, quod ex Phœnica et Lycia Cedro fit, et duobus nominibus De Cade Serbin vocant. Id autem quo nostri hîc in Gallia Celtica utuntur, quod Tacum vocant, verius è lignis Juniperorum perfici videtur, idque à morbo ovium cui mederi solet, nomen habet. Est autem contagiosa quxdam lues, quie populatim srevit et interficit oves: in quo medendo rustici, cùm nobis doctiores sint, eo opus habentes, pharmacopolas adeunt, à quibus et Tacum postulant, quemadmodum in inferiori Gallia du Cade Serbin nomine quidem vulgari, sed quod Judei populum sic docuerunt.

(2) Dans son Historia plantarum universalis (t. I ${ }^{\mathrm{er}}, 2^{\mathrm{e}}$ partie, p. 3i0) Jean Bauhin a reproduit textuellement la phrase de Belon citée plus haut. Mais une annotation insérée en marge 
Et quelle est cette localité, dont le nom latinisé par Belon, devenant à l'accusatif Sirpontem, devait être au nominatif Sirpons?

Il n'existe actuellement, et nous pouvons affirmer qu'au Xvie siècle il n'existait, dans les environs de Marscille, aucun lieu qui portât le nom de Sirpons (1).

Il n'est pas douteux que nous nous trouvons encore en présence d'un mot estropié par les typographes parisiens : n'ayant pas pu lire exactement, sur le manuscrit de l'auteur, un nom qui leur était inconnu, ils l'ont quelque peu défiguré.

Nous pensons qu'il s'agit ici de Saint-Pons de Gémenos, où il y avait, au moyen àge, un monastère de religieuses appartenant à l'ordre de Citeaux (2).

Il est rrai qu'il n'y a jamais eu, à Saint-Pons même, de population rurale agglomérée, tandis que la formule employée par Belon: " qui apud Sirpontem... agunt "semble indiquer que, de son temps, beaucoup de gens fréquentaient cet endroit.

Les deux choses ne sont pas inconciliables.

La vallée de Saint-Pons est comprise dans l'itinéraire qu'avaient à suivre les voyageurs désireux

indique quil faut lire Corranum au lieu de Cotranum. Nous ne nous expliquons pas cette rectification. Belon lui-même a d'ailleurs usé pour ce mot d'une graphie différente dans les Obscrvations de plusicurs singularilez : "En passant par l'Hellespont, dit-il, on voit les montagnes revestues de belles forests de Pins sauvage: nommés Picece : les habitants prennent de son bois nommé Teda, qui estant allumé esclaire de soymesme comme une chandelle : duquel ils font la poix noire et la Cedria, que les François appellent du nom Arabe Quodran, ou Quatran, et en Avignon du Cade Cerbin. ")

(1) Nous n'avons pas manqué de consulter l'excellent Diclionnaire topographique de larrondissement de Harseille, comprenant les noms anciens et modernes, de Mortreuil (Marseille, 1872). Gule n'y figure pas.

(2) Dont les ruines subsistent encore, dans un site éminemment pittoresque, chanté par Delille. 
d'atteindre, par la voie la plus directe, le pèlerinage fameux de la Sainte-Baume. Belon, sans doute, s'y était rendu; et c'est ainsi qu'il eut l'occasion de passer par Saint-Pons et d'observer là le Mourven qui n'a pas cessé de croître en grande abondance sur toutes les collines d'alentour.

Le De arboribus coniferis contient encore une indication que nous devons recueillir.

Ainsi que nous venons de le voir, Pierre Belon, suivant en cela les errements des botanistes anciens et de ceux de son temps, appelait Cedrus le Genévrier Oxycèdre et le Genévrier de Phénicie. On donnait le même nom au vrai Cèdre (Pinus Cedrus L. = Cedrus Libani Barr.) mais pour différencier celui-ci des autres, on employait une épithète, et l'on disait; Cedrus magna ou Cedrus alta.

Dans le chapitre où il s'est occupé de cet arbre, Belon raconte que, selon ce qui lui a été affirmé par quelques personnes très dignes de foi, le grand Cèdre croit dans les montagnes situćes au-dessus de Nice : "Audivi à quibusdam fide valde dignis hominibus Cedrum magnam supra Niceam in montibus nasci. ")

Le fait était certainement inexact, et ces hommes si dignes de foi araient induit le botaniste en erreur.

Mais la phrase que nous venons de reproduire a une portće sur laquelle il convient d’insister.

Puisque notre auteur, quand il consigne dans ses écrits une circonstance qu'il ne peut pas attester personnellement, a bien soin de le déclarer, nous devons en conclure que lorsqu'il ne prend pas la même précaution, e'est qu'il rapporte des faits directement observés par lui. Nous en étions bien sûr : nous n'en sommes pas moins très heureux de rencontrer une confirmation émanée de Belon luiniême. 
Non seulement Pierre Belon parcourut la Prorence d'un bout à l'autre, depuis Orange et Avignon jusqu'à Ramatuelle, Fréjus, Antibes et Nice, mais nous arons acquis la certitude qu'il y fit un long séjour.

C'est à Marseille qu'il demeura le plus longtemps. Au cours de ses royages en Provence, il ne s'était pas uniquement occupé de botanique. Comme l'icthyologie arait aussi beaucoup d'attrait pour lui, un stage dans la grande cité maritime lui offrait une occasion excellente de s'adonner avec profit à cette branche de l'histoire naturelle.

Dans un des ouvrages où il a traité de l'histoire des poissons, - celui qui a pour titre De aquatilibus libri duo (1), - il a fait connaître le nom provençal, usitéà Marseille, de plus de soixante des espèces qu'il a décrites et presque toujours dessinées. Il indique celte appellation populaire au moyen d'une formule qui varie peu : "Massilienses vocant..., à Massiliensibus nominatur..., Massiliensium vulgus appellat... "Et nous pouvons constater que ces applications de rocables provençaux ont été faites avec une irréprochable exactitude. Quand, par exemple, nous entendons Belon nous dire que les Marseillais nomment tel et tel poisson Bauldroy, Bogue, Cabasson, Clavellate, Fiela, Giarret, Malarmat, Palamide, Roquan, Rascasse, Sarg, Suverean, Serran, etc., nous nous trouvons en présence de dénominations qui n'ont pas cessé d'être familières aux Provençaux d'aujourd'hui (2).

(1) Petri Bellonii Cenomani de aquatilibus Libri duo cum siconibus ad vivam ipsorum effigicm, quoad cjus ficri potuit, cxpressis. - Parisiis, apud Carolum Stephanum, Typographum Regium, M. D. LIII. - L’ouvrage est dédié ad amplissimum Cardinalem Castillionceum (le cardinal de Chattillon).

(2) Nous avons exactement reproduit pour les noms eités l'orthographe adoptée par Belon. 
Or, pour arriver à connaître exactement le nom marseillais d'une soixantaine d'espèces, il a bien fallu que Belon fit à Marseille un séjour prolongé. Ses observations icthyologiques exigeaient beaucoup de temps. Ce n'était qu'en faisant, en des saisons différentes, de longues stations dans le roisinage de la mer, que le naturaliste pouvait réaliser ce qu'il ambitionnait : connaitre un grand nombre de poissons, étudicr leur conformation, les dessiner, apprendre leur nom vulgaire. Il devait, pour cela, s'astreindre à vivre dans l'intimité des pêcheurs, à les attendre sur le rivage quand ils y débarquaient le produit de leur pêche, à les accompagner quelquefois sur leurs bateaux pour assister à la levée des filets; à fréquenter aussi les marchés et les halles où le poisson était mis en vente ; à interroger patiemment pêcheurs et poissonnières ; et comme, en ce temps-lì, ni les uns, ni les autres ne parlaient, n'entendaient mème le français, il avait bien été obligé de s'exercer au préalable à se servir lui-mème de la langue provenęale.

C'est vraisemblablement à Marseille, en fréquentant les pècheurs, que Pierre Belon eut occasion de goùler d'un mets dont il a parlé dans l'Histoire des estranges poissons, et fait, en ces termes, connaître la recette :

" Je veul racompter combien l'artifice des hommes peult adjouster à nalure : car les paoures mariniers et pescheurs, aiants pris des poissons qui d'euls mesmes sont de saveur ingrate... ils leur sçavent faire une saulce si propre, que la saveur de la saulce surpasse la saveur ingrate du poisson, laquelle leur oste la mauvaise odeur et les rend delectables : et tout ainsi que les plus riches font telles saulces avec bonnes muscades, girofles, macis et canelle baltue, beurre, sucre, vin aigre, pain rosti... aussi les paoures gents n'aiants point tant de choses à commandement, aiants tant seulement des aux et des 
noix, qu'ils battent avec du pain et de l'huille et du vin aigre, ils feront une saulce à leur poisson qu'ils rendent à leur appetit si delicieuse qu'on n'en peult manger [de meilleure] : et telle maniere de saulce est generaloment cogneuë de touts pescheur, qu'ils nomment vulgairement l'Aillade (1). »)

Au cours de sa carrière scientifique, Pierre Bclon fit au moins deux fois le voyage de Provence. C'est là une circonstance dont l'exactitude semble établie par les dates de ses ouvrages :

Le De aquatilibus, qui contient une multitude de détails recueillis à Marseille, a paru en 1553. Quelques-uns de ces détails figuraient déjà dans l'Histoire des estranges poissons, publiée en 1551. C'est done antérieurement à l'année 1551 que Belon était venu une première fois en Provence et avait fait à Marseille un long séjour.

Il faut faire remonter à ce premier voyage les quelques indications relatives à la flore provençale qui ont été consignées dans les Observations de plusieurs singularitez et dans le De arboribus coniferis, ces deux livres ayant vu le jour en la même année 1553.

Pierre Belon était ensuite retourné à Paris, où les soins à donner à l'impression simultanée de trois de ses ouvrages devaient rendre sa présence nécessaire (2).

(1) Aillade est encore un mot provençal, ainsi que le reconnaissent Littré et les auteurs du nouveau Diclionnaire général de la langue française.

(2) L’épître dédicatoire des Observalions, adressée au cardinal de Tournon, est ainsi datée: "De vostre maison de l'Abbaye de Sainct Germain des prez lez Paris, 1553. " - Le cardinal étant abbé de Saint-Germain des Prés, avait offert à Pierre Belon l'hospitalité dans ectte célèbre ab)baye. 
Il revit une seconde fois la Provence lorsque, se faisant l'apôtre du reboisement, il entreprit de se mettre en quête des essences forestières qui pouvaient être introduites ou multipliées sur le sol français. Les Remonstrances, qu'il écrivit pour divulguer le résultat de ses recherches et de ses observations, parurent en 1558. Nous avons vu que dans un passage de ce livre où il a fait allusion au Pin d'Alep, il a cité la ville d'Aix en Provence et mentionné une terre appartenant au " président Destrets ", désignant ainsi Jean-Augustin de Foresta, baron de Trets, président à mortier au Parlement de Provence, investi de cette charge seulement en 1554. Si donc, comme tout le fait supposer, Pierre Belon a été reçu chez le président baron de Trets, c'est qu'il était revenu en Provence dans l'intervalle compris entre 1554 et 1558 (date de la publication des Remonstrances) ; et c'est alors qu'il a complété par de nouveaux détails les notes si pleines d'intérêt que, lors de son premier voyage, il avait commencé à prendre sur la flore de cette belle province (1).

(1) Il n'y a pas certitude absolue que Belon ait fait deux fois le voyage de Provence. Nous ne devons pas attacher une valeur décisive à l'argument tiré de ce qu'il a donné au baron de Trets un titre de président obtenu seulement en 1554. Le naturalistevoyageur pouvait très bien avoir connu Jean-Augustin de Foresta à une époque antérieure, alors que celui-ci n'était encore que conseiller, et, lors de l'impression des Remonstrances, donner au magistrat provençal son nouveau titre. En tout cas, si Belon a revu la Provence, ce ne peut être que dans l'intervalle écoulé entre 1554 et 1558 . Contre la réalité d'une seconde venue en cette province, on pourrait invoquer une phrase dans laquelle, faisant allusion aux divers voyages entrepris pour préparer son livre, il écrivait qu'il avait d̂̂ " retourner traverser tout expressement les summités des monts d'Auvergne, Savoie et Daulphiné, pour voir les arbres ». Pourquoi, dira-t-on, si à cette époque il avait de nouveau exploré la Provence, ne laurait-il pas nommée en même temps que l'Auvergne, la Savoie et le Dauphiné ? A quoi nous répondrions que dans ce passage il n'a parlé que des “ summités », que les Alpes provençales confinent au Dauphiné, 
et que pour Belon la vraie Provence était sans doute la partie inférieure du pays, de beaucoup la plus étendue, où l'on ne rencontre guère que des basses collines. Mais cette discussion serait dépourvue d'utilité. Que Belon ait fait en Provence un ou deux voyages, peu importe. Ce qui est indubitable, c'est que l'illustre naturaliste a parcouru la Provence entière et y a longtemps séjourné. 
CHARLES DE LESGLUSE 



\section{CHARLES DE L'ESCLUSE}

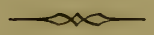

Dans le groupe des phytographes illustres qui, au $\mathrm{xvI}^{\mathrm{e}}$ siècle, inaugurèrent le règne de l'observation scientifique et méritèrent d'être appelés les Pères de la Botanique, la figure de Charles de l'Escluse (1), on est d'accord pour le reconnaître, - apparaît au premier rang. La postérité a ratifié l'éloge que fit de lui l'auteur des Institutiones rei herbariæ: "Mira fuit, - écrivait Tournefort, - Carolo Clusio in inquirendis plantis diligentia "; et lorsque, dans la

' même notice, il donnait la date de sa mort, il ajoutait : " . . omnibus desiderium suî relinquens tris-

(1) Aucun nom n'a été plus diversement présenté que celui de l'Escluse ; on rencontre tour à tour les formes l'Escluse, Lescluze, l'Ecluse, l'Ecluze, Lécluse, Lécluze. On n'attachait alors aucune importance à la graphie des noms propres, et le botaniste lui-même a varié dans la façon d'écrire le sien. Au bas de son acte d'immatriculation à l'Université de Montpellier, il signa : Carolus de Lescluze. La forme que nous adoptons était, au xvie siècle, la plus correcte et c'est celle qui figure sur le frontispice de la traduction française du Cruydtboeck de Dodoens, imprimée en 1557. - Pour se conformer à un usage universellement suivi par les savants de ce temps-là, Charles de l'Escluse dut latiniser son nom, et le transformer en Clusins. 
tissimum, simulque memoriam nominis nunquam interituram (1). ")

La plupart des bolanistes de cette époque ne s'étaient livrés aux études phytologiques que dans un intérêt professionnel : ils comptaient utiliser plus tard, au profit de la pratique médicale, leur connaissance des plantes. Tel ne fut pas le cas de Clusius. Il n'exerça jamais la médecine, voulant demeurer uniquement botaniste ; et sa longue carrière, qui lui permit d'atteindre l'âge de quatre-vingt-quatre ans, fut tout entière consacrée à la res herbaria (2).

Natif d'Arras, où il vit le jour le 19 février 1526, il était d'extraction nobiliaire. Son père, Michel de l'Escluse, portait le titre de seigneur de Watènes et remplissait la charge de conseiller à la cour provinciale d'Artois (3).

Après avoir reçu, à Gand et à Louvain, une forte éducation classique, le jeune Charles de l'Escluse se tourna tout d'abord vers la science juridique. Mais le droit n'était point son affaire. Toutes ses prédilections l'entraînaient vers l'histoire naturelle. Son goût pour la botanique, s'il faut en croire son contemporain Boissard (4), prit naissance à Montpellier.

(1) Isagoge in rem herbariam, p. 48.

(2) Charles de l'Escluse a lui-même déclaré dans le Rariorum 。 plantarum historia qu'il n'eut jamais la moindre envie de se vouer à la profession médicale. Dans le chapitre consacré à l'A quilegia, il fait connaitre les vertus de cette plante, qui lui ont èté signalées par un savant médecin de Bruges; mais il ajoute aussitôt : "tametsi ut medicinam facerem, nunquam in animum induxissem meum. " - L'Université de Leyde possède une lettre autographe adressée à Clusius par Léonard Rauwolff, et sur la suscription de laquelle celui-ci donne à son correspondant le titre de medicus eximius. Nous avons publié cette lettre, qui était inédite, dans notre travail intitulé : La Botanique en Provence au xvie siècle : Léonard Raubslff, Jacques Reynaudet (Marseille, Aubertin et Rolle, éditeurs, 1900).

(3) Edouard Morren, Charles de l'Escluse, sa vie et ses œuvres (Liège, 1875).

(4) Icones et vilce virorum illustrium (Francfort, 1592). - Le 
Nous pensons que sa vocation datait de plus loin, et qu'il était poussé par la volonté d'en assurer le développement, quand il devint élève de l'Université alors en si grand renom.

Il arriva dans le Languedoc en 1551, au commencement de l'automne (1). Il fut reçu chez le célèbre professeur Guillaume Rondelet, dont il devint l'hôte, et auquel il servit de secrétaire pendant toute la durée de son séjour à Montpellier (2). Celui-ci travaillait alors au grand ouvrage d'icthyologie qui

chapitre concernant Charles de l'Escluse a été reproduit dans le volume des Curce posteriores, à la suite de l'oraison funèbre prononcée a Leycle par Everard Vorst, à qui fut attribuée la chaire devenue vacante à la mort de Clusius.

(1) J.-E. et G. Planchon, dans l'Appendice de Rondelet et ses disciples (Montpellier, 1866), ont donné la date du 3 octobre 1551 comme celle de larrive ì Montpellier du jeune Charles de l'Escluse.

(2) Dans notre ouvrage intitulé : La Botanique en Provence au xvre siècle : Pierre Pena et Mathias de Lobel (Marseille, 1899), nous avons donné, au sujet de la carrière scientifique de Guillaume Rondelet, des détails sur lesquels il est inutile de revenir. - Le fait que Charles de l'Escluse, pendant son séjour à Montpellier, servit de secrétaire au célèbre professeur est attesté par Félix Platter, qui écrit dans ses curieux mémoires, sous la date du 6 janvier 1554: "Nous nous réunîmes au Collège, pour tirer les Rois, entre nous autres Allemands. Le vieux bedeau, qui avait longtemps habité la Grèce, n; tus faisait la cuisine. André dc Croatie eut la fève. Deux jours après. nous les tirâmes dans la maison de Rondelet, chez qui demeuraient Jérôme Betz de Constance, Clusius, qui était son secrétaire, et plusieurs autres. " (Félix et Thomas Platler à Montpellier, notes de voyage de deux étudiants bâlois, traduites par M. Kieffer.Nontpellier, 1892) - D'après Everard Vorst, Charles de l'Escluse, à cette époque, eut une hydropisie pour avoir imprudemment bu de l'eau froide en trop grande quantité. Rondelet le guerit par l'emploi du "Cichorium sylvestre ", circonstance ì laquelle Clusius a fait allusion dans les Curce posteriores où, parlant de cette plante, il ajoutait : « cujus usum olim expertus sum mihi salutarem ex consilio et prescriptione C. V. Gulielmi Rondeletii, cùm apud ipsum viverem. » 
a fait sa gloire (1). On s'est demandé si le jeune secrétaire n'aida pas son maître, tout au moins en coopérant à la rédaction latine de l'ouvrage et en concourant à en surveiller l'impression (2). Il quitta Montpellier un peu plus de trois ans après y être venu, et l'année même où parut le livre de Rondelet. La date précise de son départ nous est connue par les mémoires de Félix Platter : ce fut le 27 janvier 1554. Ce jour-là, écrit Platter, "partit de Montpellier Carolus Clusius, le secrétaire de Rondelet, chez qui il logeait déjà avant mon arrivée. Il se rendit plus tard célèbre dans la science botanique, comme ses écrits en font foi, et ne pratiqua jamais la médecine. Il m'écrivit bien souvent pour me rappeler nos relations de Montpellier (3). ")

Jusqu'à la fin de sa vie, Clusius se complut à évoquer l'heureux temps où il avait été le disciple, le commensal et le secrétaire de Guillaume Rondelet. Lorsque, près d'un demi-siècle étant écoulé, il prépare le plus important de ses ouvrages, Rariorum

(1) Gulielmi Rondeletii Doctoris Medici et Medicina in schola Monspeliensi professoris regii Libri de Piscibus marinis, in quibus verce Piscium effigies expresset sunt. - Lugduni, apud Matthiam Bonhomme, M. D. LIIII.

(2) "Clusius était déjà ce qu'on l'a connu depuis, un écrivain élégant, presque un artiste dans le maniement de cette belle langue latine qui servait alors d'organe à l'Europe savante et lettrée. C'est, dit-on, sa plume qui donna la forme, non la matière, à la première édition latine de l'ouvrage de Rondelet sur les poissons. Trois ans, au moins, furent employés à cette tâche. " (J.-E. et G. Planchon, Rondelet et ses disciples). Parmi les poésies liminaires qui, suivant l'usage du temps, ornent le De piscibus marinis, nous trouvons une longue pièce, d'une élégante latinité, intitulée : Caroli Clusii Elegia:

\footnotetext{
Quisquis squamigeros pisces, genus omne natantum, Nosse cupis, presens perlege Lector opus.

(3) Félix et Thomas Platter à Montpellier. 
plantarum historia, il n'oublie presque jamais de dire, en parlant de Montpellier, qu'il y a vécu chez Rondelet. "Eo tempore quo Monspelii apud clarissimum virum Gulielmum Rondeletium, professorem regium, vivebam ", et il donne de temps en temps quelque menu détail qui montre bien quelle fat l'intimité de leurs rapports. - Ils font ensemble de fréquentes promenades, quelquefois des voyages : un jour ils vont de compagnie jusqu'à Carcassonne (1). - Quoique Rondelet n'ait publié aucun ouvrage de phytographie, la botanique avait pour lui beaucoup d'attrait et il s'y était adonné arec ferveur. Comme la plupart des botanistes de cette époque, il possédait un jardin dans lequel il cultivait, avec les espèces médicinales, toutes celles qui offraient quelque intérêt au point de vue botanique. Quand, au cours de ses herborisations, Charles de l'Escluse rencontre un sujet remarquable, il le déracine pour en enrichir le jardin du professeur. C'est ainsi qu'il y transplante la bulbe d'un Narcisse-Tazette trouvé à Maguelone et dont le scape, - chose qui lui a paru bien singulière, - soutenait jusqu'à seize fleurs. Une autre fois, il y apporte une Fougère qu'il nomme "Phyllitis ) et qu'il a prise dans les Cévennes (2).

On voit déjà, par ces détails, combien fut grande l'ardeur du jeune botaniste pour l'herborisation. Il se mit à la conquête des plantes dès les premiers jours de son installation à Montpellier. Il nous apprend, dans le même ourrage, qu'il avait commencé, vers la fin de 1551, à explorer le littoral maritime du Languedoc et qu'il $y$ avait cueilli notamment le Medicago marina (3).

A l'exemple du plus grand nombre des étudiants que réunissait autour de ses chaires l'Université de

(1) Rariorum plantarum historia, p. 341. - En 1552.

(2) Op. cit., pp. 154 et cexiij.

(3) Op. cit., p. cexliij. 
Montpellier, il devait être tenté de franchir la limite qui séparait le Languedoc de la Provence : il n'arait pour cela qu'à traverser le Rhône.

Ce fut au cours de l'année 1552 qu'il effectua son royage en Provence (1). Il vint jusqu'à Marseille, où il avait l'intention de s'embarquer pour l'Italie. Il prit place à bord du navire qui devait l'y transporter. Au dernier moment, une raison imprévue, sur la nature de laquelle il ne s'est pas expliqué, l'empêcha de partir. Vers la fin de sa carrière, faisant allusion à cette circonstance, il constatait, non sans une certaine mélancolie, qu'il n'était jamais allé en Italic : "Je n'ai jamais vu l'Italie, disait-il, bien qu’à trois reprises je me sois mis en route pour m'y rendre: une fois par mer, et, venu à Marseille, j'étais déjà monté sur le bateau qui allait m'y conduire; les deux autres fois par les Alpes, jusqu'au pied desquelles je m'étais avancé, mais chaque fois des afiaires me retinrent. Et c'est pour cela que plus tard je renonçai à toute nouvelle idée d'entreprendre ce voyage (2). )

Nous sarons quelle était la route que prenaient généralement les étudiants de Montpellier, lorsqu’ils

(1) La date de 1552 a été donnée par Clusius lui-même dans son Histoire de quelques plantes rares observées en Espagne. I1 écrivait à propos du "Capnos Fumus terree » rencontré par lui en ce pays, et précédemment dans la Crau d'Arles : "Observare memini... supra Arelatem, dum Massilia per eam urbem anno x. D. III Mompelium redirem. ) Il avait choisi le printemps pour venir en Provence. Il dit en effet dans le même ouvrage qu ï Marseille il trouva le "Tragacantha" (Astragalus Massiliensis Lamk) couvert tout à la fois de fleurs et de fruits. Or, cette Papilionacée commence à fleurir dès le mois d'avril et en mai elle porte simultanément fleurs et fruits.

(2) Rar. plant. hist., p. 22 : "Italiam enim nunquam vidi, licet ter profectionem tentarim, semel conscensa Massiliae navi, bis ad Alpes usque progressus : sed negotia perpetuo me revocarunt. Ideocue in posterum omnem adeundi Italiam cogitationem deposui. ") 
avaient envie de renir visiter la grande cité maritime de la Provence (1). "L'itinéraire suivi au départ de Montpellier conduisait d'abord à Lunel, puis à Saint-Gilles. On franchissait là le petit Rhòne, et. sur la rive gauche de cette branche du ficuve, on abordait en Camargue. On parcourait toute la partic septentrionale du delta, et après avoir traversé le grand Rhône, on alleignait Arles. Au-delà d'Arles, on rencontrait la vaste plaine caillouteuse de la Crau, où l'on faisait halte à l'auberge de SaintMartin, et l'on se dirigeait ensuite soit vers le bourg de Saint-Chamas, soit vers la pelite ville de Salon (2). "

Certaines indications consignées dans le Rariorlim plantarum historia montrent que tel fut, en 1552, l'itinéraire de Clusius. Quelques-unes des étapes du trajet y sont mentionnées: Saint-Gilles, la Camargue, Arles, la Crau et l'auberge de Saint-Martin (3). Il eut l'oceasion de traverser une autre partie de la

(1) “ Un passage des Adversaria nous apprend qu'en venant ì Marseille, les étudiants de Montpellier n'avaient pas seulement en vue l'intérêt de leur éducation scientifique. Avant tout, c'était pour eux un voyage d'agrément... " Dum Monspellio Galloprovinciæ Massileam lusum iremus, complures commilitones... " On pouvait d'ailleurs concilier aisément le grave et le doux, le plaisir et la science, et rien n'empêchait de se livrer, le long du chemin, à des observations phytologiques. " (La Botanique en Provence: Picre Pena et Mathias de Lobel, p. 62.)

(2) Ibid , p. 63.

(3) Il est probable qu'en retournaut Clusius suivit le nême chemin. C'est ce que semble indiquer le texte relatif au "Capnos ») que nous avons cité plus haut. En tout cas, il passa deux fois par Arles et par la Crau, à l'aller et au retour. Il y avait, d'ailleurs, pour les étudiants de Montpellier, d'autres façons de se rendre en Provence, et quelquefois ils venaient ì Marseille par mer. Au sujet de ces voyages en Provence, nous avons donné de curieux détails dans nos diverses publications relatives à La Bolanique en Provence an XYIe siècle (Pierre Pena el Ifathias de Lobel, Félix et Thomas Plutler, Lionurd Runuolf et Jacques Raynaudet.) 
Provence lorsque, en 1554, il quitta définitivement Montpellier. Il se proposait de retourner dans sa patrie ; mais il ne put s'y rendre par le chemin le plus direct et le plus court, qui eût été celui du nord de la France. Il a raconté lui-même qu'à raison de la guerre qui avait éclaté entre l'empereur CharlesQuint et le roi de France Henri II, et ne se souciant pas de traverser des territoires désolés par la présence des armées belligérantes (1), il dut faire un long détour et se diriger vers la Suisse, qu'il atteignit en passant par Nimes, Avignon, Orange, Bollène, Montélimar, Valence et Grenoble (2).

Nous n'aurons pas à suivre au-delà d'Orange et de Bollène le botaniste artésien; nous n'aurons pas davantage à retracer les divers évènements de sa longue existence. Le présent travail ayant pour unique objet l'historique de ses relations avec la Provence, nous devons nous borner à extraire, des nombreux ouvrages qu'il a publiés, tout ce qui se rapporte à la flore provençale.

Rembert Dodoens (3) avait, en 1553, fait paraître son Cruydtboeck. "Cet ouvrage flamand, destiné à la

(1) Rar. plant. hist., p. cxxij : «Observare memini antè quadraginta annos, dùm per Helvetios è Galliâ Narbonensi in patriam rédirem, præclusâ per reliquam Galliam viâ, fervente bello inter imperatorem Carolum $V$ et Gallix regem Henricum II. »

(2) Rariorum aliquot stirpium per Pannoniam observalarum historia, p. 100: "Olim etiam legere memini, dùm Avenione per Arausiorum agrum et Boulline ad Montelimar proficiscerer, Valentiam Allobrogum et Gratianopolin petiturus. ”)

(3) Rembert Dodoens, Dodonceus, né à Malines ou dans la région, vers 1517 ou 1518, embrassa la carrière médicale, et tant par ses ouvrages que par des cures heureuses, y acquit de bonne heure une brillante réputation. L'empereur Maximilien II l'appela dans sa capitale et le prit pour médecin. Au bout de quelques années, dégoûté de la cour, il se démit de ses fonctions. Plus tard l'Université de Leyde lui offrit une chaire qu'il occupa jusqu'à sa mort (1585) et dans laquelle il eut pour successeur Charles de l'Escluse. Une grande amitié liait les 
vulgarisation de la botanique, eut une grande vogue, mais il n'était guère accessible, ni aux provinces wallonnes des Pays-Bas, ni à la France (1). ") Charles de l'Escluse, mis en relation, à son retour du Languedoc, avec le botaniste de Malines, entreprit de traduire le Cruydtboeck en français. Cette traduction, imprimée à Anvers par Jean Loë, parut en 1557, sous le titre suivant: Histoire des plantes en laquelle est contenue la description entiere des herbes, c'est à dire, leurs Especes, Forme, Noms, Temperament, Vertus et Operations... par Rembert Dodoens Medecin de la Ville de Malines et nouvellement traduite de bas Aleman en Francois par Charles de l'Escluse. Suit un petit traité, qui est une ouvre originale du traducteur (2), et qui est intitulé : Petit Recueil auquel est contenue la description d'aucunes gommes et liqueurs, provenant tant des Arbres que des Herbes : ensemble de quelques Bois, Fruicts, et Racines aromatiques, desquelles on se sert és Boutiques... par celuy qui a traduit l'Herbier de bas Aleman en

deux botanistes. Clusius, citant, dans son Hisloire des plantes de Hongrie, le nom de Dodoens, ajoutait: " veteri amicitia mihi conjunctus ». Ce nom demeure attaché à de nombreuses publications botaniques, dont la plus importante est le Stirpium historia Pemptades sex.

(1) Edouard Morren, op : cit.

(2) Le mot originale n'est peut-être pas tout-ì-fait exact, car voici ce que dit l'auteur de cet opuscule dans son "Advertissement au Lecteur » : "J'ay prins ceste hardiesse de recueillir les descriptions de quelques Liqueurs et Racines aromatiques qui estoient semées çà et là par l'Herbier Aleman; et les traduire en langue Française, en y adjoustant les descriptions de quelques autres Liqueurs, et Fruicts, et Bois aromatiques qui n'y estoient contenues, lesquelles ay tiré hor's des Auteurs anciens, et ramassé comme en un corps, sans le sceu toutes fois et consentement de celuy qui a fait l'Herbier... »- Nos lecteurs comprennent que par Herbier, Clusius désigne le Cruydtboeck. Le mot Herbier ou Herbaire, en latin Herbarium, s'appliquait alors au genre d'ouvrage que nous appelons aujourd'hui une Flore. 
Francois. - Nous signalons ce premier ouvrage de Clusius parce que nous aurons à y prendre la description de l'une des plantes qu'il avait observées en 1552 aux environs de Marseille.

En 1563, il fut appelé à Augsbourg par un riche habitant de cette ville, Antoine Fugger, qui désirait lui confier la mission de conduire ses deux jeunes fils en Italie (1). Le voyage eut lieu; mais par suite d'une circonstance demeurée obscure, le programme en fut modifié au dernier moment, et l'on substitua l'Espagne à l'İtalie. Les trois voyageurs parcoururent la péninsule ibérique, sur le sol de laquelle Clusius fit d'importantes découvertes botaniques. Il en rapporta les matériaux du livre qu'il fit imprimer en 1576 : Rariorum aliquot stirpium per Hispanias observatarum historia (2). - Il y a mentionné, avec leur habitat provençal, neuf des espèces dont il avait, au cours des herborisations de 1552, constaté la présence sur le territoire de la Provence.

L'Histoire des plantes d'Espagne fut dédiée à l'empereur d'Allemagne Maximilien II. Ce prince avait fait venir Charles de l'Escluse à Vienne, pour l'atlacher à la maison impériale. Clusius profita de cette circonstance pour entreprendre, à travers l'Autriche et la Hongrie, de nombreuses herborisations dont il consigna plus tard les résultats dans son Rariorum aliquot stirpium per Pannoniam, Austriam et vicinas Provincias observatarum historia (3). Disgracié sous Rodolphe II, le botaniste

(1) Ce fut en cette occasion que Charles de l'Escluse, venu à Augsbourg, y fit la connaissance de Léonard Rauwolff. Celui-ci lui montra son herbier, renfermant les plantes qu'il avait colligées en France, en Italie et en Suisse, de 1560 à 1563. (V. à ce sujet notre étude sur Léonard Rautwolff.)

(2) Antverpice, ex officina Christophori Planlini, Archilypographi Regii, M.D.Lxxvi.

(3) Antverpie, c.x officina Christophori Planlini, x.D. Lxxxun. 
quilta la capitale de l'Autriche et s'établit à Francfort-sur-le-Mein. Il y vécut dans une profonde retraite, jusqu'en 1593, année où les curateurs de l'Université de Leyde lui offrirent la chaire que la mort de Dodoens venait de rendre vacante. Il l'accepta et y siégea pendant seize ans. Il mourut à Leyde le 4 avril 1609: il venait d'entrer dans sa quatre-vingt-quatrième année.

Durant cette dernière période, "Clusius prépara les grands ouvrages qui résument l'activité d'une longue carrière de travail et qui l'ont fait placer au rang des fondateurs de la botanique. Ses œurres complètes parurent en deux rolumes in-folio successivement en 1601 et en 1605 (1) ). Le premicr de ces volumes est le célèbre Rariorum plantarum historia (2); l'autre, un recueil de diverses ourres dont la principale porte le titre de : Exoticorum libri decem (3).

Enfin, deux ans après la mort de l'illustre écrivain, ses éditeurs assemblèrent, sous le titre de Curce posteriores (4), différents opuscules que cet infatigable travailleur avait continué d'écrire pour amender ou compléter ses publications antérieures.

Pendant le long intervalle qui s'était écoulé depuis son départ de Montpellier en 1554, Charles de l'Escluse n'avait pas trouvé l'occasion de revoir le midi

(1) Edouard Morren, op. cit.

(2) Antverpia, ex officina Planliniana, apud Jounnem Morelum, 1601. - Clusius fondit dans ce grand ourrage ses anciennes publications relatives à la flore espagnole et à celle de l'Autriche et de la Hongrie.

(3) Ex officina Planliniana Raphelengii (Leyde), 1605. François Ravelingen, plus connu sous le nom de Rapheleng out Raphelengius (Peirese écrivait Raphelenge), entré comme correcteur dans limprimerie de Christophe Plantin à Anvers, devint en 1565 le gendre de celui-ci. Il vint it Leyde en 1585 pour diriger limprimerie que son beau-pere y avait établie, (qui lui fut léguée par Plantin, et qu'il transmit à ses enfants.

(4) In officina Plantiniana Raphelengii, 1611. 
de la France. Vers les dernières années de sa vie, et tandis qu'il s'occupait à Leyde de la révision et de la publication de ses écrits, une circonstance fortuite se produisit qui lui permit d'y ajouter quelques détails nouveaux, relatifs à des végétaux de la Provence.

En 1602, le vieux botanographe eut à répondre aux avances que lui fit un jeune gentilhomme provençal, alors inconnu, mais qui devait un jour rendre célèbre son nom seigneurial de Peiresc (1).

Nous avons, dans un travail récent (2), exposé

(1) Nicolas-Claude Fabri naquit le 1er décembre 1580, au château de Belğencier (petite commune qui appartient aujourd'hui à l'arrondissement de Toulon). Il était fils de Rainaud Fabri, sieur de Callas, conseiller à la Cour des Comptes, Aides et Finances séant à Aix. Il porta d'abord, comme son père, le titre nobiliaire de Callas. En 1604, il y substitua celui de Peirese : c'était le nom d'une terre apportée en dot par sa mère et située dans la Haute-Provence; mais, dans les premiers temps, au lieu de Peiresc, il écrivait Peirets. 11 notifia ce changement de nom à Charles de l'Escluse dans le post-scriptum d'une lettre qu'il lui adressait d'Aix le 25 février 1604 : «... Vous pourrés aussy sçavoir " qu'au lieu du dessus qu'aviés accoustumé de faire en mes " lettres, au sr de Callas, etc., il faudra changer et dire d'ores " en avant, au $\mathrm{s}^{r}$ de Peirets chez Monsr le conseiller de Callas à " Aix en Provence. " Ce dernier, qui était l'oncle et le parrain de Nicolas-Claude, lui transmit en 1607 son office de conseiller au Parlement de Provence. Le rôle que l'érudit magistrat a joué dans " la République des Lettres », comme on disait alors, est trop connu pour que nous ayons besoin d'y insister. Qu'il nous suffise de remettre sous les yeux de nos lecteurs l'éloquente appréciation de M. Léopold Delisle, quand, ayant à grands traits résumé la carrière de Peiresc, il le louait d'avoir été " un amateur de génie, qui a largement contribué au progiès des connaissances humaines, et qui a poussé jusqu'aux dernières limites la modestie, le désir d'obliger, la curiosité, le goût du beau, la passion de la lecture et l'amour désintéressé de la science. " (Un grand amateur français du xrir siècle : FABRI DE PEIREsc, lecture faite par MI. Léopold Delisle a la séance publique de lAcadémic des Inscriptions et Belles-Lettres en 1888).

(2) L'Indigénat en Provence du Styrax officinal: Pierre Pena el Fubri de Peiresc (Marseille, Aubertin et Rolle, éditeurs, 1901). 
comment ce jeune homme se mit en rapport avec Charles de l'Escluse. « Peiresc, encore adolescent, s'était rendu à Padoue, ville savante où il comptait poursuirre ses études et donner satisfaction à l'ardeur qui le portait indistinctement vers toutes les branches des connaissances humaines. Pendant son séjour à Padoue, il fut reçu, apprécié et pris en affection par un humaniste de mérite, Paul Gualdo, alors vicaire-général du diocèse, et aussi par JeanVincent Pinelli, un bibliophile érudit dont la renommée était grande, et qui correspondait avec Scaliger et Clusius. Pinelli mourut en 1601. Le duc della Cerenza, neveu du défunt, étant obligé de quitter Padoue, chargea Gualdo de recevoir en son absence les lettres qui viendraient à l'adresse de feu son oncle. Justement, il arriva des lettres de Scaliger et de Clusius, accompagnant l'envoi de divers objets offerts par chacun des deux savants à Pinelli. Gualdo montra le tout à Peiresc. Celui-ci, pris d'un vif désir d'entrer en correspondance avec ces hommes illustres, saisit au vol l'occasion qui se présentait de leur écrire : il leur offrit ses services, se déclarant tout disposé à leur fournir, le cas échéant, les communications pour lesquelles ils avaient l'habitude de recourir à Pinelli (1). ")

Charles de l'Escluse accueillit avec bienveillance les ouvertures de ce jeune correspondant si plein de

(1) Pinelli était un botanophile, et il envoyait des plantes rares à Clusius. Celui-ci, dans un Appendice à son Histoire des plantes, écrit à propos d'un Narcisse : "Quum ejus bulbum ab illustri viro Joanne Vincentio Pinello, missum Patavio sub initium Novembris à Christi nativitate millesimi sexcentesimi accepissem, illico in fictili terræe commitebam. ) C'est au même Pinelli qu'il a dédié son Histoire des Champignons de Hongrie. Gassendi, dans sa Vie de Peiresc, rapporte que l'envoi fait par Clusius à Pinelli, arrivé à Padoue après la mort du destinataire, se composait du Rariorum plantarum historia et d'un portrait de Mathias de Lobel. 
bonne rolonté, se montra reconnaissant, l'encouragea par le don de son portrait et d'un exemplaire du Rariorum plantarum historia, et lui envoya la liste des plantes méridionales qu'il désirait recevoir.

Les lettres de Peiresc qui ont été conservées (1) témoignent du zèle avec lequel il s'efforça de donner la plus complète satisfaction aux desiderata du célèbre professeur de Leyde.

Il se met personnellement en campagne, et comme il se défie un peu de ses propres lumières, il se fait accompagner, dans ses herborisations, par un botaniste expérimenté, capable de déterminer les plantes en toute saison (2). Il utilise, pour récolter des graines, même les parties de chasse auxquelles il prend part de temps en temps (3). De plus, " en homme loujours disposé à ne rien épargner pour rendre service à ses amis, il a recours à des méde-

(1) Les lettres de Peiresc, éparses dans diverses bibliothéques, soit en originaux, soit a l'état de brouillons ou de copies, ont eté publiées sur l'initiative du Ministre de l'Instruction publique et ont pris place dans la Collection de documents inédits sur l'Histoire de France. Le soin de les recueillir et de les coordonner avait été confié à feu M. Tamizey de Larroque, correspondant de l'Académie des Inscriptions et Belles-Lettres. Sept volumes ont paru de 1888 à $18 \% 8$ (Paris, Imprimerie Nationale). Le tome V'II contient sept lettres adressées à Charles de l'Escluse. Nais Tamizey de Larroque, ignorant que la Bibliothèque de l'Lniversité de Leyde posséde les originaux de huit lettres de Peirese à Clusius, a involontairement exclu de son recueil deux lettres écrites de Paris, et restées inédites. Nous en citerons divers passages au cours de ce travail et nous les donnerons in extenso dans un appendice final.

(2) " Comitem adhibuit Botanieum quendam plantarum quovis tempore internoscendarum peritum. " (Gassendi, Vita Pcireskii).

(3) "J'ay prins plaisir moy-mesme sourentesfois en allant a " la chasse de faire eucillir de toutes les semences qui me sem" bloient les plus extraordinaires, afin de rencontrer celles que " vous aviez marqué ". (Lellre de Peiresc à Charles de l'Escluse Aix, 15 février 1605). 
cins et à des apothicaires établis en différentes localités de la Provence (1). ")

Tandis que ces relations épistolaires suivent leur cours, le jeune érudit provençal a conçu pour Charles de l'Escluse des sentiments d'affectueuse vénération dont la force augmente de jour en jour. Il a maintenant une ambition qui lui tient fort au cœur. Il voudrait que l'éminent botaniste, nonobstant son grand àge et ses infirmités, - il a près de quatre-vingts ans et il est goutteux, - consentit à se mettre en route pour venir en Provence. Il lui offre l'hospitalité en son château de Belgencier. Il espère vaincre les hésitations que fera naître chez Clusius la perspective d'un long et difficile voyage, en lui parlant des " plantes singulieres " dont la contrée est abondamment pourvue, et surtout du Styrax découvert par Pierre Pena, quarante ans auparavant, sur les collines environnantes. C'est dans une lettre qui accompagnait un de ses envois de plantes, que Peiresc formule son invitation : " Il y en a quel" ques-unes, écrit-il, que j'ay faict r'ammasser sur " le rivaige de la mer, mais la plus part sont esté " choisies par les bois et collines qui sont autour " d'un petit villaige nommé Beaugentier, lequel est " situé entre la ville de Tollon (2) et les montagnes " de la Sainte-Baulme (3), au dessoubs de la Colle

(1) L'Indigénal en Provence du Styrax officinal: Pierre Pena et Fabri de Peiresc.

(2) Toulon.

(3) Pour ceux de nos lecteurs à qui le site célèbre de la SainteBaume n'est encore connu que de nom, nous reproduisons la description sommaire que nous en avons donnée dans notre livre sur Picrre Pena et Mathias de Lobel: "La Sainte-Baume tire son nom diune grotte (baumo en provençal) au fond de laquelle, suivant une ancienne tradition, la Magdelaine de l'Evangile, miraculeusement transportée en Provence, serait venue expier les légèretés de sa vie passée et achever ses jours dans les larmes et la prière. Cette grotte s'ouvre, à une grande hauteur, au milieu de la paroi verticale d'une chaine calcaire 
“ d'Anis(1) tant renommée pour les plantes singu" lieres que les médecins y treuvent d'ordinaire. "Nous y avons une maison où j’ay faict quelque " sesjour cest automne passé, mais je vous asseure " que ce n'a pas esté sans vous y regrelter, car je " vouldrois bien vous y tenir, pour vous y caresser " suivant noz petites forces, et vous y faire remarquer " des plus belles et plus rares plantes de toute la "Provence, et nommement le Styrax qui y croist en " grande abondance et ne se treuve poinct en aucun " aultre lieu de ce païs hors du terroir dudict lieu " de Beaugentier (2).)

Le vicillard ne se laissa point séduire et déclina l'invitation : il avait pour cela de trop bonnes raisons. Ce fut alors Peiresc qui résolut d'aller luimême faire une visite à son illustre correspondant. Il entreprit ce voyage en 1606 . Il se rendit d'abord en Angleterre, où il rit Mathias de Lobel. Au retour,

taillèe à pic du côté du nord, et dont le point culminant atteint presque une altitude de 1200 mètres. Sur le versant septentrional de la chaîne, au-dessous des escarpements, s'étale une superbe forêt que le souvenir de sainte Magdelaine a de tout temps protégée contre la cognée. Le Hêtre, l'If, l'Erable à feuilles d'Obier, le Tilleul, lllea aquifolium y sont les essences dominantes. Sous ces grands arbres et dans les escarpements de la montagne se développe une florule subalpine qui, pour la Provence partout ailleurs chaude et sèche, constitue une précieuse rareté. Aussi depuis le xvie siècle une multitude de botanistes sont venus y herboriser. 》)

(1) Colle est un mot provençal qui signifie colline. Celle dont parle Peiresc continue à porter le même nom, qui se prononce Agnis, avec l'accent tonique sur la première syllabe. Le sommet, appelé Mourre d'Agnis, a plus de 900 mètres d'altitude, et domine, du côté nord, le village de Signes.

(2) Cette lettre est une de celles dont l'Université de Leyde possède l'original. Nous l'avons citée, non point d'aprés le texte publié par Tamizey de Larroque, mais d'après une copie soigneusement collationnée sur l'original, que M. le docteur P.-C. Molhuysen, conservateur de la Bibliothèque universitaire de Leyde, a eu la bonté de nous fournir. 
il aborda en Hollande, vint à Leyde, et se présenta chez Clusius. Il le trouva, rapporte Gassendi, en train de faire graver, pour un appendice à l'Histoire des plantes exotiques, un champignon que Peirese lui avait envoyé de Provence, en même temps, ajoute le biographe, qu'une quantité presque innombrable de plantes, de racines et de graines. En outre, le visiteur, auquel, lorsqu'il traversa Paris, Vespasien Robin avait montré les fruits de certaines plantes étrangères inexactement décrites par Clusius, put signaler à celui-ci les rectifications à faire (1).

Revenu en Provence, Peiresc continua de correspondre avec Charles de l'Escluse. La dernière lettre qu'il lui écrivit, partie d'Aix en février 1609, ne parvint à Leyde qu'après la mort du botaniste, survenue, nous l'avons dit, le 4 avril de la mème année (2). Cette lettre contenait un dessin de Tragacantha que l'éditeur des Curæ posteriores, comme nous le verrons plus loin, eut soin de faire graver pour l'insérer dans le recueil posthume.

Nous allons maintenant passer en revue les diverses espèces appartenant à la flore die Provence que

(1) « Deprehendit autem [Clusium] imprimi curantem in Appendice altera Exoticorum plantarum figuram Fungi Coralloidis quem ad illum ex Provincia, cum aliis penè innumeris plantarum, radicum, seminumque generibus transmiserat. Commodùm etiam illum admonuit circa Indicas quasdam plantas, in quibus describendis errasset, et quasdam, de quibus niliil audiisset, idque prolatis commentariis juxta ostensos sibi Parisiis à Vespasiano Robino fructus. ") (Gassendi, Vita Peireskii.)

(2) Gassendi nous apprend que pour arriver à Leyde, une lettre devait passer par Augsbourg et Francfort. Elle y mettait du temps et courait bien des hasards. "Porro ambages erant magne, cùm oporteret literas Auğustâ, atque Francofurto transdere in Hollandiam. » (Op. cit.). 
Charles de l'Escluse a mentionnées dans ses ourrages avec indication de leur habitat provençal (1).

Nous donnerons à la suite une des listes, - la seule qui nous soit parrenue, - de plantes envoyées à Leyde par Peiresc.

Fumaria spicata L. - Clusius donnait à cette espèce le nom de "Capnos tenuifolia ". Il l'avait observée en divers lieux de la Gaule Narbonaise (2), et " principalement, dit-il, au-dessus d'Arles, quand, en 1552, je retournai, par cette ville, de Marseille à Montpellier (3). » - Cette mention, insérée dans le Rariorum plantarum historia, avait déjà figuré dans le Rariorum stirpium per Hispanias observatarum (4).

Lepidium Draba L. - C'est dans la Camargue que notre auteur rencontra cette Crucifère, si abondante partout, qu'il a enregistrée dans le Rariorum plantarum sous le nom de «Draba I vulgaris ». Il a

(1) On ne s'étonnera pas que le nombre de ces espèces soit minime. Charles de l'Escluse ne vint qu'une seule fois en Provence. En outre, comme la flore de la Provence ressemble fort à celle du Languedoc, il s'abstint, sans doute, de noter, pendant son voyage à Marseille, les plantes qu'il avait déjà observées aux alentours de Montpellier.

(2) Lexpression de "Gallia Narbonensis", - nom d'une ancienne division administrative qui, sous la domination romaine, avait, pendant quelque temps, englobé les territoires devenus plus tard ceux de la Provence et du Languedoc, permettait aux écrivains du $\mathrm{xvI}^{e}$ siècle de ne point distinguer entre les deux provinces et de les désigner simultanément.

(3) Rariorum plantarum hisloria, p. clxxxviij : "Nonnullis Narbonensis Galliae locis observare memini, presertim supra Arelatem, dum Massiliâ per eam urbem, anno M. D. LII, Mompelium redirem. ")

(4) P. 374. 
désigné d'une façon très précise le grand delta rhodanien. "Je me souviens, écrit-il, d'avoir cueilli cette plante dans l'île que forme le Rhône, partagé en deux bras, entre l'église de Saint-Gilles et Arles, tandis que je faisais route vers Marseille (1). »

Rhus Cotrnus L. - « Je me rappelle, - dit-il dans le Rariorum aliquot stirpium per Pannoniam observatarum historia, - avoir pris autrefois le Cotinus (2), lorsque, parti d'Avignon, je me dirigeais, à travers le territoire d'Orange et de Bollène, du côté de Montélimar, ayant l'intention de gagner ensuite Valence en Dauphiné et Grenoble (3). » - Pierre Belon, ayant affirmé, dans ses Remonstrances sur le default de labour, que "Sumacs ont leurs semences vulgairement vendues es boutiques des Apoticaires, cueillie des Guarrigues d'autour Montalimar et Orenge pres du Rhosne », Charles de l'Escluse, dans la version qu'il a donnée de cet ouvrage sous le tilre de De neglecta cultura (4), a traduit ainsi ce passage : " Rhus in solitudinibus Montelimar et Auraica vicinis ad Rhodanum crescit, cujus semina in Phar-

(1) Rar. plant. hist., p. cxxiij : "Memini etiam hanc plantam legere in insula illa quam facit Rhodanus in duo cornua divisus inter I). Egidii phanum et Arelatem, dum Massiliam proficiscerer. ")

(2) Quelques floristes du xvie siècle donnaient le nom de "Coccygria " ou "Coggygria " au Rhus Cotinus de Linné. D'autres l'appelaient "Cotinus Plinii ». Dans le Rariorum plantarum historia, où il a transporté l'indication d'habitat déjà consignée dans sa Flore de Hongrie et d'Autriche, il s'est servi du mot Coggygria.

(3) P. 100.

(4) Petri Bellonii Cenomani medici de neglecta Plantarum Cultura, atque earum cognitione Libellus : edocens qua ratione Silvestres arbores cicurari et mitescere queant. - Imprimée une première fois séparément, cette traduction a été jointe ensuite au volume des Exotiques. 
macopolarum officinis venalia sunt. „) Et il a joint à cette phrase une note marginale où il dit : "Carolo Clusio istac iter facienti nullum Rhus conspectum, sed Coccigrya plurima, non minus Rhoë ad densanda coria utilis : sed agro Mompelliano frequenter. »)

Anagyris fatida L. - Il existe, à quatre kilomètres d'Arles, un petit massif de roches calcaires, qui formait un îlot, au temps où la ville elle-même était entourée d'étangs et de marais. Des ruines encore imposantes couronnent le sommet du monticule : ce sont les ruines de Montmajour, abbaye bénédictine dont jadis la célébrité fut grande (1). On trouve autour de ses vieilles murailles de nombreux pieds d'Anagyris foetida. L'Anagyre se perpétue là depuis

(1) " Non loin d'Arles, à Mont-Majour, sur un rocher alors entouré de marais, les Bénédictins avaient fondé, au x siècle, un de leurs monastères. Il n'en reste aujourd'hui que des ruines; au moyen âge, il était dans toute sa splendeur, et comptait parmi les Lieux saints de Provence les plus vénérés. En 14:9, au mois de mai, nous dit Boysset, fut donné lou perdon de $S$. Peyre de Montmajour. Il a tout vu, et il déclare être en deçà de la vérité, en évaluant à 150.000 le nombre des romicus qui y vinrent : en loqual perdon foron romieus, e vengueron de lot lo monde plus de cent cinquanta milia chrestians e chrestianas, $e$ plus vous dic per veritat, non solamen per atsir, mas per veser... Louis II, roi de Sicile et comte de Provence, y était présent en noble compagnie. En cette année 1409 , le 16 janvier, au château d'Angers, Yolande d'Aragon lui avait donné le deuxième de ses fils, celui-là même qui devait être le roi René, et l'heureux père, alors en Provence où il se préparait à entreprendre à nouveau la conquête de Naples, s'était fait romicu à Montmajour pour en rendre grâces à Dieu. ) (Charles de Ribbe, La Société provençule à la fin dlu moyjen àge, Paris, 1898). Bertrand Boysset, eitoyen d'Arles, a laissé des mémoires " contenant ce qui est arrivé de plus remarquable, particulièrement à Arles et en Provence, depuis 1372 jusqu'en 1413 ». Ces mémoires ont été publiés dans le Musée, revue historique et littéraire d'Arles (1876-1877). 
un temps immémcrial (1). Le premier document imprimé qui fasse mention de cet habitat est l'opuscule que Conrad Gesner a intitulé Horti Germaniæ et qu'il fit imprimer à Strasbourg, en 1561, à la suite des ouvres de Valerius Cordus : “ Anagyris, - écrivait l'illustre naturaliste de Zurich, - prope Arelaten locis paludosis gignitur, Matthiolo ignota...(2). »

(1) Ch. Martins, directeur du Jardin botanique de Montpellier, a publié dans le Bulletin de la Société botanique de France (t. xvi, pp. 100-102) un article intitulé: L'Anagyris foetida considéré comme un des types exotiques de la flore française, où il s'exprime ainsi : "La localité de Montmajour, ancien couvent de Bénédictins, bâti sur un îlot molassique de la plaine d'Arles, est connu depuis longtemps; mais le voisinage des ruines, au milieu desquelles il se trouve, pourrait faire concevoir quelques doutes sur sa spontanéité; il y existe en tout cas depuis fort longtemps, car il est cité p. 391 dans le P'inax de Gaspard Bauhin, imprimé à Bâle en $1623 \ldots$ Cette plante est, selon moi,une espèce tertiaire ou une forme dérivée d'une espèce tertiaire qui, comme d'autres types exotiques, le Palmiernain (Chamcrops humilis), le Myrte, le Caroubier (Ceratonia Siliqua), le Laurier d'Apollon et le Laurier-rose, ont survécu à l'époque glaciaire dans le midi de la France, seulement dans quelques localités privilégiées, mais se sont maintenus partout dans le reste du bassin méditerranéen. ") - L'habitat arlésien de l'Anagyris foetida était comnu bien avant la publication du Pinax, ainsi qu'il résulte d'un texte de Conrad Gesner que nous allons citer et qui paraît avoir échappé à Ch. Martins.

(2) A la façon dont est conçue la phrase de Gesner, il semblerait que l'Anagyris est une plante hydrophile, naissant au milieu des marais. L'indication donnée dans les Horli Germanice est pourtant d'une stricte exactitude, puisque le rocher de Montmajour, où croît cette plante, était alors, ainsi qu'on l'a vu, entouré d'eau stagnante. - Plus d'un siècle après Gesner, Tournefort se rendit à Arles pour y prendre l'Anagyre. " $M \mathrm{I}$ de Tournefort, écrivait Garidel, nous avoit aporté cet arbuste d'une petite colline qui est auprès d'Arles, où Clusius l'avoit observée, pour la planter dans le jardin de $\mathrm{M}^{\mathrm{r}}$ de Beaumont, où elle a été cultivée pendant un fort longtems. 》) (Hisloire des plantes qui naissent aux environs d'Aix, p. 32.) - Cette rare Papilionacée n'a point abandonné les ruines de la vieille abbaye et nous y avons nous-même constaté récemment sa persistance. - Dans le Catalogue des Plantes de Provence (Marseille, 1881- 
D'où Gesner tenait-il la connaissance de ce fait? Avait-il lui-même vu et cueilli l'Anagyris lorsqu'il vint dans le Midi de la France (1)? Quoi qu'il en soit, la présence à Arles de cette rare espèce était connue à Montpellier, et quand Charles de l'Escluse manifesta l'intention de se rendre en Provence, Guillaume Rondelet lui conseilla d'aller, puisqu'il devait passer par Arles, rechercher l'Anagyre de Montmajour. C'est ce que Clusius ne manqua point de faire. Il retrouva plus tard en Espagne, près de Séville, de Malaga et de Valence, la même Podalyriée; et dans son histoire des plantes espagnoles, il raconta qu'il l'avait vue jadis, pour la première fois, aux environs d'Arles, d'après les indications que lui donna Rondelet : "Primò hanc arbusculam nascentem inveni primo ab Arelate lapide, saxoso quodam colle qui dicitur Divi Antonii, monente clarissimo viro, eodemque professore primario Academix Monspelians D. Gulielmo Rondeletio (2). " Cette phrase a été reproduite, avec quelques légères variantes, dans le Rariorum plantarum historia (3).

1891). Honoré Roux a indiqué, pour l'Anagyris fotida, la station de Nontmajour, en ajoutant : " où il a été planté ". - L'auteur du Catalogue, que nous avons personnellement connu et quelquefois accompagné dans ses herborisations, ne nous a jamais dit sur quelle autorité il se fondait pour affirmer que l'Anagyre n'était point spontané en cet endroit.

(1) "Conrad Gesner, l'illustre naturaliste de Zurich, ne fit qu une courte apparition à Montpellier, vers la fin de l'année 1540 , peut-être au commencement de lannée 1541. Il ne s'y arrêta pas longtemps, dit-il, parce qu'il ne trouva pas de médecin qui pût le loger chez lui, et qu'il aurait voulu profiter de la conversation quotidienne de médecins distingués, plutôt que des leçons publiques. Il avoue, néanmoins, y avoir gagné quelques connaissances en anatomie et en botanique. ») (J.-E. et G. Planchon, Rondelet et ses disciples, Appendice.)

(2) P. 189.

(3) P. 93. 
Astragalus massiliensis Lamk. - Lorsque Charles de l'Escluse vint à Marseille en 1552, il alla herboriser près du rivage de la mer; il y rencontra la Papilionacée épineuse et frutescente que les floristes du $x I^{\mathrm{e}}$ siècle appelaient " Tragacantha ", à laquelle nous appliquons aujourd'hui la dénomination, créce par Lamarck, d'Astragalus massiliensis. Il donna de cette plante une description détaillée dans le Petit Recueil d'aucunes gommes et liqueurs qu'il publia en 1557 , nous l'avons dit, à la suite de sa traduction française du Cruydtboeck de Dodoens.

Nous transcrivons ici en son entier le chapitre xvi de cet opuscule (1). Nos lecteurs y verront Clusius, alors à ses débuts comme descripteur, manifester déjà ces qualités de précision qui ont fondé sa renommée :

"La forme. - Tragacantha à mout de branchettes ramues, lentes et flechiles (2), estendues au large, de sorte qu'une plante occupe aucune fois pied, ou pied et demi de terre en rondeur. Les feuilles sont petites, comme celles de la Lentille, blanchàtres, et quelque peu lanugineuses, situées l'une à l'opposite de l'autre le long d'un pedicule ou queüe (3), ne plus ne moins qu'à la Lentille. La fleur ressemble à celle du Cicer, blanchâtre, aucune fois distinguée de lignes purpurées. La graine est enclose en petites siliques, semblable bien pres au Lotus sylvestris. Toute la plante est garnie de tous costés d'espines bien aigües, poignantes et fermes. La racine s'estend en longueur sous la terre, comme celle de la Regulisse vulgaire, jaulne par dedans et noire par dehors, lente et difficile à rompre, laquelle jette és grandes chaleurs, comme és jours caniculaires, une gomme blanche qui se trouve attachée à icelle.

(1) Le titre de ce chapitre est ainsi conçu : «De Tragacantha. Chap. XVI. Tragacantha. Espine de bouq. »

(2) Souples et flexibles:

(3) Rachis de la feuille. 
"Le lieu. - Tragacantha croist en Mede et Crete, comme dit Pline; il s'en trouve aussi en autres regions, comme en la Province (1) pres de Marseille là où j'en ay trouvé en abondance.

"Le temps. - Tragacantha fleurit au mois d'avril. La graine est meure en juin, et és jours caniculaires se trouve la gomme attachée à la racine.

( Les noms. - Cette plante est appelée en Grec Toryaxdy incognue és Boutiques, voire mesme de ceux chez lesquelz elle croist (2). »)

Le Petit Recueil présente en outre, encadré par le texte, une figure du ( Tragacantha ) gravée sur bois, d'une exactitude très suffisante, dessinée d'après nature, sans aucun doute, par l'auteur lui-même pendant son séjour à Marseille.

En Espagne, Charles de l'Escluse trouva près de Cadix, et en une autre localité dépendant du royaume de Grenade, une plante, alors dépourvue de fleurs et de fruits, mais qui lui sembla presque identique " quàm simillima ", disait-il, au Tragacantha de Marseille. Pourtant les folioles étaient caduques et non persistantes comme chez la plante de Provence. Il crut donc avoir affaire à une espèce différente, et en la décrivant dans l'ouvrage consacré à la flore d'Espagne, il lui donna le nom de «Tragacantha altera " ou " Poterium ». A cette occasion il rappelle sa trouvaille de Marseille: « Tragacanthr, quam aliquando Massilia florentem et fructu pragnantem observavi, quàm simillima est hæc planta... (3). »)

(1) Provence.

(2) Allusion évidente aux apothicaires de Marscille, chez lesquels, ou quelques-uns d'entre eux, Clusius était, sans doute, allé vérifier le fait.

(3) Rar. per Hispan., p. 215. 
Tout ce passage fut ensuite reproduit dans le Rariorum plantarum historia(1).

Même après la publication de ce grand ouvrage, la question du Tragacantha continua de préoccuper Clusius; il aurait eu le désir de revoir la curieuse plante observée par lui, cinquante ans avant, aux environs de Marseille, et qu'il avait décrite dans le Petit Recueil.

Aussi, quand l'obligeant et zélé Peiresc offrit arec tant d'empressement de lui envoyer des plantes de Provence, il se hâta de réclamer des graines de Tragacantha, au moyen desquelles il espérait voir pousser à Leyde des sujets dont il aurait tout le loisir de suivre le développement.

Par certaines lettres du jeune botanophile d'Aix qui nous sont parvenues, nous connaissons quelques-uns des desiderata du vieux botaniste. Celui-ci, enroyant à Aix, en 1603, son portrait et un exemplaire du Rariorum,demandait en même temps des graines de l'Astragale marseillais. Peiresc répondit le 25 février 1604 :

" Je serois bien en peine de trouver des termes " tels que je desirerois pour vous remercier selon " mon devoir de vostre livre des plantes et de vostre " portraict, que je reçus sur la fin de decembre der" nier, le tout tres bien conditionné, dont je vous " demeureray redevable à jamais. Je n'ay regret " d'aultre chose si ce n'est de ce que vostre lettre ne « m’a esté rendue un mois plus tost, carj'eusse tasché " de recouvrer encor ceste année de la graine de " Tragacantha que vous desirez: ce qui ne se pourra " faire jusqu’à l'année qui vient. Cependant j'ay " jugé que vous ne treuveriez peult estre pas mau" vais que je rous envoyasse de la racine. Et de

(1) P. 107. 
“ faict j'en ay mandé cüeillir à Marseille et ensemble " un peu d'une aultre plus rare que les mariniers " appellent Tartonraire et de laquelle ils se servent " pour se purger d'autant qu'elle faict une merveil" leuse operation tant par le haut que par le bas. " J'en ay rempli une petite boitte que je vous " envoyerai par la premiere commodité, dans " laquelle vous treuverez aussy un peu de graine " fort fresche de nostre Seseli de Marseille, et la ( racine d'une aultre plante qui est assez lamilicre (" en cez quartiers, que l'apoticaire appelle Cento" nica : je ne sçay s'il se trompe. On m’a conseillé " d'enfermer le tout dans un peu d'argille paistrie " avec le miel. Dieu veuille que le tout puisse " arriver sain et sauve! C'est bien en ceste sorte " que se conservent les greffes qu'on nous apporte " des pays orientaulx. ")

La boite promise est partie pour Leyde. Aura-t-elle échappé à toutes les vicissitudes qui menacent de scmblables expéditions et sera-t-elle arrivée en bon état? Peiresc n'est pas sans quelque inquiétude. Il écrit de nouveau, et dans une lettre dont nous ne connaissons pas la date, mais qui est manifestement postérieure à celle du 25 février 1604, il s'exprime ainsi :

( Despuis avoir receu vostre beau livre Rariorum " plantarum dont je vous remercie de rechef très " humblement, je rous escrivis par la voye de " messicurs les Bonvisi, et quelques jours apres je " vous envoyai par la voye de la derniere foire de " Francfort une boitte (dont le port estoit payé jus" qu’à Francfort) plaine de racines de Tragacantha " et de quelques autres plantes de cez quartiers... " J'attends vostre response pour sçaroir si vous " aurez pour agreable que je vous en envoye d'au" tres. Et cepandant je procureray d'aroir de la 
" graine du Tragacantha pour vous la faire tenir, " s'il est possible, par la foire de septembre. "

Une nouvelle lettre de Charles de l'Escluse arrive à Aix le 10 septembre 1604 . Il insiste pour aroir ses graines de Tragacantha. Mais à cet égard Peiresc joue de malheur. Les apothicaires marseillais qu'il a chargés dela récolte de ces graines se sont moqués de lui, évidemment : ils soutiennent que le Tragacantha ne fructifie pas dans le terroir de Marseille. En préparant un nouvel envoi, le bon Peiresc a done le regret de ne pouvoir y joindre l'objet que Clusius désirait le plus; il l'en informe par une lettre qu'il écrit d'Aix le 15 février 1605 :

" Suivant ma promesse et voz commandements, " ayant mandé diverses copies de la liste des plantes " que vous desiriez à plusieurs medecins et apoti" caires de ce païs, je n'ay sceu recouvrer aultres " graines pour ceste année que celles que vous (" recevrez dans une boette à ovalle, à ceste prochaine " foire de Francfort dans laquelle boette est encloz " tout ce que vous treuverez cotté en l'inventaire " que je rous mande maintenant avec promesse " infaillible d'enroyer, s'il plaict à Dicu, l'année qui " vient toutes les aultres semences que nous n'arons " pas sceu recouvrer astheure (1), tant pource que " le temps de les recueillir estoit desja passé lorsque " vostre lettre me fust rendüe (qui ne fust que le " 10 septembre 1604): que pour la negligence de " ceux à qui j’en avois donné la charge, laquelle " vrayment ne se peult excuser, nommement pour la " Tragacantha dont je suis resolu d'aller moy " mesme chercher la graine lorsque le temps en sera " venu, puisqu'eux n'en savent poincl trouver. Car

(1) A cette heure. 
" de croire (ce que me veullent asseurer quelques" uns des plus capables apoticaires de Marseille) " qu'elle ne face poinct de semence en ce païs, il ( m'est impossible, veu qu'ils m'accordent qu'elle y ( fleurit. J'ay prins plaisir moy mesme souventes " fois en allant à la chasse de faire cüeillir de toutes " les semences qui me sembloient les plus extra" ordinaires, afin de rencontrer celles que vous " aviez marqué, et de faict en fin de conte par ce ( moyen là je m'en suis treuvé tout plein entre " mains que les apoticaires n'avoient sceu treuver : " mais il y en a eu aussy plusieurs aultres que vous " n'aviez pas demandé, lesquelles neantmoins j'ay " vouleu vous envoyer puisqu'elles estoient cüeillies, " croyant que vous ne láisriez peult estre pas d'y " prendre plaisir."

Ces graines de Tragacantha, qu'il n'avait pas pu obtenir des apothicaires de Marseille, Peiresc, ainsi qu'il l'annonçait, s'était décidé à les venir chercher lui-même. De Paris, où il s'est rendu dans le courant de cette même année 1605 , il répond, le 25 août, à une lettre que lui a écrite Clusius :

"Monsieur, quattre ou cinq jours avant mon ( despart de Provence je receus la vostre du 12 May, " et fus bien aise d'entendre que la derniere boette " que je vous avois envoyé estoit arrivée à bon port " et qu'elle vous aroit esté agreable. J'escrivis " incontinent à Frejus, à Thollon, à Mompellier, en " Avignon et encor ailleurs, et priay tres instemment " des amys que j'y ay partout de me recueillir " toutes les semences que vous desirez. Je fus en ( mesme temps à Marseille et y laissay la mesme " charge à quelqu'auitre ; tellement que j'espere " qu'entre touts on aura tout ce que vous desirez : " mais à grand peine se pourra il rien envoyer vers " vous avant la foire de Pasques, avant lequel temps 
" j'espere estre de retour en Provence. Et quand cela

" ne seroit, mon frere recevra le tout de toutes pars,

" et me l'adressera en ceste ville afin que je vous le

" puisse faire tenir par les marchands qui iront à la

" foire. Estant à Marseille je me laissay porter à ma

" curiosité jusqu'au lieu où se treuve quantité de

" Tragacantha, où en ayant diligemment esplusché

" beaucoup de plantes enfin j'en recueillis la

(" semence que je vous envoye maintenant. Je vous

" en envoyerai dadvantaige lorsque je seray de retour

" en Provence (1). "

Sur ces entrefaites, Charles de l'Escluse a reçu le précédent envoi de Peiresc. Mais, hélas! la boîte expédiée est restée si longtemps en route que les diverses racines qu'elle contenait, et notamment celles de l'Astragalus massiliensis, sont arrivées à Leyde entièrement desséchées. Peiresc en est informé pendant qu'il se trouve encore à Paris. Désolé de ce fâcheux contre-temps, il écrit aussitôt (6 février 1605):

( Monsieur, je suis marry que les plantes du Tra" gacantha et Tartonraire que je vous avois envoyé " dans la premiere boitte ne vous ayent esté rendües " que si tard, que elles estoyent desja toutes fles( tries : el suis toutefois bien aise que vous les ayiez " receües quand ce ne seroit pour autre chose que " pour vous servir de tesmoignage de ma diligence " et du desir que j'avois eu d'executer voz comman-

(1) Celte lettre de Peiresc à Clusius et celle qui suit sont inédites. Nous avons eu l'occasion d'expliquer, dans une note précédente, que ces deux lettres, ignorées de Tamizey de Larroque, ne figurent pas dans le recueil qu'il a publié. Nous en devons la communication à l'obligeance de M. le docteur P.-C. Molhuysen, conservateur de la Bibliothèque de l'Université de Leyde. Ainsi que nous l'avons annoncé, nous les imprimerons en entier à la fin de ce travail. 
“ dements. Que si cela n’est bien reusci, ce n'est " poinct par ma faulte, car j'y avois assez bien jour" veu s'il me sembloit, et avois enveloppé cez " racines dans de l'argille si fraische, que si la boitte " fust allée par son droit chemin, c'est sans doubte " qu'elles ne se seroyent pas sitost sechées et que (" vous les auriez eu toutes vives, mesmes attendu " la charge que j'avois donné au messagier qui s'en " chargea jusqu'à Lion, d'envelopper souvent la " boitte dans un drappeau mouillé. Des autres ( plantes que vous aviez desiré depuis, je crains " bien que mon absence de Provence ne soit cause " qu'il en manque quelqu'une que nous aurions " possible recouvré : mais j'ay tant recommandé " cest affaire à mon frere, que je m'asseure que " nous en aurons la plus grande partie Je luy ai " escrit de me les envoyer icy, afin que je les vous " puisse faire tenir par les libraires qui s'en iront à ( Francfort ceste foire de Pasques. Je les attends au " premicr jour."

Les graines « espluschées » par Peiresc eurent-elles meilleur sort que les racines? Clusius les reçut-il en bon état? La correspondance ne nous le dit pas. Mais il est certain que jusqu’à son dernier jour, l'éminent botaniste ne cessa point de s'intéresser au Tragacantha de Marseille; et ce fut sans doute sur sa demande que P'eirese se mit en devoir de lui en fournir un dessin exécuté avec la plus consciencieuse fidélité (1). Une lettre partie d'Aix en férrier 1609 accompagnait l'enroi du dessin. Quand le pli arriva en Hollande, au mois d'avril suivant, Charles de l'Escluse venait de mourir. Mais l'éditeur chargé

(1) La figure de l'Astragale de Marseille était accompagnée de divers détails d'analyse que le graveur a reproduits : feuille avec ses folioles, rachis de la feuille transformé en épine après la chute des folioles, fleur, gousse, graines. 
par testament de donner, sous le titre de Curce posteriores, un recueil d'opuscules et de notes préparés par le défunt (1), fit graver la figure du Tragacantha et l'inséra dans l'ouvrage posthume avec cette légende: Tragacanthce in Gallice Provincià nascentis icon accuratior, et en rendant un juste hommage au zèle du magistrat provençal (2).

Paronychia argentea Lamk. - Clusius cueillit en Espagne cette Paronyque, à laquelle, dans sa florule espagnole (3), il donna le nom de "Paronychia hispanica». A cette occasion il rappela que jadis, passant par la Crau, lapidoso illo campo supra Arelatem, il rencontra la même plante « non loin de l'auberge de Saint-Martin où passe la route de Marseille "), indication consignée ensuite dans le Rariorum plantarum historia (4).

Seseli tortuosum L. - Les vertus merveilleuses que Dioscoride attribuait à son Séséli Massilioti-

(1) "Posthuma hujus [Clusii] opera sive Posteriores Curas edidit curator testamento datus Franciscus Raphelengius.» (Gassendi, Vita Peireskii.)

(2) Curæe posteriores, p. 112 : " Historiæ Rariorum plantarum, post finem capitis Lxxvi de Tragacantha et Poterio, addi posset sequens Tragacanthre icon, qua nobis transmissa est $\dot{e}$ Gallire Provinciâ, nempe Aquis Sextiis, ab amplissimo et nobilissimo viro Nicolao Fabricio, Domino de Peirese, Consiliario regio in supremo Senatu Aquensi, cum literis ad clarissimum Clusium anno 1609 destinatis mense Februario : quae literae quamvis aliquot diebus post obitum Cl. Clusii ad nos perlate sint ; tamen cùm hane Tragacanthe exactiorem quàm usquam alibi excusa sit, delineationem animadverteremus, tantum tanti viri negligendum beneficium esse rati sumus : sed calci hujus capitis adjiciendam. "

(3) P. 477.

(4) P. clxxxij. 
que (1) inspirèrent aux bolanographes de la Renaissance un vif désir de retrouver l'espèce décrite et prônée par le grand maître de la Matière médicale. Ils s'accordèrent généralement pour l'identifier avec l'Ombellifère que l'Ecole de Montpellier nommait "Fœniculum tortuosum ) et dont Linné a fait le Seseli tortuosum.

Charles de l'Escluse arait eu de fréquentes occasions d'apercevoir cette plante, à l'époque où il résidait chez Rondelet. Il la revit aux alentours de Salamanque, et dans son Histoire des plantes rares observées en Espagne il en fit mention sous le nom de "Selinum peregrinum ». Mais en écrivant ce nom en tête du chapitre y relatif, il eut soin d'ajouter entre parenthèses "Seseli Massiliense fortè » et d'introduire dans le texte cette déclaration : « mihi plurimùm ad Seseli Massiliensis descriptionem à Dioscoride traditam accedere videtur. " Il rappela que longtemps auparavant il avait vu cette "Ombellifère » dans la campagne de Montpellier, et sur tout le territoire qui s'étend jusqu’à Marseille, « multos annos antè agro Mompeliano, et toto illo tractu Massiliam usque (2). ") - Ces divers détails passèrent ultérieurement dans le Rariorum plantarum historia (3).

Plumbago europaa L. - Cerlains floristes du $\mathrm{XVI}^{\mathrm{e}}$ siècle avaient déjà donné à cette espèce le nom de Plumbago. Aussi Clusius la désigne-t-il sous cette forme : “Plumbago quorundam ». Il n'en indique pas de station précise: il se contente de dire qu'il l'a observée en divers endroits de la Provence

(1) Nous les avons fait connaitre dans notre première étude sur la Botanique en Provence au xvic siecle: Pierre Pena el Mathias de Lobel.

(2) P. 432.

(3) P. cxcix. 
et du Languedoc. Il signale en même temps une propriété, singulière mais bienfaisante, qu'aurait eue le Plumbago. On le regardait comme souverain contre le mal aux dents. Il suffisait même, pour supprimer la douleur, nous dit Clusius, de tenir dans la main un rameau de la plante(1). Il ajoute qu'à raison de cette vertu, les gens de Montpellier l'appelaient "Dentilaria ". Le nom de Dentelaire a persisté, mais non point, hélas! le pouvoir antiodontalgique (2).

Obione portulacoides Moq. - C'est en traversant la Camargue, quand il se rendait de Montpellier à Marseille, que Charles de l'Escluse remarqua son "Halimus II ". Il trouva la même espèce en Espagne, et dans le livre consacré aux plantes de ce pays il écrivit (3): ( Memini etiam vidisse in aggeribus (4) illius insula, quam duo Rhodani cornua faciunt inter Arelaten et Fanum D. Egidii ", phrase qu'il a plus tard transportée dans le Rariortum plantarum historia (5).

(1) Rar. plant. hist., p. cxxiiij : "Mompellianis meo tempore Dentilaria appellabatur, quòd dentium dolori mederi cre-. deretur, etiam manu retenta ».

(2) Déjà le Stirpium Adversaria de Pierre Pena et Mathias de Lobel nous avait appris que le nom en usage parmi les étudiants de Montpellier était celui de "Denlillaria Rondelletii». Ce fut, parait-il, le célèbre professeur qui, le premier, employa le Plumbago contre ce que l'on appelait alors, aussi bien qu'aujourd'hui, les rages de dents. "Dentillariam, aut potius Dentariam vulgus studiosorum putabat vocatam ì Rondelletio qui , ut Pyrethris aut similibus curantibus utebatur, ad rabidum dentium cruciatum placandum. ") (Stirp. Adv., p. 136)

(3) P. 74.

(4) Par le mot aggeribuss, Clusius désignait les chaussées ou levées de terre bordant soit le cours du Rhône, soit les canaux du delta.

(5) P. 54. 
Euphorbia Characias L. - Clusius a mentionné cette Euphorbe dans son grand ouvrage sous le nom de « Tithymalus Characias », en indiquant qu'il la rencontra jadis « au-dessus d'Arles, sur la route de Marseille » (1), renseignement qu'il avait déjà donné dans l'Histoire de quelques plantes rares observées en Espagne (2).

Quercus Ilex L. - Sous la rubrique « De Ilice majore », nous lisons dans cette même Histoire (3): ( Narbonensis Gallia et Provincia eâdem etiam abundat, sed glande minore quàm Hispanica. Nomen Græcum est $\pi$ pĩvoc, Latinum Ilex, Hispanicum Euzina, Gallicum Eoule ou Chesne verd. » Eoule était une faute d'impression que l'auteur a corrigée quand il a inséré ce passage dans l'Histoire des plantes rares (4). Le mot Eouse est le nom provençal du Chêne-vert (5).

Quercus coccifera L. - Dans un chapitre de sa Flore d'Espagne intitulé (De Ilice coccigera) (6), Clusius écrivait : “Crescit multis Hispanire locis, in Gallia etiam Narbonensi et Provincia. »

Il a maintenu le même nom et les mêmes indications dans le Rariorum plantarum historia (7).

Il y a donné, en outre, au sujet de l'insecte parasite producteur de la couleur d'écarlate, - le « Coccus baphicus », ainsi l'appelait-on alors, - des détails empruntés à Quiqueran.

(1) P. clxxxviij : "Supra Arelatem itinere Massiliensi 》.

(2) P. 435 .

(3) P. 33.

(4) P. 23.

(5) V. ce que nous avons dit à ce sujet dans l'étude sur Pierre Belon, qui précède celle-ci.

(6) P. 33.

(7) P. 34 . 
L’Arlésien Pierre Quiqueran de Beaujeu, nommé, à dix-huit ans, évêque de Senez par le roi François $\mathrm{I}^{\mathrm{er}}$, a composé, en l'honneur de la Provence, un panégyrique latin qu'il a intitulé De laudibus Provinciœ (1). Cet ouvrage, d'assez médiocre valeur, fut, un peu plus tard, traduit en français par un archidiacre d'Arles (2).

Quiqueran a résumé dans son livre tout ce que l'on savait à cette époque au sujet des métamorphoses de la Cochenille que Linné a nommée Coccus Ilicis.

Au lieu de reproduire, en son texte latin, le passage extrait par Clusius, nous aimons micux donner la naïve mais exacte traduction de l'archidiacre Claret :

" Nous avons de deux races d'Yeuse; l'un jette ses forces en tige et en branches, montant à la hauteur d'un Arbre sans estre doüé d'autre singularité. L'autre n'est qu'un petit Arbuste ne passant plus outre que d'un pied et demy. Il se maintient toujours vert, sans se faner. Ses feuilles crenćes et cochées en forme de scie, armées de petites pointes fort piquantes, sont tres luisantes... Sur le mitan de la prime-rere ces arbres nains, arrousez de pluye, poussent le vermillon (3) en ceste sorte. Premierement au bas de ceste plante, où le premier neud se separe en deux branches, comme font quasi tous

(1) Pelri Quiquerani Bellojocani Episcopi Senecensis, de Laudibus Provincice libri tres... - Parisiis, apud Lambertum Dodu, 1551. - Nous arons, dans Pierre Pena et Mathias de Lobel, donné sur Quiqueran de Beaujeu des dètails auxquels nous renvoyons nos lecteurs.

(2) La Provence louée par feu Messire P. de Quiqueran de Beaujeu gentilhome d'Arles Eveque de Senes divisée en trois livres traduitz du Lalin par MrF. de Clarel Docleur es droitz, Archidiacre de la Ste Eglise d'Arles.- A Lyon, pour Rob. Reynaul Libraire d'Arles, 161\%.

(3) Sur l'étymologie du mot Vermillon, v. ci-dessus Pierre Belon. 
les arbrisseaux ne croissans cn tige, ains multipliant par les rejets, là dis-je entre ces deux branches croît je ne sais quoi de rond, de la couleur et grosseur d'un pois. C'est ce qu'on appelle la Mere, parce que d'icelle naissent tous les autres grains. A l'entrée de l'Eté, voire mêmes au gros du chaud, ces Meres s'entrourrent par en haut, et épandent des bandes de vermisseaux si drus et deliez qu'à peine les peut-on discerner avec la veüe. Cette nouvelle engeance sourd après en petites bestioles de couleur blanche, qui prenent la route pour s'en monter ez cimes de cet Arbuste; et l'endroit où elles rencontrent la ramure, là elles s'agrafent, et en leur accroissement deviennent à la grosseur d'un grain de millet. A même qu'elles croissent plus gayement, leur couleur blanche se change en gris cendré. Alors vous ne les prendriez plus pour des vers, ains de rechef pour des pois. ")

Et voici maintenant comment s'opère la cueillette:

(" Ces graines chargées de vermisseaux cramoisis, venues en parfaite maturité, sont cueillies en la saison. La gouffe, ou la peau, en serrant ce grain, est si deliée qu'en la transportant elle se froisse toute. Mais pour cela les Marchans ne la rejettent point. Le vermillon depoüillé vaut un écu d'or la livre. Celui qui est encore avec tout son marc, un quart d'écu. Cependant ces vermisseaux comme tous engourdis demeurent sans se remuer. Et le tems arrivé, on les amasse en un linge pour les exposer au soleil; de sorte qu'à mesure qu'ils en sont touchez, sentans la chaleur, vous les verriez grouiller dedans ce linge, cerchans à se derober à la fuitte. Celui qui se trouve là commis à les garder ne bouge de la place; ains en secoüant le linge les fait rentrer si avant qu'il les void tous perir devant soi. Pendant qu'on s'attand à cela, voire trois jours après, un odeur s'exhale si douce qu'elle surpasse la senteur du Musc, de la Civette, de l'Ambre gris, 
voire de la fleur même des Citrons. Si par megarde quelques grains eludent la reüe ou les mains de l'amasseur, ils epandent par l'air des bandes innumerables de petis moucherons ailez. On a observé que le revenu du vermillon cueilly celte année au terroir d'Arles a eté evalué jusques à la somme de onze mil écus (1). »)

Après avoir cité ce passage, Charles de l'Escluse confirme le récit de Quiqueran en y ajoutant ses propres observations.

Il fait d'abord cette remarque: l' "Ilex coccigera", très répandu en Espagne, en Languedoc, en Provence, et sans aucun doute en beaucoup d'autres pays, n'est point partout productif de kermès. On ne trouve le vermillon que dans les régions voisines de la Méditerranée et les mieux exposées à un soleil brûlant.

Comme il a lui-même assisté aux opérations de la récolte, il rapporte que dans les enảroits où elle a lieu, les habitants ont des aires spéciales, entourées d'une petite margelle. On y étale un linceul de toile sur lequel on épand le Coccus. Malgré l'extrême ardeur du soleil, les gardiens ne s'éloignent pas un scul instant; il battent sans cesse avec une baguette les bords du linceul pour faire rétrograder vers le centre les vermisseaux prompts à s'érader. Et Clusius termine en disant qu'il n'a jamais senti, - bien qu'il ait l'odorat subtil et délicat, - l'odeur suave dont a parlé Quiqueran (2).

(1) “ La plus grande abondance et le meilleur du pays vient plantureusement de la Crau d'Arles ", ajoutait Quiqueran (Traduction Claret).

(2) Rar. plant. hist., p. 25: "Similem Cocci parandi rationem in Galliâ Narbonensi, atque in Hispaniâ, dum istic degerem, observare memini. Areas enim sub dio habebant ad eam rem destinatas, eminente aliquantulum margine, quibus lineo panno instratis coccum effundebant, custodibus summo fervore solis perpetuo assidentibus, et extrema lintei bacillo concutientibus, 
Asphodelus fistulosus L. - L'Asphodèle fistuleux, auquel Clusius appliquait le nom d' "Asphodelus minor », est, encore de nos jours, extrêmement commun dans toutes les parties incultes de la Crau d'Arles. C'est là même que l'illustre botaniste le récolta, il y a trois siècles et demi. « Je me rappelle, - dit-il dans le Rariorum plantarum historia, l'avoir cueilli autrefois le long des sentiers, dans cette plaine pierreuse située au-dessus d'Arles, tandis que je me rendais à Marseille (1). »)

Clathrus cancellatus L. - Dans sa lettre du 15 férrier 1605 , dont nous avons plus haut donné un extrait, Peiresc annonçait à Clusius l'envoi " d'une merveilleuse espece de champignon » qu'il venait de trouver à Belgencier.

Voici en quels termes il s'exprimait à ce sujet :

" J'ay creu d'estre obligé de rous en mander, (" pour aroir recogneu par vostre commentaire de " Fungis (2) qu'il rous a pleu m'envoyer, combien "vous aviez esté curieux de rechercher le naturel " de semblables choses, oultre que je m'y suis " aussy laissé porter par ma propre curiosité, n'en " ayant sceu voir jusqu'astheure aucune descrip" tion en aucun lieu. Ils naissent sur terre en " forme d'un œuf de poulle blanc comme neige, et " venant à se meurir, l'œuf se cresve peu à peu, et " de là dedans sort comme une bource (s'il est loisi-

ut vermiculos effugere properantes, in interiorem lintei partem repellerent : istam tamen summam odoris suavitatem non sensi licet satis acres et sagaces habcam nares. ")

(1) P. 197 : "... Olim etiam campo illo lapidoso supra Arelatem, Massiliam proficiscens secus senitas colligere memini, 》)

(2) Fungorum in Pannoniis observatorum brevis historia it Carolo Clusio conscripta. - Imprimée à la suite du Rariorum plantarum historia. 
“ ble de parler ainsin) toute percée à jour (à la

" façon de l'ouvraige que les dames de France ( appellent rasoir) distinctione cancellatim reticu" latà, et semble que les cordons ou branches entre“ lassées qui forment la figure de ceste bource soient " aultant de branches de vray corail, tant pour la " couleur qui est parfaitement rouge, que pour la " grosseur qui est fort proportionnée à celle des " rameaulx de corail. Au reste pour recevoir de la " terre la nourriture convenable, la nature leur a " baillé une racine fort deliée divisée en plusicurs " petits filets de mesme blancheur que la peau de " l'œuf, à laquelle ils sont attachez. Mais l'admi( rable beaulté de ceste creature insensible, qui ne " sçaurait, s'il semble, estre plus belle en son " espece par l'exterieur, est entierement r'avallée " par l'odeur qu'elle rend si puante et fetide, qu'elle " est presque insupportable, mesmes que par dedans " la bource les rameaux rouges sont chargez d'une " liqueur crasse et espoisse de couleur grize, qui est " possible cause en partie d'une si grande puan" teur. Toutefois j'ay tousjours jugé qu’il y devoit " avoir quelque bonne qualité en icelle et quelque " vertu occulte bien signalée; 'veu qu'à peine est “ elle achevée d'esclorre, qu'ell'est tout aussy tost ( mangée par une infinité de petis animaulx insec" tes, lesquels quittent (pour courir à celle-cy) toute " aultre viande, mesmes plusieurs aultres sories “ de champignons que nous estimons tres bons à " manger. Si j'eusse eu un painctre sur le lieu, j'en " eusse volontiers faict paindre quelques unes avec " leurs vives couleurs, et leur vraye proporlion, " mais je tascheray de le faire faire à la première " occasion. Cependant si vous faictes tremper dans " l'eau quelqu'une de celles que je vous ay envoyé " dans la boitte des graines (lesquelles cn se des" seichant se sont diminuées de plus de la moilié, " et mesmes se sont ternies beaucoup de leur pre- 
( miere couleur) vous la verrez r'enfler, et revenir " jusqu'à sa primitive grandeur, et reprendre quel" que peu dadvantaige de couleur. J'en ay rencon" tré quelquefois par les bois du susdict lieu de " Beaugentier, mais plus souvent entre des cannes " [roseaux] qu'on plante sur le bord d'une petite " rivière (1) qui arrose la plus part de ce (" terroir (2). "

Charles de l'Escluse créa pour ce champignon la dénomination de "Fungus coralloeides cancellatus». Ayant, sur le conscil que lui donnait Peiresc, mis à macérer dans l'eau l'échantillon reçu, il put ensuite le faire dessiner et graver. Dans la description latine qu’il rédigea, il introduisit les détails que son correspondant lui avait communiqués. Cette description, accompagnée de la figure gravée, a pris place à la fin d'un supplément au second appendice de son Histoire des plantes rares (Auctarium appendicis alterius ad rariorum plantarum historiam), inséré dans le volume des Exotiques (3).

(1) Le Gapeau, qui a sa source près de Signes et ra se jeter directement dans la mer, au voisinage des Salins d'Hyères.

(2) Nous rappelons que cette lettre, dont nous avons plus haut dommé un extrait, est ici reproduite, non point d'après le texte fautif du recueil Tamizey de Larroque, mais d'après l'original même conservé à Leyde.

(3) Notre regretté confrère de la Société botanique de France, Ernest Roze, a traduit en français le Fungorum in Punnoniis observalorum brevis hisloria. Sa traduction, à laquelle il a donné pour titre : "Le petit traité des champignons comestibles et pernicieux de la Hongrie, décrits au xví siecle par Ciharles de l'Escluze, d'Arras ", a paru dans le Bulletin de la Sociélé mycologique de France (t. XV). L'auteur y a joint la traduction du passage consacré par Clusius, dans l'Auclarium, au "Fungus corallocides cancellatus ». - Précédemment, Ernest Roze avait public, dans le Journal de Botanique (t. XII), sous le titre de Florule francaise de Charles de l'Escluse, une "liste des plantes observées en France par ce célèbre botaniste et signalées par lui dans son Rariorum plantarum historia. ’) 
Charles de l'Escluse, en écrivant à Peiresc, avait annoncé qu'il lui ferait don d'un exemplaire sur grand papier de cet ouvrage (1). Peiresc, dans sa réponse du 25 août 1604, en exprima sa reconnaissance :

" Je vous remercie par adrance de tout mon " cour, du livre qu'il vous plait me promettre de " voz Exotiques en grand papier, lequel attendant, " je n'ay pas laissé d'en achepter icy un des com( muns pour m'y entretenir, comme j’ay fait fort " souvent et avec beaucoup de contentement. "

Et il ajoutait en post-scriptum :

" J'oubliois de vous dire que le portraicl que vous " avez fạit faire de vostre Fungus coralloides ( cancellatus represente fort bien le naturel. Je “ suis bien aise qu'il vous aye agreé et vous remercie " de la mention de mon nom qu'il vous a pleu d'y " faire. Nostre petit village de Peiresc s'appelle

(1) En conformité d'un désir que Peiresc avait formulé. Presque au début de ses relations avec Charles de l'Escluse, il lui écrivait : "Infiniment desireux de trouver des occasions de vous " rendre service et supportant impatiemment l'attente de voz " commandements pour rous donner sujet de m'en honorer " deshormais avec toute liberté, je suis contrainct de franchir " les bornes de mon devoir avant qu'avoir rien merité de pareil " en vostre endroict et vous prier de m'envoyer vostre por" traict, et ensemble un exemplaire de vostre histoire des " plantes avec vostre nom au-dessus, et s'il est possible en plus " beau papier que les autres, car jai aprins de feu Mons Pinell * d'estre si curieux et delicat en matiere de livres et de tascher " tousjours de les avoir en plus grand papier que l'ordinaire. " - Il semble, du reste, que Clusius distribuait ses ouvrages avec beaucoup de générosité. Il avait envoyé à Pinelli quatre exemplaires du Rariorum plantarum hislorict, qui arriverent à Padoue après le décès du destinataire. L'héritier de Pinelli disposa d'un de ces exemplaires en faveur de Ferrante Imperato, pharmacien napolitain et botaniste renommé. 
" dans les vieux cadastres latins Castrum de

"Petrisco (1). ")

Au sujet des envois de plantes que Peiresc fit à Charles de l'Escluse, nous possédons un document intéressant. C'est un " inventaire » des divers objets dont la lettre du 15 février 1605 annonçait le départ. Nous ailons y trouver mentionnés quelques-uns des desiderata de Clusius (2).

(1) Dans lituclarium, Charles de lEscluse, tout en donnant à Peiresc son nouveau titre de seigneur ou sieur de Peirese " P'cirets toparcha ", continuait a l'appeler $N$. de Callas, ne tenant compte qu'à demi du changement de nom que Peiresc lui avait signalé par le post-scriptum de la lettre du 25 février 1604. Cette mention élogieuse de Peiresc, à propos du champignon trouvé par celui-ci à Belgencier, Clusius la lui avait promise dans une lettre dont Gassendi eut connaissance, et qu'il a ainsi résumée dans sa Tita Peireslii, sous le millésime 1605 : " Pratereo ipsi [Peiresc] deberi Fungum coralloidem dictum, de quo cum Clusius rescriberet, mentionem, inquit, faciam in auctario ad Exolicorum hisloriam quam spero brevi publici juris facere, Fungi cognitionem tibi acceptam relaturus. ')

(2) Tamizey de Larroque a reproduit ce document dans le tome VII des Lelltes de Peiresc, d'aprés une copie conservée à la Bibliothéque Méjanes (registre III, folio 287). Nous le donnons ici d'après l'original même existant à Leyde. - Antérieurement à la publication faite par Tamizey de Larroque, M. Charles Joret, aujourd'hui membre de l'Académie des Inseriptions et Belles-Lettres, alors professeur à la Faculté des Lettres d'Aix, avait inséré ce même Inventaire dans la Revue des langues romanes ( $t$. V'II de la $t^{e}$ série), d'après l'exemplaire de la Méjanes. Il a fait suivre la liste dressée par Peirese d'un tableau sur lequel il a inserit : $1^{\circ}$ les noms botaniques modernes; $2^{\circ}$ les noms français; $3^{\circ}$ les noms provençaux actuels. Au sujet des noms modernes de certaines espéces, nous sommes en désaccord avec le savant professeur. Nous indiquerons en note quelles sont celles pour lesquelles nous n'arons pas accepté ses déterminations. En ce qui touche les noms provençaux, nous prendrons la liberté d'adresser à M. Charles Joret un petit reproche: pourquoi a-t-il adopté une ortho- 
Cet inventaire est, en effet, divisé en deux parties (1).

La première contient l'énumération de certaines plantes (phanérogames) que le botaniste de Leyde avait expressément demandées. Les noms de ces plantes sont inscrits sur deux colonnes parallèles. La colonne de gauche est formée des noms latins que conférait à chaque espèce la nomenclature du temps (2), accompagnés, suivant le cas, de quelques indications en français. Sur la colonne de droite, Peiresc a inscrit, en regard des noms latins, les dénominations provençales parvenues à sa connaissance.

La seconde partie de l'inventaire donne la liste des plantes que Peiresc envoyait d'office à Clusius, sans que celui-ci les eût demandées. Elle est disposée de la même façon que la première (noms latins sur une colonne, noms provençaux vis-à-vis, sur l'autre).

A la suite du texte original fidèlement reproduit, nous dresserons une liste comparative, destinée à fixer, arec autant d'exactitude qu'il sera possible, l'identité des espèces désignées par Peiresc.

graphe fantaisiste cu'il n'était plus permis d'employer, nous semble-t-il. après l'œurre considérable d'épuration accomplie par Frédéric Mistral, et fixée dans le Trésor du Félibrige dont un prix de dix mille francs accordé par l'Académie des Inscriptions a consacré le mérite et l'autorité ? - Il y a beaucoup de fautes dans le texte de l'Inventaire imprimé par Tamizey de Larroque. Ignorant sans doute la langue provençale, il n'a pas su lire, notamment, quelques-uns des noms provençaux inscrits par Peirese sur ces listes.

(1) Nous devrions, pour être exact, dire trois. Ainsi qu'on va le voir, deux listes de graines sont suivies d'une troisième qui mentionne, outre un échantillon de gomme d'Oranger et trois Champignons, les noms des divers fossiles que par la même occasion Peiresc expédiait à Clusius.

(2) Les noms latins portés sur cette premiere liste de graines sont évidemment ceux mêmes que Charles de l'Escluse avait employés pour faire connaitre les espèces dont il désirait recevoir les semences. 


\section{INVENTAIRE}

DE CE QUI EST CONTENU EN LA BOITTE

QUE DE PEIRETS ENvoye A Mr DE L'Escluse

PAR LA FOIRE DE FRANCFORT

SEMENCES DE PLUSIEURS PLANTES IDE PROVENCE

de celles que ledict $s^{r}$ de l'Escluse avoit demandé

1: Arbutus (1) vulgò (2) d'Arboussier

2. Centonica Absynte marin Graine barbouline

3. Ilex major Eoüve

4. Ilex coccigera Avaux

5. Lentiscus Lentiscle

6. Narcissus medioluteus Judioüves (les bulbes seulem̄t)

7. Olea

Olivier

(1) Les chiffres qui précèdent chaque nom de plante, sur la colonne de gauche, ne figurent pas à l'original. Nous avons numéroté tous ces noms afin d'établir une concordance entre l'Invenlaire et le tableau comparatif qui suivra, dans lequel, d'une part, nous substituerons aux noms latins inserits par Peiresc les dénominations actuelles, et d'autre part, nous rectifierons, d'après les règles de l'orthographe régnante, les appellations provençales placées en regard.

(2) Le texte donné par Tamizey de Larroque d'après la copie de la Bibliothèque Méjanes porte, au lieu de vulgí, ces mots : "vulgairement en provençal $)$. 
8. Oleaster Olivastre

9. Philirea tenuifolia d'Alader

10. Pinus sylvestris Pin sauvaige

11. Rhamnus. Aigue Sponche

12. Rhus coriariorum, Sumac Foüvil

13. Smilax aspera

14. . . . . .

Tartonraire

15. Terebinthus

Petelin

16. Tithymalus

17. Thymelea

Bouffe-Galine

de celles que de Peirets a rencontré par les champs en allant à la chasse, tantost sur le rivaige de la mer, tantost par les bois et nommement par le terroir de Beaugentier.

18. Acer montanum que les paysans appellent Agast

19. Cineraria

20. Creta marina Bassilles

21...... vulgò Dagon

22. Epithin

23. Hyppoglossum Valentinum de vostre livre

24. Iva moscata

Herbe de musquet 
25. Ligustrum

26. Myrtus

27. Paliurus seu Rhamnus

28. Seseli Massiliensis

29

30. Stecas, cueilly au terroir d'Yères, vulgò

31. Styrax de Mr Pena dont les graines s'appellent

32. Tetragonia

33. Tracheleon majus

34. Trifolium hemorroidalis

35. Viburnum mas
Olivier sauvaige

Nerle (de la blanche)

Arnavez

Fenouil tort

Rousselte

Mourrenieu

Alibouffier

Guilloffes

Bonnet de capellan

Herbe de nostre dame

Voici maintenant quelles sont, à notre avis, avec l'appellation que la nomenclature moderne leur a conférée, les Phanérogames dont Peiresc envoyait les graines à Clusius, et comment doivent être présentement orthographiés les noms provençaux que le collecteur de ces graines avail eu soin d'inscrire sur sa liste :

1. Arbutus Unedo L.

Arboussié (1)

(1) Le texte de Peirese porte " d'Arboussier". Encore aujourd'hui les Provençaux appellent indifféremment cet arbre Arboussié ou Darboussić. La première forme s'accorde mieux avec le latin Arbutus, d'où elle dérive. Dans la seconde, le D initial ne serait-il pas dû à l'adjonction de l'article? A quelqu'un qui lui demandera le nom provençal de l'Arbousier, le paysan interrogé répondra de préférence : "Es d'arboussié, ", au lieu de: "Es un arboussié ". C'est ainsi que larticle élidé a pu se confondre et faire corps avec le nom. Il semble que tel était lavis de Peiresc, qui séparait par une apostrophe le D qu'il écrivait au-devant du mot Arboussier. 


\section{Santolina Chamæcypa-} rissus L. ?

3. Quercus Ilex L.

Éuve (2)

4. Quercus coccifera L.

Avaus

5. Pistacia Lentiscus L.

Lentiscle

6. Narcissus Tazetta L.

Judiéuvo (3)

8. $\}$ Olea europæa L.

$\left\{\begin{array}{l}\text { Óulivić } \\ \text { Óulivastre }\end{array}\right.$

9. Phillyrea angustifolia L.

Aladèr (4)

(1) L'Inventaire donne, comme nom latin, le mot Centonica. Cette appellation n'a jamais existé dans la nomenclature du xvie siècle. Si c'est Charles de l'Escluse qui l'a insérée lui-même sur sa liste de desiderata, il l'aura fait parce que Peiresc lui avait parlé le premier de cette plante dans sa lettre du 25 février 1604 : \& Je vous envoyerai... " la racine d'une aultre plante qui est assez familiere en cez quartiers, " que l'apoticaire appelle Centonica; je ne sçay s'il se trompe.» Peutêtre l'apothicaire ignorant dénaturait-il ainsi le "Cenlonia » de Conrad Gesner ou le "Santonicum minus» de Valerius Cordus. En ce cas, la plante serait bien, comme nous le croyons, le Santolina Chamacyparissus de Linné. Il est vrai qu'à côté du mot Centonica le texte porte : "Absynte marin ). Le nom d'Absinthe s'appliquerait alors à l'un de nos Artemisia: ce ne pourrait être que l'A. glutinosa Gay ou l'A. gallica Willd. Le nom provençal mis en regard, Grano-barbontino (en français barbotine, semencine, semen-contra) s'applique à une poudre vermifuge dans la composition de laquelle les apothicaires faisaient entrer les capitules de diverses Armoises.

(2) Le vrai nom provençal du Chêne-vert est Éuse. Mais en certaines parties de la Provence, et notamment dans la région que fréquentait Peiresc, la prononciation transforme souvent $S$ en V; et c'est ainsi qu'Éuse devient Éuve.

(3) Ici M. Charles Joret inscrit sur sa liste Narcissus poeticus L. Nous croyons que c'est une erreur. Les floristes du xvie siècle donnaient le nom de "Narcissus medioluteus " au N. Tazetta L. Ils appelaient " N. mediopurpureus ) ou "N. mediocroccus " le Narcisse des poètes. Le vocable provençal judiéuvo (littéralement juive) s'applique encore au Narcisse à bouquets (F. Mistral, Le Trésor du Félibrige).

(4) Ou Daladèr. Même observation que pour Darboussié. 
10. Pinus sylvestris L.?

11. Rhamnus Alaternus L.

12. Rhus Coriaria L.

13. Smilax aspera $L$.

14. Passerina Tarton-raira DC.

15. Pistacia Terebinthus L.

16. Euphorbia

17. Daphne Gnidium L.
Pin sóuvaigi (1)

Aigo-espouncho (2).

Fáuvi

Tarton-rairo (3)

Petelin

Boufo-galino (5)

(1) Les anciens botanistes employaient l'adjectif sylvestris par opposition à celui de sativa qu'ils appliquaient au Pinus Pinea L. Il est impossible de savoir exactement si Peiresc arait envoyé à Clusius des graines de Pin d'Alep ou de notre Pinus sylvestris. Observation déjà faite, avec raison, par M. Charles Joret.

(2) L'expression provençale Aigo-espouncho désigne le Nerprun, (F. Mistral, op. cit.), et non point, comme l'a cru M. Charles Joret, l'Hippophae rhamnoides L. cui se nomme en provençal Argousié ou Rebaudin.

(3) Le lecteur curieux de connaitre l'origine de ce singulier nom provençal en trouvera l'explication dans notre étude sur P'ierre Pena et Mathias de. Lobel.

(4) L'accolade qui figure, it cette place, sur l'original de l'Inventaire, indique que Peiresc fit parvenir à Clusius des graines de trois espèces d'Euphorbe. M. Charles Joret a supposé que dans le nombre se trouvait l'Euphorbia Characias L. C'est bien possible. Mais nous ne pouvons pas le saroir avec certitude, le nombre des Euphorbes que possède la flore provençale étant de beaucoup supérieur à trois.

(5) M. Charles Joret a traduit par Passerina annua Spreng. le "Thijmel(e $(a)$ du texte. C'est inadmissible. Les floristes du xvic siècle furent unanimes à nommer ainsi l'espèce qui est devenue, de par Linné, Daphne Gniclium, tandis que notre Passerine annuelle fut appelée "P'asserina 》 par Tragus, Camerarius, les Aciversuria, Jean Bauhin, et "Lithospermum ") par d'autres botanographes, notamment par Gaspard Bauhin : aucun d'eux n'eut l'idée d'en faire une Thymelcea. L'expression provençale Boufo-galino (littéralement qui fail en/ier les poules), allusion aux propriétés toxiques du Garou, est sans doute tombée en désuétude, puisque nous ne la trouvons pas dans le Trésor de F. Mistral. 
18. Acer monspessulanum L. . Agast (1)

19. Senecio Cineraria D C.

20. Crithmum maritimumL. Bacilo

21. Aphyllanthes monspeliensis L.

Dragoun (2)

22. Cuscuta Epithymum L.

23. Globularia Alypum L.

24. Ajuga Iva Schreb.

Erbo dóu musquet

25. Ligustrum vulgare $\mathrm{L}$.

Óulivié-fèr

26. Myrtus communis L.

Nerto (4)

27. Paliurus australis Rom. et Sch.

Arnavés (5)

28. Seseli tortuosum L.

Fenoui-tort

(1) Agast est le nom provençal de l'Érable de Montpellier (F. Mistral, op. cil.) et non point de l'Acer campestre, ainsi que l'a traduit M. Charles Joret. D'ailleurs l'Inventaire porte "Acer montanum». Aucun des floristes du xvi siècle, à notre connaissance, n'a nommé ainsi l'A. campestre.

(2) L'Aphyllanthe de Montpellier porte aussi en provençal les noms de Barjavoun, Bragoun, Bregaloun.

(3) C'est bien le Globularia Alypum que Charles de l'Escluse a décrit et figuré dans le Rariorum planlarum historia (p. 90) sous le nom de "Hippoglossum V'alentinum », ainsi que l'indique l'Inventaire de Peirese. Clusius explique pourquoi il repoussait le nom d'Alypum que certains floristes avaient adopté : "Alii Alypum nominare malunt . sed cùm planè arida sit et succi expers, non video qua ratione suam sententiam stabilire possint. )

(4) Ici l'Inventaire ajoute entre parenthèses: " de la blanche n. Peiresc désigne ainsi une variété de Myrte dont les baies restent blanches, variété qui se retrouve encore dans quelques localités de la Provence maritime.

(5) Ou Arnavèu, forme peut-être plus usitée. 
29

30. Lavandula Stœechas L.

31. Styrax officinale L. dont les graines s'appellent

32. Evonymus europæus L.

33. Campanula

34. . . . .

\section{Viburnum Lantana L.}

Rousseto (1)

Mourreniéu (2)

Aliboufié

Gaiofo (3)

Bounet-de-capelan

Erbo-de-Nosto-Damo

Anbre-blanc (6)

(1) Le Trésor du Félibrige ne mentionne aucune plante ainsi nommée en provençal. Comme Peirese ne donne pas d'autre indication, il nous est impossible de savoir quelle était la graine qu'il envoyait sous ce nom.

(2) Ce nom à physionomie si provençale est probablement abandonné. Il ne figure pas dans le Trésor. Le nom, le plus usité actuellement, de cette Lavande est Queirelet.

(3) \& Je n'ai pu trouver nulle part, écrit M. Charles Joret, quelle plante ou quel fruit Peirese a pu désigner par les noms de Roussette et de Guilloffes. " Frédéric Mistral, que nous avons consulté, nous a répondu : "J'estime que Peiresc a mal entendu prononcer le mot * qu'il écrit Guilloffes. Ce mot ne peut être que le provençal classique "Gaiofo, que Brueys, contemporain et compatriote de Peiresc, écrit "Galhofo et qui signifie " cosse de légumes, balle de maïs, etc. " "C'est un nom générique au fruit de diverses plantes et qui a pour " similaires caiofo, calofo, cofo. " Quant à Rousseto, l'auteur du Trésor suggère l'idée que Peiresc a peut-être employé ce mot en place d'Erbo-rousso, nom provençal du Pterotheca nemausensis Cass. Mais cette assimilation demeure forcément hypothétique.

(4) Il est difficile desavoir au juste quelle était l'espèce de Campanule que Peiresc appelait "Tracheleon majus ». Clusius, en son Histoise des plantes rares, donnait le nom de "Trachelium majus " au Campanula latifolia L., qui n'appartient pas à la flore de la Provence. Mais l'épithète de majus, employée par Peiresc, ne pouvait être appliquée qu'aux $C$. Medium L., C. Trachelium L. ou C. persicifolia L. Le nom provençal Erbo-de-Nosto-Damo ne nous est ici d'aucun secours. Un assez grand nombre de plantes ont été ainsi nommées, "parce que, dit F. Mistral, on les a remarquées dans des lieux consacrés à Notre-Dame, ou parce qu'elles fleurissent à une fête de Notre-Dame.

(5) Pas plus que M. Charles Joret, nous ne sommes parvenu à découvrir ce que le bon Peirese entendait (avec un solécisme!) par Trifolium hemorroidalis.

(6) Appellation appliquée aussi à diverses espèces. 
La boîte expédice par Peiresc à Charles de l'Escluse au mois de février 1605 ne contenait pas seulement les graines de Phanérogames dont la liste précède. D'autres objets y avaient élé joints, qu'il est intéressant de faire connaître. C'étaient d'abord :

\section{Gummi seu lacrymae, ex Aureâ malo fluentes, mense Octobri 160\% collecto.}

Au sujet de ces gommes ou larmes, la lettre du 15 février 1605 donnait l'explication qui suit. Après avoir demandé à Clusius, à propos du Styrax, de lui « en" seigner le moyen d'en tirer la goumme, car cez " arbres n'en produisent poinct sans artifice", Peiresc ajoutait :

" Trop bien les Orangers, mais particulierement " ceux que l'Espaignol nomme Naraenias de figuras " que nous appellons Oranges bigarrez, sur lesquels " j'ay souvent recüeilly de la goumme qui en dis" tille sans aucun artifice, et vous en envoye un peu, " avec pasche (1) que si vous y descouvrez quelque " belle proprieté, ou quelque qualité extraordinaire, " vous m'en communiquerez s'il vous plaict quel" que chose. "

L'Inventaire mentionne ensuite trois espèces de Champignons dont un certain nombre d'échantillons avaient pris place dans la boìte :

(1) Ce mot, qui a fort embarrassé Tamizey de Larroque (il l'a, dans une note, déclaré incompréhensible), est une expression provençale signifiant pacte, convention, accord. Le sens de la phrase est celui-ci : "Il demeure convenu entre nous que si vous y découvrez... ) 
Fungorum reticulata species coralli effigie

Alia Fungorum perniciosorum species gummosa, viscosum succum emit- Belgenseritens

Alia Fungorum arboreorum species, colore aureo
Ex agro

ensi

Le premier de ces Champignons était le Clathrus cancellatus, au sujet duquel nous avons donné plus haut de longs détails.

Relativement aux deux autres, voici ce qu'en disait Charles de l'Escluse, à la fin du chapitre consacré, dans l'Auctarium, au "Fungus coralloeides cancellatus » (1):

" Ce genre de Champignon [Clathrus cancellatus] doit prendre place parmi les Champignons pernicieux (2); personne, je crois, ne sera d'un autre avis. Il en est de même de deux autres genres de Champignons que N. de Callas avait ajoutés à son envoi. L'un était encore fixé à un fragment d'écorce de l'arbre ou du rameau de cet arbre qui gisait sur le sol, et sur lequel il avait pris naissance ; il était de couleur d'or et non très dissemblable du quatrième genre des Pernicieux (3) que j'ai décrit et fait connaître et qui comprend des espèces variées, différant entre elles par la grandeur et la couleur. L'autre Champignon m'a paru avoir une grande ressem-

(1) Nous citons la traduction d'Ernest Roze.

(2) Charles de l'Escluse avait divisé ses Champignons de Hongrie en deux sections : les Comestibles (Fungi esculenti) et les Pernicieux (Fungi noxii et perniciosi).

(3) Polyporus versicolor, d'après Fries (Note d'Ernest Roze). 
blance avec la première espèce du vingtième genre des Pernicieux (1), car il s'en rapprochait par sa forme et sa grandeur; mais lorsque N. de Callas l'examinait, il avait remarqué qu'une certaine liqueur en imprégnait l'extrémité des bords et le pédicule, et cette liqueur, sur l'échantillon desséché, conservait encore sa couleur brune et son aspect luisant. "

Enfin, passant du domaine de la botanique dans celui de la minéralogie, ou plutôt de la géologie, l'Inventaire annonçait, en dernier lieu, à Charles de l'Escluse, l'envoi de divers échantillons que Peiresc considérait comme des pierres, lapides varii, mais qui étaient, en réalité, des fossiles, (coquilles et polypiers).

\section{LAPIDES VARII}

Astriles, ejusque in formam planta nascentis ramuli

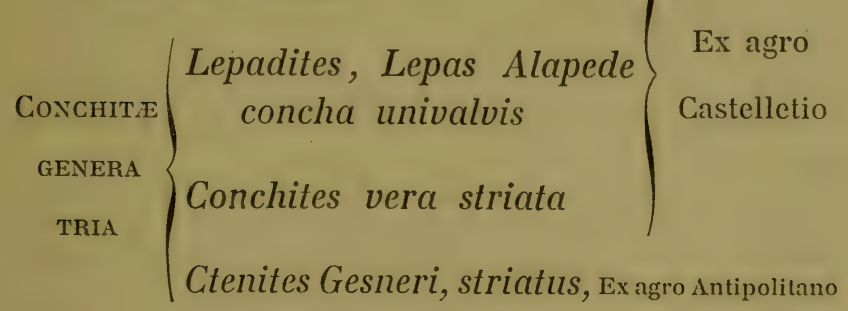

Voici les éclaircissements que fournissait à ce sujet.la lettre du 15 février 1605 :

" L'occasion de ceste boitte m'a faict y adjous(' ter oultre voz semences, quelques petites pieces

(1) Boletus pachypus, d'après Fries. Peut-être s'agissait-il ici du Boletus luteus ? (Id.). 
" de nostre pierre Astrites, qui se treuve dans terre ( en forme pareille à celle des rameaux de corail, (" vray est que les rameaux de corail sont rouges, là " où ceux cy sont de couleur grisastre et sont tous " parsemez d'estoilles. On en treuve à deux lieües " de Beaugentier, au terroir d'un petit villaige " nommé le Castellet (1), où j'en ay veu un grand " rameau tout entier, qui sembloit estre de corail " blanc (2); et c'est aussy de là que j'ay eu une " espece de Conchites qui ressemble à la vraye "Concha striata (3) et une aultre sorte de pierre " qui est peult estre Trochites Jo. Kentmanni et "Gesneri (4), laquelle ressemble entierement à " une sorte de coquille de celles qui s'attachent " contre les rochers que les Marseillois appellent " des Alapedes (5), et pour ce je l'appellerois (s'il " m'estoit loisible) Lepadites, plus tost que Tro( chites. L'autre espèce de Conchites, je l'ay

(1) Le Castellet est actuellement une commune qui dépend du canton du Bausset et de l'arrondissement de Toulon (Var). On y trouve une grande quantité de fossiles.

(2) Il s'agit ici d'un Polypier appartenant très probablement aux couches à Hippurites du Crétacé inférieur. Telle est l'opinion de l'éminent professeur de géologie de la Faculté des Sciences de Marseille, M. Vasseur, que nous avons consulté à ce sujet.

(3) Le nom de Concha striata avait été employé par Guillaume Rondelet, dans son livre De piscibus marinis, pour être appliqué à un Pecten; et e'est sans doute un Pecten fossile quie Peiresc avait trouvé au Castellet.

(4) Lillustre Conrad Gesner, génie universel, publia en 1565 à Zurich un volume intitulé : De omni rerum fossilium genere, gemmis, lapidibus, metallis et hujusmodi libri aliquot. Il y inséra une œuvre personnelle (De rerum fossilium, lapidum et gemmarum maximè figuris el similitudinibus liber) quil fit précéder de quelques opuscules relatifs au même sujet, et provenant de divers auteurs, parmi lesquels Jean lientman, médecin à Dresde.

(5) Les Marseillais donnent eneore le nom d'Alapedo ou Arapedo aux Patelles ou Lépas, genre de mollusques qui s'attachent aux rochers. Nous supposons que le fossile pour lequel Peirese crée ici le nom de Lepadiles était en réalité un Cyclolite. 
“ recouvrée d'Antibou (1) où lon les treuve en " coupant le roc et c'est peult estre Ctenites de "Gesnerus (2). Si cecy vous est agreable, je tas(" cheray de vous mander quelqu' aultre curiosité ».

Nous arons raconté plus haut que les relations épistolaires de Peiresc avec Charles de l'Escluse se prolongèrent, toujours fréquentes, jusqu'à la mort de l'éminent botaniste (3). Quand la dernière lettre du magistrat provençal et ses dernières expéditions arrivèrent à Leyde, Clusius venait de rendre le dernier soupir. Outre la figure du Tragacantha dont nous avons parlé, l'ultième envoi parti d'Aix contenait des échantillons de deux fruits exotiques, que Raphelenge, l'éditeur des Curce posteriores, fit graver pour ce recueil (4).

(1) Aujourd'hui Antibes, chef-lieu de canton de l'arrondissement de Nice.

(2) Bien que Conrad Gesner, dans l'ouvrage précité, ait don!é, sous le nom "Ctenitce species ", la figure d'une coquille trourée à Hildesheim, et que lui avait communiquée Jean Kentman, il ne nous est pas possible d'indiquer. même de façon approximative, quel était le fossile rapporté d'Antibes par Peirese.

(3) Peiresc avait un frère, plus jeune que lui, Palamède Fabri, sieur de Valavez, avec leçuel il entretint toujours des relations d'étroite amitié. En 1608, Palamède se disposant à entreprendre un long voyage qui, de Paris, devait ensuite le conduire en Hollande, Peiresc lui donna ses instructions dans une note détaillée que Tamizey de Larroque a publiée (t. VI, Mémoire à mon frère de Vallavez). Voici ce qu'il prescrivait, sous l'intitulé LEIDEN : "M. Clusius, à qui vous pourrez bailler la boyte que je " luy adresse avec l'espy des Indes qui y est enclos, dont je luy " ay cy devant envoyé le dessin. Que s'il offre de la vous randre " aprez en avoir prins ses memoires, vous la pourrez retirer. "Sinon ne la luy reclamez pas. " La même note nous apprend que Peiresc recevait par l'entremise du libraire Raphelenge " tout ce que M. Clusius m'a envoyé en diverses fois."

(4) Curce posteriores, p. 84 (Fructus squammosi alia delineatio) et p. 85 (Nucula Indica secunder accuratior delineatio; . 
Peiresc arait joint à ce même envoi la copie d'une lettre écrite par un médecin d'Aix, le docteur Jacques Fontaine (1), au général Blaise Capisula, gouverneur pour le pape de la cité d'Avignon et du Comtat Venaissin.

Voici quel était l'objet de cette lettre :

Il existait dans le jardin d'un bourgeois d'Avignon, nommé Doins, un pied d' "Aloes » (Agave americana L.), planté là depuis une centaine d'années, à ce que l'on croyait. Au mois de mai 1599, une hampe surgit tout-ì-coup, qui, dans l'espace de quarantecinq jours, atteignit la hauteur de trente-deux palmes. Ce phénomène végétal, nouveau pour les Àvignonais, excita chez eux autant de surprise que de curiosité. Des gens de toute condition accoururent, même des villes voisines, parmi lesquels certains royageurs, qui, se flattant d'avoir parcouru l'univers entier, déclaraient qu'en aucun lieu du monde ils n'avaient rien vu de pareil (2).

Le docteur Fontaine ne fut pas le moins étonné. Il médita sur cette extraordinaire croissance, qu’il regardait comme un prodige et qui lui parut une manifestation céleste provoquée par la piété des

(1) Jacques Fontaine, né à Saint-Maximin (Var), en 1551, fut régent à la Faculté de Médecine de l'Unirersité d'Aix. Il publia divers ouvrages, parmi lesquels nous citerons un Traité de la Thériaque (Arignon, 1601) et le Discours des marques des sorciers (Paris, 1611). La remarquable monographie due à M. F. Belin, recteur de l'Académie d'Aix, IIistoire de l'ancienne Ĺniversilé de Provence (Paris, 1896), contient des détails intéressants sur le docteur Fontaine.

(2) "Accurebant cives undiquaque, nec non è proximis urbibus homines promiscuè omnis conditionis; inter quos multi aderant viri prestantissimi, qui plurimas orbis regiones suis peregrinationibus perlustraverant; qui ingenuè profitebantur se Aloës propè infinitas in variis mundi partibus conspexisse, nunquam tamen caulem parem. " (Letlre de Fontaine à Capisula). 
habitants d'Avignon (1). C'est pourquoi il voulut faire part de ses réflexions au gourerneur pontifical. Comme il était le médecin de Peiresc, il eut l'occasion de parler de sa lettre à l'érudit Conseiller. Celui-ci jugea qu'elle méritait d'être transmise à Clusius.

Elle n'arriva pas à Leyde assez tôt. Mais Raphelenge en prit connaissance, la troura intéressante et l'inséra dans l'ouvrage posthume (2).

Le caractère épisodique et tout spécial de ce travail n'exige pas que nous lui donnions pour conclusion un jugement d'ensemble sur la haute personnalité et la longue carrière de Charles de l'Escluse.

Il y eut pourtant chez Clusius une vertu que nous tenons à mettre particulièrement en relief : ce fut sa probité scientifique.

(1) “Forsan caulis hic, omnium sententiâ, incrementi celeritate prodigiosus, significat miram hujus nobilissimæ Civitatis pietatem et divini cultûs miram observantiam. ) (Id.).

(2) Curce posteriores, p. $119:$ Aloe quedam qua Avenione crevit. - Le botaniste anglais Jean Ray, auteur d'une Histoire des plantes et qui rint herboriser en Provence, se montra sceptique au sujet de ce phénomène de rapide croissance. Credat Juclausus Apella! 》 disait-il. Cette incrédulité mit fort en colère l'honnête Garidel : "Si c'est une foiblesse de croire trop facilement, c'est aussi un entêtement de ne vouloir point croire ce que nous n'avons pas eu occasion de voir, quoique la chose nous paraisse extraordinaire; c'est à la vérité donner un démenti à bien de gens, et traiter un peu trop cavalièrement d'imposteurs tant d'homnêtes gens qui ont été témoins oculaires, et qui ne parlent pas sur un ouï-dire. Jacques Fontaine étoit trop honnête pour vouloir en imposer, lorscu'il écrivoit à un Gouverneur, et à toute une ville d'Avignon, à qui cette merveille étoit connuë. M. Raï aura un autre sentiment de Fontaine, quand il saura qu'il étoit honoré de l'estime et de la confiance de cet illustre et sçavant personnage M. Claude Fabri, sicur de Peyresc, comme on peut le voir dans Gassendy, in Vita Peiresliti. " 
La précision et la sincérité ne cessèrent jamais d'ètre son idéal. Il dut à ces qualités la considération dont l'entourèrent ses contemporains, et la renommée que la postérité a consacrée. "Il s'était fait une loi, a dit un de ses biographes, de ne se fier à personne et de n'en croire que ses yeux. Aussi l'exactitude la plus scrupuleuse règne dans ses descriptions et dans ses figures (1). "

Et nous ne saurions mieux finir cette étude qu'en montrant, par une déclaration extraite du principal de ses ouvrages, combien scrupuleuse, en effet, était la conscience du grand botaniste.

Il reprochait à Mathias de Lobel, auquel d'ailleurs il témoignait une amicale estime (2), d'avoir, sans motifs suffisants, appliqué à certaine plante un nom nouveau. Et il exposait avec quelles précautions lui-même procédait en pareil cas.

( A mon avis, dit-il, Lobelius ne devait point changer le nom d'une plante qu'il n'avait jamais vue. Pour ma part, je me tiens en garde contre une précipitation déréglée ; et avant de les avoir soigneusement observés, je m'abstiens de modifier le nom de végétaux jusque-là inconnus pour moi. Ce n'est qu'après une étude approfondie de leurs divers caractères et de toutes les circonstances qu'il importe de considérer, que je me décide à donner à l'un d'eux le nom qui me paraît lui convenir, ainsi que l'auront aisément remarqué tous ceux que mes écrits intéressent et qui les lisent avec une attention soutenue. J'aimerais mieux en réalité, - comme je l'ai fait quelquefois dans ces Commentaires, - laisser des plantes sans dénomination spéciale, quand le

(1) Nonvelle Biographie générale, article LÉcLuse.

(2) Dans son Histoire des plantes rares, Charles de l'Escluse cite quelquefois le nom de Mathias de Lobel, qu'il appelle presque toujours "Lobelius noster" ) et encore "doctissimus Lobelius ». 
nom qu'on leur donne communément ne me satisfait pas, plutôt que de leur attribuer témérairement un nom quelconque ne répondant pas assez bien à la nature de l'objet (4).»

La tendance qui pousse certains auteurs à changer arbitrairement le nom des genres ou des espèces est, on le voit, un mal ancien. Et combien, parmi les modernes, auraient bien fait de s'en tenir aux sages conseils donnés, il y a trois siècles, par Charles de l'Escluse !

(1) Rar. plant. hist., p. cxxx. 



\section{APPENDICE}

\section{LETTRES}

(INÉDITES)

\section{de N.-C. FABRI DE PEIRESC \\ à CHARLES DE L'ESCLUSE}

Monsieur, quattre ou cinq jours avant mon despart de Provence je receus la vostre du 12 May, et fus bien aise d'entendre que la derniere boette que je vous avois envoyé estoit arrivée à bon port et qu'elle vous avoit esté agreable. J'escrivis incontinent à Frejus, à Thollon, à Mompelier, en Avignon et encor ailleurs, et priay tres instemment des amys que j'y ay partout de me recueillir toutes les semences que vous desirez. Je fus en mesme temps à Marseille et y laissay 
la mesme charge à quelqu'aultre ; tellement que j'espere qu'entre touts on aura tout ce que vous desirez : mais à grand peine se pourra il rien envoyer vers vous avant la foire de Pasques, avant lequel temps j'espere estre de retour en Provence. Et quand cela ne seroit, mon frere recevra le tout de toutes pars, et me l'adressera en ceste ville afin que je le vous puisse faire tenir par les marchands qui iront à la foire. Estant à Marseille je me laissay porter à ma curiosité juscu'au lieu où se treuve quantité de Tragacantha où en ayant diligemment esplusché beaucoup de plantes enfin j'en recueillis la semence que je vous envoye maintenant. Je vous en envoyeray dadvantaige lorsque je seray de retour en Provence. On m'a promis à Aix de me faire avoir des bulbes du Narcissus totus albus qui croist es montaignes voisines. Mais il fauldra attendre l'année prochaine afin que voyant la fleur on en puisse marquer les plantes pour les arracher au mois d'Aoust, aultrement on ne les sçauroit distinguer des aultres qui sont presque semblables. Passant par Lyon, je voulus sçavoir de $\mathrm{Mr}$ Vincent marchand libraire, qu'estoit devenüe la premiere boëtte que je vous envoyay il y a un an et demy, pour laquelle il m'a faict payer deux escus de port de Lyon à Francfort, et toutefois vous ne me marquez poinct de l'avoir receüe. Il me respondit qu'elle avoit esté seurement consignée entre les mains de messieurs les Raphelenges à Francfort, et qu'il m'en fairoit voir le memoire du chargement. Je suis bien esbahi que ne l'ayez receüe, et en suis marry 
pour le dessein du puys artificiel de Mompelier et pour tout plein d'aultres curiositez que j'y avois encloses. J'ay veu le livre des Anneaulx antiques du sr Abr. Gorlaeus, et y ay prins plaisir : mais parce quoil promet des aultres recueils de medailles et aultres antiquitez, je desirerois bien de sçavoir dans combien de temps, à peu pres, il espere de les mettre en lumiere et nommement ce qui concerne les medailles grecques, desquelles j'ay recueilly grand nombre en mon voyage d'Italie. Vous m'obligerez beaucoup de m'en donner quelque particuliere information mais nommement de la capacité, humeur et complexion de l'autheur, parce que, si c'est un homme accostable, je desirerois avoir sa cognoisçance, pour conferer quelque fois quelqu'une de mes medailles avec les siennes pour nous servir d'entretien. Je n'ay pas encores veu $\mathrm{Mr}^{\mathrm{r}}$ le presidant du Thou pour sçavoir par quel chemin se sont perdües les lettres que je luy avois recommandé pour vous envoyer. J'espere de ne m'arrester pas en ceste ville plus haut de deux ou trois mois tout au plus. Cependant vous pourrez laisser l'adresse de messieurs les Bonvisi de Lyon pour la reprendre quand je seray hors de Paris, et faire vos faulces couvertes « à $\mathrm{Mr}$ Hadrian Beys, Marchand Libraire à la rue St Jacques, à l'enseigne de la rose blanche » lequel me les faira tenir chez moy seurement. Quant aux vers qu'on avoit desiré en louange de Mr Pinelli, j'eusse creu que Mr H. Grottius ou quelqu'un de ces aultres messieurs qui l'ont cogneu, en eussent faict apres sa mort et particulierement Mr Scaliger : mais je 
serois marry d'avoir importuné personne. Il me reste à vous r'amentavoir que je seray à jamais

Monsieur

Vostre tres affectionné serviteur

\section{N.-C. DE Peirets}

De Paris ce 25 Aoust 1605.

De la main de Charles de l'Escluse :

1605

N.-C. DE Peirets

Paris le 25 Aoust à celle du 12 May

Receu

en Leyden le 3 Novembre

Respondu le 12

Adresse :

A Monsieur

Monsieur de l'Escluse

à Leyden en Hollande. 
Monsieur, je suis marry que les plantes du Tragacantha et Tartonraire que je vous avois envoyé dans la premiere boitte ne vous ayent esté rendües que si tard, que elles estoyent desja toutes flestries : et suis toutefois bien aise que vous les ayiez receües quand ce ne seroit pour autre chose que pour vous servir de tesmoignage de ma diligence et du desir que j'avois eu d'executer voz commandements. Que si cela n'est bien reusci, ce n'est poinct par ma faulte, car j'y avois assez bien pourveu s'il me sembloit, et avois enveloppé cez racines dans de l'argille si fraische, que si la boitte fust allée par son droit chemin, c'est sans doubte qu'elles ne se seroyent pas sitost sechées et que vous les auriez eu toutes vives, mesmes attendu la charge que j'avois donné au messagier qui s'en chargea jusqu'à Lion, d'envelopper souvent la boitte dans un drappeau mouillé. Des aultres plantes que vous aviez desiré depuis, je 
crains bien que mon absence de Provence ne soit cause qu'il en manque quelqu'une que nous aurions possible recouvré : mais j'ay tant recommandé cest affaire à mon frere, que je m'asseure que nous en aurons la plus grande partie. Je lui ay escrit de me les envoyer icy, afin que je les vous puisse faire tenir par les libraires qui s'en iront à Francfort ceste foire de Pasques. Je les attends au premier jour. Et vous remercie par advance de tout mon cœur, du livre qu'il vous plait me promettre de voz Exotiques en grand papier, lequel attendant, je n'ay pas laissé d'en achepter icy un des communs pour m'y entretenir, comme j'ay fait fort souvent, et avec beaucoup de contentement. Mais à vous dire la vérité, j’ay esté bien estonné de voir que voz mariniers Hollandois qui vont si librement par toutes les Indes, se soyent si mal acquittez deleur devoir envers vous, et qu'ils ne vous ayent apporté plus grand nombre de curiositez, et notamment qu'ils n'ayent esté plus soigneux de vous apporter non seulement les semences ou fruicts, mais les branches mesmes de la pluspart des plantes où ils se cueillent. Je croyois que les nostres ne nous sceussent rien apporter qui ne vous fust commun : et c'est au contraire. Carje vois bien maintenant que je vous eusse peu envoyer tout plein de brouilleries que vous eussiez peut estre veu volontiers. Entr'autres choses pour ceste petite Noix qui est peinte au livre 2 , chap. 26 num 2 j'ay un gros bouquet en forme d'espi pailleux et espineux, où il y a cinq ou six de cez Noixsettes lesquelles je n'eusse jamais creu devoir croistre en ceste sorte; veu 
la dureté de leur noycau. On me l'apporta de la Guinée d'Afrique et me racontoit on des merveilles de l'arbre qui porte ce fruict et de ses usages. On m'apporta en mesme temps deux grands fruicts de Baobab de ce païs là lesquels avoient la poulpe fort rougeastre à la mode des melons, ce qui s'accorde aucunement à ce qu'en dit l'Alpinus. J'en fis semer plusieurs graines, dont il n'en sortit que deux seulles qui avoyent desja fait des feuilles comme celles de l'Oranger, mais excessivement grandes ; on les laissa mourir dans peu de temps à mon grand regret. Quant à vostre Cancer Mollucanus, Mr de Mons (qui a la commission d'occuper le païs de Canada) en a apporté un de Lacadie, avec un Aillan tout vif, un de voz oyseaux Ourissia (lequel oultre son aultre nom est aucunement divers du vostre) et mille aultres raretez : mais il dit que ceste Escrivice a la coquille vuide et qu'elle est neantmoins pleine de chair fort delicate à manger et raconte mille aultres belles choses de ce païs là. L'Ichneumon de vostre Bellonius est assez bien descript verbalement, mais le portraict n'en est pas fait bien au naturel ; car il y en a un au Louvre qui se nourrit privement dans la propre chambre du Roy, lequel convient du tout à ce qu'en escrivent touts les anciens mais non pas au portraict de Bellonius. Je croys aussy qu'il aye aulcunement failly au portrait de Scaurus, car j'en ay un que feu mons. G. Vincenzo Pinelli avoit envoyé querir en Candie, lequel n'est pas semblable à celui-cy, particulièrement pour l'endroict de la bouche et des dents, en quoy il est plus approchant 
de la description des anciens. Or il est meshuy temps de clore ceste lettre. Servez-vous de moy je vous supplie, monsieur, et me tenez s'il vous plaict tousjours pour

\section{Vostre plus affectionné serviteur}

\section{Peiresc.}

De Paris ce 15 Fevrier 1606.

J'oubliois de vous dire que le portraict que vous avez fait faire de vostre Fungus coralloides cancellatus représente fort bien le naturel. Je suis bien aise qu'il vous aye agreé et vous remercie de la mention de mon nom qu'il vous a pleu d'y faire. Nostre petit village de Peiresc s'appelle dans les vieux cadastres latins Castrum de Petrisco.

De la main de Charles de l'Escluse :

\section{6 \\ PeIResG}

Paris le 15 de Fevrier à celle du 12 Novembre

Receu

A Leyden le 7 Mars

Respondu le 28. 
ANTOINE CONSTANTIN 



\section{ANTOINE CONSTANTIN}

Au cours de nos précédentes études sur l'histoire de la Botanique au xvi siècle, nous avons eu maintes fois l'occasion de dire quelle fut alors l'importance du rôle dévolu, dans l'enseignement médical, à la science phytologique, puisque, - il est inutile de le répéter, - c'était le règne végétal qui, presque seul, fournissait matière à l'art du pharmacien.

Le botaniste dont nous allons maintenant nous occuper prétendit, - et c'est en cela que consiste sa principale originalité, - qu'en Provence croissent toutes les plantes propres à guérir les maladies auxquelles les Provençaux peuvent être sujets; d'où il concluait à une transformation complète de la Pharmaceutique provençale. La Provence cesserait d'être, pour ses médicaments, tributaire des pays orientaux, et désormais ses apothicaires n'auraient plus besoin de se procurer à grands frais des drogues étrangères, dont le haut prix ruinait les malades.

Sa thèse, basée sur cette croyance que l'auteur de la nature a toujours placé le remède à côté du mal, il l'étayait au moyen de différents exemples que lui arait suggérés son érudition biblique : 
" Moyse, pour chasser l'amertume des eaux et les rendre potables, manda-il ses droguistes aux Antipodes (comme nous faisons à tout propos) plustost que d'experimenter la vertu de l'arbre voisin du fleuve? - Elisée mundifia-il les eaux de Jericho avec autre drogue qu'arec celle qui est en chasque maison usuelle et familiere, assavoir avec le sel ? - Thobie le jeune, pour curer la cecité de son pere, de quel collyre ou de quelles autres drogues usa-il en ceste operation, que du fiel du poisson qu'il pescha dans le fleuve voisin? "

Or, s'il est de règle que partout l'antidote aroisine le venin, y aurait-il exception pour la Provence ? (1)

"Quand on voudroit bien faire ce tort à la nature, de l'accuser qu'elle eust laissé quelques contrees despourreuës et indigentes de remedes necessaires à la conservation el restauration de la santé des hommes qui les habitent: oserions nous dire cela de nostre Provence? De laquelle semble que la mesme nature ait voulu faire un abregé de tout le monde, et y renfermer la foccondité de tout ce qu'elle a esparsement distribué entre toutes les autres du globe. Elle nous a produit toutes les especes de grains, vins, huiles, sels, bestails, poissons, et toutes sortes de fruicts, soyes, laines, brief tout ce qui est propre pour la nourriture, entretien et plaisir des hommes. Elle nous exhibe le vermeillon, le safran, quand bon nous semble, la soulde, le pastel, la guesde. Elle nous

(1) A l'appui de cette vérité, ou prétendue telle, que la nature place toujours le remède à proximité du mal, notre auteur invoquait une observation faite par un conseiller au Parlement d'Aix. Cet ingénieux magistrat faisait remarquer que les fruits astringents, tels que ceux du Cornouiller ou du Sorbier, mûrissent à l'époque même où ils peuvent servir à combattre les dyssenteries produites par l'excès des fruits laxatifs comme les melons et les raisins. 
presente pierre de toutes sortes, pour bastir et ediffier, plastrer, mouldre, cruser, et à faire verres. Le bolus (1) encores, le talc, le jayet, le coral, la croye (2) et l'ocre. Elle enferme dans ses flancs l'or, l'argent, le mercure, le plomb, le soufre, le fer, le vernis et le charbon naturel (qui est une espece de bitume) pour purifier et rendre tous lesdicts mineraux propres à nostre usage. Et pour la guarison de plusieurs maladies, par autre artifice incurables, elle nous elixe, dans ses entrailles, de bains naturels et tres-salutaires, à Digne et dans ceste cité d'Aix. Et neantmoins, quoyque nous habitions une tant fertille province et si apte à la production de toutes choses: nous ne voulons confesser estre abondans et tres-riches de remedes. )

L'auteur de ce patriotique dithyrambe se nommait Antoine Constantin. Il était originaire de la Haute-Provence. « Il nâquit, dit Garidel (3), à Senez, ville Episcopale de cette Province (4). Après avoir

(1) Bolus, bol d'Arménie, médicament qui, au xvie siècle, était employé contre la peste, et dans la composition duquel on faisait entrer une sorte de terre ou de pierre friable apportée d'Arménie. - Le botaniste provençal Hugues de Solier affirme dans ses Scholies sur Aetius, que l'on extrayait cette même terre " de certaines petites collines situées près de Montmajour, aux environs d'Arles, ville très ancienne et très illustre de notre Provence. " (La Bolanique en Provence an xvie siecle: Hugues de Solier.)

(2) Nom provençal de la craie.

(3) Histoire des plantes qui naissent aux environs d'Aix, Explication des noms des Auteurs botanistes, p. virr. - Antoine Constantin était fils de Claude Constantin, dont Garidel ne nous fait pas connaitre la profession, et de Jaumette Maicox.La date de sa naissance n'est pas indiquée. Mais comme nous savons qu'il se maria en 1580 , si nous admettons qu'il était alors âgé d'environ trente ans, il serait né vers le milieu du xvic siecle.

(4) Le petit village de Senez, aujourd'hui chef-lieu de canton de l'arrondissement de Castellane (Basses-Alpes), fut jusqu'à la 
fini ses études en Medecine, il prit le degré de Docteur dans l'Université d'Aix, où il exerça la Medecine pendant un assez long temps arec l'entiere satisfaction du Public... Il étoit très-versé dans la connoissance de la matiere medicinale, il possedoit à fonds les Auteurs Arabes ; ce qui lui donna lieu d'examiner si, sans les drogues Arabesques, l'on ne pourroit pas guérir aussi-bien les maladies avec les remedes du Païs. »

L'exemple populaire arait, du reste, confirmé ce novateur dans l'idée de substituer les remèdes indigènes à ceux apportés des pays lointains :

(I Le vulgaire, et mesmes les femmeletles semblent en cecy avoir esté plus curieuses et diligentes que nous : car elles ont mises les facultez de plusieurs medicamens en lumiere, lesquelles nous estoyent auparavant incognuës. Et quant aux purgations la plebee coustumierement mesprise les estrangers, use de la catapuce, de la laureole, du tytimal, de l'hieble, et autres que la necessité leur a faict experimenter. Brief la populace met en besongne les medicamens produits en nostre Provence, tant aux internes qu'aux externes maladies, quelquefois avec meilleur succés et toujours avec moins de frais que nous qui, preferans le rheubarbe, les tamarins, les mirobolans, la casse et autres drogues estrangeres, adulterees ou vermoulues et chanssies de vieillesse, outre le trouble que donnons aux malades à cause de l'odeur et du goust mausade, odieux et ingrat, sommes cause que les Apothicaires sont contraints (estant les drogues estrangeres si cherement acheptées) d'espuiser la bource des pauvres malades : tellement que nous en royons plu-

Révolution le siège d'un évêché.-Parmi les évêques de Senez, nous rappelons qu il y eut, au xvie siècle, le jeune Quiqueran de Beaujeu, auteur du De laudibus Provincia. 
sieurs ceder pluslost à l'impetuosité des maladies et aymer mieux mourir, que de recourir à nous, sachans fort bien qu'ils ne pourroyent eviter les drogues Orientales et Indiennes, ny le registre des Apothicaires. )

Mais Constantin se gardait bien de faire le procès aux apothicaires, avec lesquels, évidemment, il tenait à ne pas se brouiller :

"Les Apothicaires, quant en ce faict, doivent estre deschargez de toute accusation et blasme. Car ils ne peuvent ni doivent meubler leurs boutiques d'autres drogues que de celles que les Medecins mettent ordinairement en praticque. Lesquelles, estant acheptées cheres, ne peurent estre vendues qu'à cher prix. "

Les médecins sont les seuls coupables. L'emploi des médicaments exotiques impose actuellement aux apothicaires des voyages coùteux et pénibles, qu'ils n'auront plus l'obligation d'entreprendre, lorsque la matière médicale leur sera fournie par la Provence :

"S'ensuit done que despuis qu'arec beaucoup moins de despence et autant ou plus de commodité, nous pouvons faire la medecine en ce païs, des medicamens qui sont en iceluy nourris, nous faisons tort à la nation Provençale de la frustrer des biens que nostre Seigneur semble avoir preparez pour elle et desquels nous avons esté faicts les fidelles dispensateurs : comme aussi les Apothicaires et droguistes ont de quoy se plaindre de nous, de ce que nous les contraignons naviger jusques aux extremitez de la terre, pour recourrer avec grands perils, frais et despens ce que se peut sans danger, sans grand pourchas et à bon conte recouvrer en ce païs. " 
Notre médecin, ayant longuement expérimenté sur ses malades l'effet des plantes médicinales récoltées en Provence, prit le parti d'écrire un ouvrage spécial pour préconiser sa méthode.

Le traité de la pharmacie provençale, - tel était le titre projeté, - devait, dans la pensée de l'auteur, exiger plus d'un volume. Un seul a paru. C'est celui où il est question des plantes purgatives, les premières qu'Antoine Constantin tenait à faire connaître.

Ce livre fut imprimé à Lyon par Thibaud Ancelin, imprimeur du roi, et vit le jour en 1597.

La publication d'un livre nouveau était alors un événement que les amis de l'auteur, quand ils se croyaient poètes, célébraient à l'envi, toujours prodigues d'hyperboles; et le volume étalait avec orgueil sur ses premières pages les sonnets ou autres pièces qu'il avait inspirées.

S'il faut en juger d'après l'enthousiasme des poètes qui saluèrent par avance l'œuvre d'Antoine Constantin, l'idée pour laquelle celui-ci s'était mis en campagne allait être accueillie avec la plus grande faveur.

Dans un premier sonnet, un poète qui jouissait en ce temps-là d'une certaine renommée, Louis de Gallaup-Chasteuil (1), prévoyait le vide que la médi-

(1) La Biographie universelle n'a point passé sous silence le poète Louis de Gallaup-Chasteuil. Voici la notice qui le concerne: "Issu d'une famille noble et ancienne, originaire de Naples selon quelques-uns, mais plus probablement du Languedoc, laquelle vint s'établir à Aix-en-Provence à la fin du $\mathrm{xv}^{\text {· }}$ siècle, il naquit dans cette ville, vers l'an 1550 . Son père et son aïeul sétaient distingués dans la carrière des armes. Tous deux cultiverent les lettres, goût que partagea Louis et qui fut commun à ses descendants. Louis fit de bonnes études et devint un des hommes les plus savants de son temps. Il faisait des vers avec facilité, et son génie brillait surtout dans les inscriptions et les devises. Charles-Emmanuel Ier, duc de Savoie, l'ho- 
cation nouvelle ferait bientôt sur les rives du Styx, et il s'alarmait, pour l'inventeur, de la colère des dieux infernaux :

Je crains qu'un Dieu jaloux ne retranche son âge ;

Sa main prive Caron de l'importun naulage (1);

Eacue aux champs herbeux n'attend plus le mortel.

Un avocat au Parlement d'Aix, N. Perrin, apostrophait ainsi les Indiens qui, désormais, ne trouveraient plus d'acheteurs pour leurs drogues :

Dites-nous, Indiens, qui vous rend estonnez ?

Quelle est votre douleur? Quoy! vos drogues moisies Ainsi qu'auparavant ne seront plus choisies, $\mathrm{Ny}$ ros fruits abuseurs dans nos havres trainez?

Un autre " Advocat au Parlement de Provence », B. Bernardi, vaticinait en ces termes :

Fidelles gardiens du recours de la vie, Sacres-saincts heritiers de l'Epidaurien, N'allez plus outre-mer rechercher nostre bien, Ny relisez plus tant les secrets d'Arabie.

Ce livre seul pourra contenter vostre envie Sans relire sans fin le divin Galien, Et fournira pour vous et au Pharmacien Le rheubarbe et la casse en vostre champ sortie.

Cacochimes François, vous en estes aussi ; Et vous, ô Provençaux, lisez ce livre icy, Car surlout c'est pour vous qu'il est mis en lumière...

norait de son estime, et en recevait volontiers des conseils. I1 rendit a Henri IV, dans le temps de la Ligue, d'utiles services que ce prince reconnut par une charge de conseiller d'Etat. Il mourut à Aix, l'an 1598, n'étant âgé que de quarante-huit ans. $n$

(1) Nolis, prix du passage (payé au batelier infernal). 
Et comme parmi les productions littéraires l'anagramme était alors fort en honneur, N. Perrin composa un second sonnet pour y insérer celle-ci :

Nul d'eux (1) eut toutesfois l'authorité si grande Que nostre Constantin qui, des lors qu'il commande, Aux malades il donne incontinent santé.

Nous ne devons pas nous étonner qu'au nombre des rimeurs qui prônèrent la Pharmacie provençale il y eût deux avocats : Constantin, bien aise de mettre son traité sous la protection de l'autorité judiciaire, l'avait dédié «à mes seigneurs de la Cour de Parlement de Provence ». Il craignait que son succès ne lui suscitât beaucoup d'envieux, et il essayait de s'attacher par avance d'illustres défenseurs :

" Mes seigneurs, c'est l'ordinaire des hommes qui font profession des lettres, principalement de ceux qui recelent beaucoup plus à l'intérieur qu'ils n'en portent au front, d'estre long temps suffoquez et comme ensevelis parmi les tenebres des plebees, si quelque grand personnage ne les sousleve et leur soustienne le menton. C'est quasi aussi l'ordinaire entre ceux qui courent en mesme lice, de mesdire et detracter des labeurs et actions d'autruy. Et c'est pour autant qu'un chascun desirant sa renommee nager au-dessus, et gaigner le haut, tasche par tous moyens mettre à fons et ensevelir la memoire non seulement de ses contemporains, mais voire mesme de ses antecesseurs... Ce vice a faict que nostre medecine a perdu les escrits d'un Herophile, d'un Crisippe, d'un Diocle, d'un Prodique, d'un Praxagore, d'un Erasistrate, d'un Themisson, et d'une infinité d'autres... Si donc les detractions ont eu

(1) Hippocrate et Galien. 
tant de pouvoir sur les œuvres de tant et tant de renommez personnages, que doibs-je esperer de ce petit surgeon, sinon de le voir assailli par les morsures empestees de plusieurs mesdisans, plus addonnez à detracter du labeur d'autruy que diligens et curieux de mieux faire?... Tels mesdisans et mal affectionnez, considerans les merites et grandeurs de vostre tres auguste Compagnie, pleine d'humanité, de doctrine, de prudence, de pieté, de foy et de religion tout ensemble, seront contraincts puser les armes et caler les voiles, le voyant esclos soubs la protection et sauvegarde de ce tres illustre et royal Senat. "

Il y avait donc, en ce bon vieux temps, chez les botanistes et les médecins, des mesdisans addonnez à detracter du labeur d'autruy! Mais nous pensons bien qu'avec le puissant patronage du Parlement de Provence le subtil docteur aixois put échapper à leurs morsures empestées.

Nous avons dit plus haut qu'en écrivant son livre, Constantin se proposait de l'intituler: "Traité de la pharmacie provençale ». Il n'avait point renoncé à ce titre lorsqu'il remit son manuscrit à l'imprimeur lyonnais, et durant l'impression du texte, rien ne fut modifié. En tête de la page qui porte le chiffre 1, nous voyons un titre d'entrée ainsi conçu : "Premiere partie de la pharmacie provençale"; ces mots : “ de la pharmacie provençale » sont reproduits sur les titres-courants, au sommet des pages suivantes; et le volume se termine par cette formule : "Fin de la pharmacie provençale ».

Mais quand, l'impression du corps de l'ouvrage élant achevée, il ne restail plus qu'à imprimer en dernier licu, comme il est d'usage, une première feuille contenant le frontispice, l'avis au lecteur, la dédicace et les poésies liminaires, Constantin se ravisa. 
Il jugea sans doute qu'il assurerait à son traité un débit plus étendu si, en modifiant le titre, il enlevait à l'ouvrage un aspect trop exclusivement provençal. Au mot provençale, qui accompagnait celui de pharmacie, il substitua l'adjectif provinciale, et il arrêta en cette forme la rédaclion définitive du frontispice: "Brief traicté de pharmacic provinciale et familiere, suivant laquelle la Medecine peut estre faicte des remedes qui se treuvent en chasque province, sans qu'on soit contrainct les aller mandicr ailleurs, dressé et faict vulgaire par M. Antoine Constantin, d. en medecine à Aix en Provence ».

De celte façon, l'ouvrage paraissait écrit, non point seulement pour les Provençaux, mais pour les habitants de chacune des autres provinces du royaume; ce que, du reste, l'auteur déclarait en termes exprès, dans son "Advertissement au lecteur $)$ :

( Ne pense pas, ami lecteur, combien que ce traicté semble s'adresser seulement aux Provençaux, qu'il ne soit aussi basti pour toutes les provinces de la France, et ne se puisse encore estendre plus loing... »).

D'après le plan conçu par Constantin, ce volume, ainsi que nous l'avons indiqué, n'était que le commencement d'une série; uniquement réservé aux purgatifs, il avait pour objet de vulgariser les substances, douées de la virlus purgativa, qui pouvaient être empruntées aux ressources particulières du terroir provençal.

Le traité de la Pharmacie provençale est divisé en trois livres :

Le premier, qui ne porte pas de titre spécial, est affecté à l'examen d'un groupe d'espèces végétales ayant la propriété de purger avec énergie et appar- 
tenant presque toutes à la flore spontanée de la Provence;

Le deuxième livre est intitulé : Des medicamens qui purgent sans faire aucune violence ou bien peu au corps humain; il y est encore fait mention de diverses plantes spontanées;

Enfin, le contenu du troisième est indiqué au moyen de l'énonciation suivante: Des medicamens qui, outre ce qu'ils purgent le corps, ont aussi quelque pouvoir de le nourrir. Parmi ces médicaments alimentaires, l'auteur introduit un cerlain nombre d'arbres fruiticrs ou de plantes potagères.

Nous roulons ici demeurer fidèle à la règle dont nous ne nous sommes jamais départi en écrivant nos études de botanique rétrospective. Nous n'envisagerons Antoine Constantin qu'en sa qualité de botaniste. Nous laisserons de côté tout ce qui, dans son ouvre, intéresse l'art médical ou pharmaceutique Des divers chapitres consacrés aux plantes médicinales, nous extrairons seulement les passages qui peurent offrir un intérèt botanique.

L'auteur de l'Histoire des plantes qui naissent aux environs d'Aix a fait un reproche à Constantin, considéré comme botaniste. Après avoir reconnu qu’ "il possedoit à fonds les Auteurs Arabes ", Garidel ajoutait : "Il paroit que nôtre Auteur n'avoit pas de grandes lumieres dans la Botanique moderne, qui lui auroit fourni infailliblement de quoi enrichir son livre "; et il appréciait ainsi la Pharmacie provençale: "Cet ouvrage est plus à estimer par raport au dessein de l'Auteur que par l'exécution ".

L'instaurateur de la médication nouvelle était, il est rrai, profondément imbu de l'antique doctrine : il trouve des occasions fréquentes d'invoquer Hippocrate, Théophraste, Dioscoride, Galien, Oribase, Paul d'Egine, et, parmi les auteurs arabes, Mesué, Avicenne, Avenzoar, d'autres encore. Mais il semble 
n'avoir eu qu'une connaissance bien incomplète de ce que Garidel appelait " la Botanique moderne », c'est-à-dire l'ensemble de ces grands ourrages de phytographie que la seconde moitié du $x^{\prime} I^{e}$ siècle vit éclore en si grand nombre et qui, en sulsstituant au principe d'autorité l'observation directe des phénomènes de la nature, ouvrirent à la science émancipée la voie du progrès illimité. Des botanographes de son siècle, c'est à peine s'il nomme Ruel, Matthiole, Léonard Fuchs et Jean Costrus.

Il est à remarquer que bien souvent Constantin évite de donner, aux plantes dont il traite, les noms latins inscrits dans les Flores contemporaines. Il les désigne par le nom français, auquel il ajoute quelquefois le vocable provençal. Etait-ce parce qu'en pareil cas il ignorait le nom latin? On peut supposer aussi qu'étant désireux de laisser à son Brief traicté le caractère d'œuvre populaire et, suivant son expression, " familière ", c'est intentionnellement qu'il s'abstenait d'employer, pour la désignation des simples, la langue scientifique.

Nous allons maintenant passer en revue les plantes énumérées dans la Pharmacie provençale. Nous les présenterons sous le nom adopté par l'auteur et nous conserverons l'ordre qu'il a suivi.

Cocombre Sauvage. - Il s'agit ici de la Cucurbitacée que nous nommons aujourd'hui Ecballium Elaterium Rich. (Momordica Elaterium L.) " Le vulgaire, écrit Constantin, l'appelle Cocomerasse (1). Il croit tout proche des murailles, presque de tous les lieux de ce païs, mais aussi il entre maugré nous jusques aux jardins, desquels il ne peut bonnement estre extirpé, dans l'enclos desdittes murailles. "

(1) Ce nom provençal n'est point tombé en désuétude. Le Trésor du Félibrige donne aussi les formes Coucoumourasso, Coulcouroumasso, Coucoumbrasso. 
Catapuce. - L'auteur réunit sous ce titre deux Euphorbiacées bien différentes : le Ricin (Ricinus communis L.) et l'Epurge (Euphorbia Lathyris L.). Voici comment il s'exprime au sujet de ces deux espèces :

" Je ne m'arresteray pas à descrire l'histoire de la catapuce, non plus que des autres simples desquels j'ay deliberé de parler, tant pour ce qu'ils sont cogneus presque de tous et mesmement du vulgaire, qu'à cause que les herboristes (1) recens en ont suffisamment escrit.

"Les herboristes en ont remarqué de deux sortes, l'une qui est grande, qu'autrement nous appellons ricinus à cause que sa graine represente un petit animal livide, qui s'attache aux boufs, aux chevres et autres bestes : on l'appelle en nostre langue provençale cascaillons (2). Le vulgaire nomme ceste plante palma christ (3).

"L'autre espece est petite, qui proprement est celle que nous appellons catapucia, Galen la nomme lathiris. La catapucia minor, que les Provençaux entendent seulement par le nom de caquapuce (4), les François la nomment espurge. i)

Tithymale. - "C'est, dit Constantin, la plante que les barbares (5) appellent esula,les Latins lactuca

(1) Le mot herboriste n'avait pas alors la signification que nous lui donnons aujourd hui. Il sappliquait aux botanistes, avec le sens plus spécial que comporte l'expression moderne de floriste.

(2) Constantin veut ici parler de la lique, insecte que les Provençaux continuent à nommer cascaioun.

(3) Le nom provençal du ricin est présentement paumocristo; palma-crisl est la forme languedocienne (V. le Trésor de F. Mistral.)

(4) Le mot catapuço est encore usité en Provence avec la même signification, ainsi que la forme altérée cacapuço.

(5) Constantin entend par là ceux qui parlaient un latin barbare, et il visait, sans aucun doute, le personnel des officines où 
caprina, herba capraria, les François l'herbe à lait, et les Provençaux lachuscle (1). Les Medecins qui ont escrit des simples medicamens, tous d'un commun accord confessent qu'il y en a de sept especes. Ores qu'en ce païs, à mon opinion, nous ayons toutes les especes, tant aux parties maritimes que ès montagnes, nous prendrons neantmoins celui qui nous est plus à port, qui croit partout, jusques aupres des murailles des villes et villages, ès lieux cultivez et incults, et n'est autre que celuy que Mathiol et Dioscoride appelle helioscopius; qui est en malignité ct rehemence inferieur aux autres especes. » - C'est donc notre Euphorbia Helioscopia L. que le médecin réformateur recommandait à ses malades sous le nom de "Tithymale ».

Thymelea et Chamelea. - Nous nous trouvons ici en présence d'une difficulté. Le texte porte: «De ces deux plantes, les anciens n'en ont usé que de la graine : l'une desquelles ils appellent granum cnidium, l'autre cneorum. ")

Par thymelea, il y a certitude que Constantin désignait le Garou (Daphne Gnidium L.), nous avons, pour n'en point douter, l'autorité de Garidel (2).

l'on désignait les plantes médicinales par des noms spéciaux, à désinence latine, mais différant des termes, réputés classiques, dont se servaient les botanistes. V. à ce sujet notre étude sur Hugues de Solier : cet auteur a, pour la plupart des plantes qu'il mentionnait, fait connaître les appellations en usage chez les apothicaires.

(1) Nom que la langue provençale continue de donner aux diverses Euphorbes, et dont la racine est le mot la ou lach, lait.

(2) « Le Garou, ou Thymeleca foliis Lini C. B. Pin., contient un sel âcre caustique .. Les plus anciens botanistes conviennent que le Granum Cnidium des Anciens est le fruit de cette plante, dont Hippocrate se servoit pour purger ses malades. Dioscoride a rangé cette plante parmi les remèdes purgatifs; Mesué lui a 
C'est du reste à cette espèce que beaucoup de floristes du $\mathrm{xvI}^{\circ}$ siècle araient appliqué le nom de Thymeloca.

Matthiole, Dodoens, Cordus, Pierre Belon, Conrad Gesner et d'autres domnaient celui de Chamalea à la plante que les Adversaria, l'Historia Lugdunensis, Charles de l'Escluse en son Histoire des plantes rares, Jean et Gaspard Bauhin appelèrent Chamcelea tricoccos et dont Linné a fait son Cneorum tricoccum. Nous serions donc porté à croire que c'est bien de cette espèce qu'il est question dans le passage cité plus haut, et le mot cneorum, qui y est employé, confirmerait notre assimilation. Mais est-il possible de la concilier avec les détails donnés par Constantin au sujet du Thymelcea et de son prétendu Chamelca ? "Ces deux plantes, dit-il, sont si vulgaires en ceste province, mesmement au païs bas, qu'il n'y a presque lieu incult qui n'en soit peuplé, mesme que tous les chemins pres la ville d'Aix en sont bordez. "

Le Daphne Gnidium est assez commun dans la Basse-Provence (1), mais le Cneorum tricoccum y est d'une extrême rareté. Honoré Roux, l'auteur du Catalogue des plantes de Provence, ne l'a cité que dans le département des Alpes-Maritimes. Un ouvrage antérieur, le Catalogue des plantes qui croissent naturellement dans le département des Bouches-du-Rhóne, de Castagne, l'avait signalé aux environs d'Arles. Mais on ne l'y a pas retrouvé, puisque le consciencieux Honoré Roux s'est abstenu de reproduire cette indication. Est-il possible

donné la même place... Nôtre Constantin n'a pas fait difficulté de suivre Mesué et les Auteurs ci-devant cite\%. ) (Hisl. des pl., p. 461.)

(1) " Cette plante, écrivait Garidel, est fort commune dans nôtre terroir, on la trouve presque partout sur nos collines du Monteiguez, du Tholonet et ailleurs. » (Ibid., p. 460). 
d'admettre que si le Cneortum, pendant le xvi siècle, était aussi abondant aux alentours d'Aix que l'affirmait Constantin, il cût, depuis lors, entièrement disparu ? (1).

Ellebore.- " Les herboristes depeignent deux principales sortes d'ellebore, le blanc et le noir : toutes les deux on treuve en ceste province et principalement aux montaignes qui voisinent le Dauphiné et Terre-Neuve (2) d'où elles peurent estre transplantees en nos jardins, comme plusieurs autres plantes, afin que nous puissions au besoin estre plus promptement et commodement secourus. " Parmi les botanistes du $\mathrm{xvI}^{\mathrm{e}}$ siècle, les uns appelaient Helleborus niger l'espèce à laquelle Linné a confirmé ce nom (Helleborus niger flore roseo de Gaspard Bauhin); les autres, celle que l'auteur du Species a nommée Helleborus viridis. Il est probable que par Ellébore noir Constantin entendait l'Helleborus niger L. « L'Hellebore noir dont nous nous servons

(1) La rareté du Cneorum tricoccum en Provence au xvi siècle avait été constatée par Pierre Pena qui a fourni au Slirpium Adlversaria tous les articles relatifs à la flore provençale. Après avoir signalé une station de cette plante à Frontignan en Languedoc, il déclarait qu'elle était rare partout ailleurs et notamment en Provence : "nec quidem in Galloprovincia, ubi tamen nascitur, multo prodit proventu. ") (Slirp. Adlv., p. 157) Dans les nombreuses herborisations qui nous ont fait parcourir en tous sens les cinq départements découpés dans l'ancien territoire de la Provence, nous n'avons pas rencontré une seule fois le Cneorum. Honoré Roux, que nous venons de rappeler, ne l'avait jamais récolté lui-même; il l'indique à Antibes, d'après Huet, à Nice, Menton et Monaco, d'après Arduino. - On a vu plus haut que Pierre Belon, vers le milieu du xvie siècle, trouva cette Térébinthacée à Ramatuelle, près Saint-Tropez (Var).

(2) Vallée de Terre neuve, Terre neuve de Provence, sont les noms "que les Piémontais donnaient autrefois au comté de Nice, depuis son annexion au duché de Savoie en 1388. ” (F. Mistral, Trésor du Félibrige). 
en Medecine, écrivait Garidel, est l'Helleborus niger flore roseo C. B. Pin., qui vient dans la haute Provence, dans les montagnes de Colmars et de Seyne, et dans celles du Dauphiné (1). »- Quant à l'Ellébore blanc, il n'est pas douteux que c'était pour l'auteur de la Pharmacie provençale la Colchicacéc à laquelle Dodoens, Valérius Cordus et d'autres avaient déjà conféré le nom de Veratrum album qu'elle porte encore de nos jours. "Nos Provençaux apellent cette espece Varaire, du nom corrompu de Veratrum, qui est l'Hellebore blanc. Aujourd'hui on se sert rarement de l'Hellebore blanc, à cause des terribles symptômes qu'il excite (2). ")

Turbith. - Turbilh est un nom arabe employé par Avicenne.

Les écrivains de la Renaissance, qui tenaient tant à pouvoir appliquer avec certitude les noms anciens aux espèces qu'ils avaient sous les yeux, ne parvinrent pas à se mettre d'accord sur l'identité du Turbith. Les uns donnèıent ce nom à diverses Euphorbes, d'autres à plusieurs Ombellifères, quelques-uns à la plante exotique que Linné nomma Convolvulus Turpethum. Les mêmes divergences

(1) Histoire des plantes qui naissent aux environs d'Aix, p. 226. - Garidel avait reçu cette plante de son correspondant Jean Saurin, apothicaire à Colmars, lequel avait aussi trouvé dans les mêmes parages l'Helleborus viridis L. Il disait de la première : " Mr Saurin nous assure que cette plante vient sur la pente de la montagne appelée le Col de Champ, ou la Conello de Champ, du côté d'Entreaunes, dans les lieux septentrionaux et couverts d'arbres, à une lieüe et demie de Colmars " ; et de l'Ellébore vert : «On tr:ouve cette espece d'Hellebore dans les mêmes endroits du terroir de Colmars, comme l'a observé Mr Saurin. " - Voir, au sujet du correspondant de Garidel, notre Nolice sur le botaniste provençal Jean Saurin (Pari., 1899).

(2) Garidel, loc. cit. 
d'opinion se manifestèrent à propos du mot grec Thapsia, trouvé dans Théophraste. Les deux noms finirent par être confondus, cerlains auteurs, tels que Césalpin et Conrad Gesner, ayant indifféremment appelé la même plante Turbith ou Thapsia.

C'est ce que fit aussi Constantin : “ Ie sçay qu'on objectera que la thapsia, de laquelle je parle, n'est pas le turbith qui est mis en ourre aux boutiques de nos Apothicaires; mais ce m'est tout un, pourveu que par experiences infaillibles, et par le tesmoignage de quelques auteurs recens, de renommee non vulgaire entre les Medecins, soit notoire et manifeste que nostre thapsia a les mesmes puissances de purger la grosse et crasse phlegme, que Mathiol attribue au tripolion, qu'il pense estre le turbith. )

Le Turbith ou Thapsia qu'Antoine Constantin faisait figurer parmi les plantes purgatives indigènes, est une Ombellifère qui se rencontre assez communément sur les collines de la Provence méridionale: le Thapsia villosa L., auquel, arant Linné, Gaspard Bauhin, dans le Pinax, avait déjà imposé l'appellation de Thapsia latifolia villosa (1).

A cet égard aucun doute n'est possible; nous avons encore ici l'appui de Garidel.

En son Histoire des Plantes, il a consacré un long article au Thapsia latifolia villosa du Pinax : "La racine de cette plante, dit-il, rend un suc lacticineux, fort âcre et amer au goût, qui excite des nausées, et qui s'épaissit en forme de gonme quand il est sec... Plusieurs de nos Auteurs ont crù que le Turbith des Arabes étoit la racine du Thapsia... Nôtre Constantin étoit dans le même sentiment. Il assure qu'il s'en étoit servi avec heureux succez, dans le

(1) La plupart des floristes du xvie siècle, antérieurs à G. Bauhin, l'appelaient Seseli Peloponesiacum. 
village où il avail commencé de faire la Medecine (1). »

S'il faut en croire l'auteur de la Pharmacopée provençale, le Thapsia villosa était extrèmement abondant aux alentours d'Aix. "Combien qu'il croisse en affluence en ce païs de Provence, mesme que les coustaux et monlagnes, tant du terroir de la ville d'Aix que des lieux circonvoisins, en sont toutes couvertes (2), si est-ce que les droguistes et grossiers (3) de Marseille (desquels nos Apothicaires l'acheptent bien cherement) le ront chercher, à grands frais et despens, en regions estranges. ») Et il relatait ce détail qui n'est pas sans intérêt au point de vue de l'histoire du commerce : «Les marchands de la basse et haute Bretaigne le viennent querir au bas Languedoc, vers Montpellier et Nismes, auquel païs s'ils ne la trouroyent, suis asseuré qu'ils viendroyent querir le nostre et accuseroyent la negligence de nous autres Medecins Provençaux. »)

(1) a C'est une erreur de croire, ajoutait Garidel, que le Thapsia dont nous parlons, non plus que le Thapsia IIontis Gargani, dont on se sert dans la Sicile, nous fournisse le véritable Turbith. Le véritable Turbith est une espece de Lizeron, qui croît à Guzarata, dans les Indes Orientales, et que lillustre IIr Herman, Professeur Botaniste à Leyden, appelle Convolvulus Indicus, alalus, maximus, foliis Ibisco non nihil similibus, Turbith officinartum. Caspar Bauhin l'appelle Turpelhum repens foliis Allhece, vel Indieum. "C'est cette plante que Linné a nommée Convolvulus Turpelhum.

(2) Il semble qu'au siècle suivant, le Thapsia villosa était devenu plus rare aux environs d'Aix. "L'on trouvoit autrefois eette plante, déclarait Garidel, sur les collines du Montaiguez. Mr Fouque [professeur de botanique à l'université d'Aix] l'a trouvée en deçi du Pont dei tres Sautez: je lai trouvée en assez grande quantité dans l'endroit appelé lou Devens de Pourrieros, dans celui de Rians nommé la Garduello, et dans le bois d'Ollieres. ")

(3) Grossicrs, marchands grossiers, commerçants en gros. 
Flanne ou Glayeul. - Constantin applique évidemment ces deux synonymes à l'Iris germanica L.

"La flamme, ou iris, ou glayeul, dit-il, est celui que nous voyons aux jardins : ausquels estant une fois tant soit peu enraciné, il pullule si bien qu'il n'a besoin de culture pour se presenter, avec ses couteaux verdoyans, enrichi de diverses couleurs. »)

Il nous apprend que déjà la parfumerie utilisait la bonne odeur qu'exhale, quand elle est desséchée, la racine d'iris, et il nous fait connaître les noms singuliers de deux des produits que cette industrie en obtenait. Il qualifiait l'Iris germanique de " fidelle conservateur de toutes odeurs plaisantes", et il ajoutait aussitôt : « lequel les perfumeurs mettent pour fondement et base de leurs pommes, oyseaux de Cypres, et autres senteurs. )

Sureau et Hieble. - La signification de ces deux mots français n’a pas varié. Ils désignaient, comme aujourd'hui, les deux espèces, l'une et l'autre très répandues en Provence, du genre Sambucus : l'espèce arborescente, Sambucus nigra L., et l'espèce herbacée, Sambucus Ebulus L. "Dioscoride, écrit notre auteur, faict seulement deux especes de ceste plante: l'une qu'il appelle en sa langue grecque acte, l'autre chamacacte. La premiere est celle que les François nomment sureau, les Latins sambucus, desquels nous avons retenu le nom sambuc (1) ... Le chamaacte de Dioscoride est plustost herbe que arbrisseau, et

(1) Nom provençal du Sambucus nigra. - Il est à remarquer que le pronom pluriel nous, dans ce membre de phrase, est mis par opposition aux substantifs qui précèdent : « Les François... les Latins... 》; il signifie : "Les Provençaux 》. La Provence devant, aux termes du testament de son dernier Comte, être rattachée a la France " non point comme un accessoire à un principal, mais comme un principal a un autre principal », les Provençaux n'entendaient pas abdiquer leur nationalité. 
n'est autre que celle que nous appellons en François hieble, en latin ebulus : le vulgaire en Provence le nomme dooulgues (1)".

Brionia ou Coluvrée. - La nomenclature moderne a conservé, comme nom de genre, le vocable Bryonia. Il n'en existe en Provence qu'une seule espèce, Bryonia dioica Jacq., qui croît dans les haies, ainsi que Constantin l'indique fort exactement. Il nous révèle qu'elle était employée par les femmes à un usage cosmétique. "Combien que la brionia, que les Latins appellent vitis alba, les François la colltvrée, ou feu ardant, soit un simple tres frequent, tant aux montaignes que aux païs bas de ceste province, et qu'elle croist au long des chemins, et principalement aux hayes des jardins et vignes : si n'estelle que des herboristes cognuë, et de quelques femmes qui la recherchent curieusement, non pour la dedier à la purgation, ains plustost pour en faire un fard, tres accommodé pour l'embellissement de la face, et pour esfasser les taches et cicatrices des playes, à quoy elle est excellente, si au jus de sa racine on mesle la farine de febres, ou des pois ciches, et est faict un liniment pour l'appliquer sur le visage ou sur tout autre partie ».

Laureole. - C'est le Daphne Laureola L. Constantin avoue que Mesué, son auteur de prédilection, n'ayant point fait mention de la Lauréole " en son catalogue des simples dediez aux purgations", il l'aurait lui-même passée sous silence, si un paysan de Lambesc n'était venu lui en révéler la "faculté purgative ". "Un rustique villageois de Lambese m'en apporta une branche, de la laureole masle, de

(1) La forme provençale, encore usitée, est Ougue. Le I) initial qu'emploie Constantin a la valeur de larticle pluriel élidé $l^{\prime}$. 
laquelle (comme il m'asseura) luy et toute sa famille s'estoyent purgez ceste annee, craignans la peste: et mesme qu'il m'asseura qu'il avoit esté guari de la fievre quarte, par l'usage de la decoction des feuilles d'icelle. "

Notre auteur a donné, relativement à l'habitat de la Lauréole, l'indication que voici :

"Ce simple croit principalement aux montaignes, et par le rapport de plusieurs, il s'en trouve copieusement au bois de Valbonette (1) $).$

PIed de veau. - " Ill est un simple si frequent et cogneu en ce païs, qu'il n'y a personne, entre les plebees, qui ne le cognoisse fort bien : car il croit quasi partout, tant aux forests qu'aux lieux proches des villes, aux hayes des vignes et jardins, et combien qu'aucuns commandent de le cueillir au Printemps, les autres à l'Automne, si est-ce qu'il se trouve tousjours verdoyant et en toutes les partics de l'année mesmement en ce païs temperé : veu aussi qu'il se nourrit entre les buissons et les hayes vives, desquelles il se pare et ỉefend du froid et neges. "

Il est infiniment probable que Constantin ne distinguait pas l'Arum maculatum L. de l'A. Italicum Mill., et les détails que nous venons de transcrire

(1) Le bois de Valbonette est situé non loin de Lambesc. Du temps de Garidel, la Lauréole n'avait pas déserté cet habitat. " J'ay trouvé cette plante, écrivait-il, dans l'endroit apellé lou Devens de Rians et dans le Bois de la Sainte-Baume ; on la trouve aussi clans les Bois de.Valbonette, de Valfere, et ailleurs. " Nous avons nous-même revu le Daphne Laulreola, il y a quelques années, et tout récemment encore, dans les bois de Valbonette et de Valfère. V. notre note intitulée: Le Vallon du Dragon à Rognes dans la Revue IIorlicole, journal des travaux de la Société d'Horticulture et de Botanique des Bouches-duRhône (Marseille, 1897). 
font supposer que les deux espèces ont été ici confondues.

Le rédacteur de la Pharmacie provençale n'a pas manqué de mentionner les noms de " segueirons ou fugueirons " que les Provençaux donnaient au Piedde-veau (1). Il nous apprend encore que les femmes s'en servaient pour accroître la beauté de leur visage : (de la racine tres belle et blanche, dit-il, elles composent un fard qui n'est de peu d'efficace.»

Geneste. - « Nous n'avons remarqué en ce païs que deux sortes de la geneste, l'une qui est grande, de laquelle les verges sont assés longues, et sans fueilles, laquelle est tres frequente en la basse Provence, combien qu'on en despopule bien fort le terroir d'Aix, quoyque ce simple ne face injure à personne: car il n'occupe que les lieux incults, arides et steriles. ")

A la description de cette première espèce de "Geneste ", il est aisé de reconnaître le Spartium junceum L. Mais pourquoi les gens d'Aix tenaientils tant à en " despopuler » leur terroir ?

( L'autre, poursuit Constantin, est beaucoup moindre, de laquelle les virgules sont beaucoup moins longues et moins rondes, vestues de quelques petites feuilles : cestuy-cy (à mon advis) ne croit qu'aux montagnes seulement. »

Il devient ici bien difficile de se prononcer avec certitude, et nous devons simplement hasarder une hypothèse. Nous inclinons à croire que c'est au Coronilla juncea L. qu'il y aurait lieu d'appliquer la phrase qui précède.

(1) Les formes Segueiroun, Fugueiroun ou Figuciroun n'ont pas cessé d'être employées, et le Thesaurus de F. Mistral constate qu'elles s'appliquent aussi bien à l'Arum maculatum qu'à l'A. italicum. 
Si, comme Garidel le lui a justement reproché, le docteur Antoine Constantin n'arait pas autant négligé de se familiariser avec la "Botanique moderne ", il aurait donné aux espèces dont il s'occupait les noms adoptés par les floristes contemporains : nous nous trouverions dès lors en présence de dénominations qu'il serait beaucoup plus facile de traduire.

Lentiscle. - Dans le chapitre consacré à la "Geneste ", Constantin mentionne incidemment le Pistacia Lentiscus L., à propos du mastic, dont il aurait bien, en certains cas, conseillé l'emploi; mais, disait-il, "nous ne voulons chercher aucun medicament hors de nostre province, dans laquelle le mastic ne se treuve point, par nostre faute toutesfois, et negligence de cultiver les lentiscles (1) d'où il est tiré, ou plustost de ne savoir le moyen de le faire, puisque nous avons lesdits lentiscles autant bons que sçauroyent estre ceux de l'Isle de Cyo (2)».

Aristolochie.-Sous ce titre il comprend trois espèces d'Aristoloche : Aristolochia Clematitis L., A. rotunda L., A. longa L. (3). Mais nous croyons qu'il les distinguait mal. Après avoir dit de l" "Aristolochie " in genere : "Elle croit abondamment en ce païs de Provence », il ajoutait : "L'aristolochie clematis se treuve fort rarement et est

(1) Les Provençaux traduisent par Lentiscle le nom latin Lentiscus. Dans Geneste, il est facile de retrouver l'étymologie Genista.

(2) Chio.

(3) Les noms spécifiques adoptés par Linné pour ces trois espèces d'Aristoloche leur avaient déjà été appliqués par la plupart des floristes du xvie siècle, Matthiole, Anguillara, Pierre Pena, Mathias de Lobel, Charles de l'Escluse, etc. - Sic, pour l'A ristolochia Pistolochia L. 
cognuë de bien peu de gens... - Quant à l'aristolochie ronde et longue, elles se trouvent assés frequentes en ce païs, celle-là croit le plus aux vallees pleines de joncs et dans les prés qu'on n'arrouse guieres, ceste-cy dans les vignes, desquelles les vignerons ne les en peuvent despeupler, "

Oignon marin.- Il applique cette expression à une Liliacée, Scilla maritima L. (Urginea Scilla Steinh.) et à une Amaryllidée, Pancratium maritimum L. " Dioscoride, dit-il, en faict de deux sortes, qu'il distingue en deux divers chapitres : l'une est grande, laquelle nous entendons principalement par le nom de scille, l'autre petite, que luy mesme appelle pancration. Toutes les deux ont mesme puissance, combien que la petite est de moindre vertu, elles sont aussi fort bien peuplees en ce païs principalement aux parties maritimes. ") Il n'était pas tout-àfait exact d'affirmer que ces deux espèces sont " fort bien peuplees en ce païs 》 : la Scille maritime, surtout, est une plante rare en Provence.

Chou marin. - Constantin désigne par ces mots le Convolvulus Soldanella L., que les botanistes du xvi ${ }^{e}$ siècle nommaient Brassica marina. " Nostre intention, dit-il, n'est pas de parler en ce lieu de toutes les especes de chous, quoyque toutes ayent puissance de purger : mais seulement de celuy qui se treuve au bord de la mer, ayant les fueilles semblables à celles de l'aristolochie ronde. Cette espece n'est pas tant vulguaire que les autres simples, desquels nous avons fait auparavant mention, à cause qu'elle ne croit qu'aux parties maritimes, meslee parmi le sablon de la mer... On fait à Montpellier une composition, intitulée Electuarium de soldanella incerti authoris : duquel le chou marin, qui n'est autre chose que la soldanella, est la 
base et principal ingredient. " Notre docteur attribuait spécialement à cette plante le pouvoir d'évacuer " les mucositez et la pituite, laquelle abonde plus aux gens maritimes qu'aux autres hommes" ; et il en prend texte pour nous " faire admirer la providence de Dieu, lequel a donné la varieté des remedes, accommodez à la diversité des maladies qui coustumierement adviennent selon la varieté des lieux. "

Le Convolvulus Soldanella clôt la liste des simples qui forment la matière du premier livre de la Pharmacie provençale. L'auteur y ajoute cette conclusion :

" Me semble d'avoir assés prouvé ma proposition en ce premier genre de medicamens, laquelle tend à cela, que, pour faire la medecine, il n'est ja de besoin que nous employons les drogues estrangeres... Je ne doute point que si nous faisons une enqueste, arec les diligences requises, par tous les carrefours de ce païs, nous n'en trouvissions beaucoup plus qu'il ne nous en faut. De sorte qu'en lieu que nous fussions contraints d'aller mandier les estrangers, que plustost nous aurions de quoy fournir aux medecins moins curieux, ès autres provinces. "

Dans le deuxième livre, où vont être examinés, nous le rappelons, les médicaments " qui purgent sans faire aucune violence au corps humain ", nous ne relevons qu'un petit nombre de plantes appartenant à la végétation spontanée du pays. Les voici encore dans l'ordre où nous les rencontrons :

Frangula. - "Pour commencer ce second catalogue par les medicamens qui purgent avec mediocrité, je mettray en tesle la frangula, qui est un 
arbre de médiocre grandeur, ayant les fueilles semblables à celles du cornouillier, ou acuernier en provençal, des fleurs blanches, son fruict petit, de la grosseur d'un pois. Ce simple a le bois fort imbecille et frelle, facile à rompre, de laquelle facilité elle porte le nom de frangula. ')

Matthiole, Dodoens et l'Historia Lugdunensis avaient appelé Frangula l'arbrisseau dont Linné a fait le Rhamnus Frangula. C'est bien cette espèce que Constantin a insérée parmi ses purgatifs bénins. Il en indique ainsi l'habitat :

"Cette plante se treuve aux montagnes de l'haute Provence en plusieurs endroits : n'y a pas longtemps qu'elle y a esté recognuë, je suis asseuré qu'on la trouveroit à la saincte Baume (1), et qu'elle pourroit estre cultivec et nourric par tout ce païs, mesme dans les jardins. »)

Par l'association des idées, à propos d'acclimatation, il s'étonne qu'on n'ait pas essayé de cultiver en Provence la rhubarbe : "Je m'esmerveille que depuis le temps qu'il y a que le rheubarbe a esté en si grand pris entre nous, qu'on n'aye taché d'en prouvoir ce païs, qui est une region temperée, tout ainsi qu'on y cultive maintenant les cannes à sucre, les pistaches, les palmes, et plusieurs autres plantes estrangeres (2). Mais en cela nous avons deux empeschemens principaux : l'un est la non-chalance et

(1) Il ressort de divers passages de la Pharmacie provencale qu'Antoine Constantin, assez pietre botaniste comme on a pu voir, n'avait pas dû herboriser beaucoup. S'il était allé à la Sainte-Baume, il aurait constaté lui-même que le Rhamnus Frangula ne s'y trouve point. Mais en montant tout près de la barre rocheuse que domine le Saint-Pilon, il n'aurait pas manqué d'apercevoir le $R h$. alpinus.

(2) Il est certain qu'au xvi e siècle la canne à sucre était cultivée en certains endroits de la Provence. Ce que dit Antoine Constantin confirme à cet égard le témoignage formel de Pierre 
negligence nostre, qui a faict que nous ne roulons ou n'osons adjouster rien à ce que nos predecesseurs ont inventé ; l'autre est l'impieté et meschanceté des barbares, lesquels trouvent si bon que nous n'employons presque autres drogues que les leurs, qu'ils ne nous mandent rien qui ne soit adulteré et corrompu. Il est certain que le rheubarbe, en leur païs, est une drogue de grand efficace; mais celuy qu'ils nous envoyent est de fort peu de valeur, et la plupart sert mieux à l'embellissement des cheveux des femmes que pour autres medecines. "

Décidément nos Provençales du Xvi ${ }^{\mathrm{e}}$ siècle prenaient grand soin de leurs charmes, et, pour se faire belles, appelaient à leur aide non seulement des plantes indigènes, telles que la Bryone ou le Gouet, mais aussi l'exotique Rhubarbe !

Epithyme ou Goutte du Thym. - Ces deux synonymes nous présentent notre Cuscuta Epithymum L. “ Il n'y a herboriste, écrit Constantin, qui n'aye en plusieurs endroils veu et recogneu l'epithime, qui est un simple de soy sans aucune racine qu'immediatement prenne nourriture de la terre, ains croit par dessus le thym, qu'il enveloppe en forme de cheveux rogeastres. D'iceluy nous avons aussi peu d'indigence que du thym son nourrissier. ")

ABsinthe. - a Il n'y a herbe plus commune et plus cogneuë en ce païs que l'absinthe, et toutesfois le vulgaire n'a encores prins garde à sa faculté laxative... Des especes d'absinthe que les herboristes ont cogneu et remarqué, nous n'en avons en ce païs que deux : l'une qui a les fueilles minces, petites et

Pena dans les Adversaria, et celui de Thomas Platter en ses mémoires.- Voir, dans la série de nos études sur la Botanique en Provence au xvi siècle, Pierre Pena et IIathias de Lobel et Félix et Thomas Platter. 
blanchastres, qu'on nomme absinthe romain ou pontique, duquel on en treuve seulement dans le jardin des Apothicaires quelques plantes : l'autre a les fucilles plus grosses et deschiquetees, lequel est tres-frequent, tant aux jardins de la basse Provence qu'aux lieux incults et pierreux des montagnes. Et de cestuy-cy je veux que nos Provençaux usent. »)

Nul doute que l' "absinthe romain ou pontique », cultivée par les apothicaires en leurs jardins, ne fût l'Artemisia Absinthium L. Mais quel nom porte dans la nomenclature actuelle l'espèce indigène, dont le seul carnctère signalé ici est le suivant: "feuilles plus grosses et deschiquetees ) ? On peut hésiter entre Santolina Chamacyparissus L. (1) et l'une de nos Armoises méridionales : A. camphorata Vill. ou A. campestris L (2).

Fumeterre. - « La fumeterre (ainsi appelée parce que si on met son suc sur les yeux pour les esclaircir, à quoy elle a grand efficace, elle excite les larmes, tout ainsi que la fumee) croit en grande affluence aux vignes, aux jardins, et par tous les champs : de sorte qu'elle est cogneuë d'un chacun ".

Il n'est pas toujours facile de distinguer telle et telle espèce de Fumaria, quand on les a vivantes sous les yeux. Il serait donc téméraire de tenter ici une spécification. Il est probable, du reste, que Constantin englobait sous le nom générique de Fumeterre les diverses espèces de Fumaria plus ou moins abondantes en Provence.

(1) Le nom provençal de l'Absinthe est Aussent (b.latin. Absentum). Les Provençaux appellent Gros-Aussent la Santoline (F. Mistral, Trésor du Félibrige).

(2) Peut-être aussi Artemisia glutinosa Gay ou A. gallica Willd, qui ne sont point rares en Provence. 
Mercuriale. - Notre auteur s'est contenté d'admettre la Mercuriale dans la seconde série de ses purgatifs, sans donner aucune indication phytographique. Il envisageait vraisemblahlement le Mercurialis annua L., qui est l'espèce de beaucoup la plus commune.

Clochettes. - "Celles que nous avons remarquees en ce païs sont de deux sortes que le vulgaire appelle du nom commun de Corregioles (1). L'une est petite et croit aux champs cultivez et aux vignes: et de ceste-cy la plebee se sert à la guarison des playes..., et mesme les moissonniers, lorsqu'ils s'offensent et blessent avec leurs faucilles. L'autre est assés grande quant aux fueilles, laquelle se treuve embrassant les hayes des jardins, et bien souvent les chanvres, qu'elle suffoque quelquefois. "

Les détails qui précèdent empêchent toute hésitation : ils s'appliquent manifestement au Convolvulus arvensis L. et au C. sepium L.

Polypode. - " Nous avons retenu le nom de polypode des Grecs, ainsi appellé, pource qu'il est une racine qui est attachee en beaucoup d'endroits, comme par plusieurs pieds: on l'appelle aussi la petite fougere, à cause de la similitude que ses fueilles ont avec la fougere grande. Ce simple croit en nostre province, autant ou plus copieusement qu'en aucune autre : et se prend coustumierement aux chaines, rochers, en lieux humides et opaques ".

La Fougère mise par Constantin au rang des simples qui ont la propriété de purger sans violence, est bien notre Polypodium vulgare. Cette dénomination binaire, adoptée par Linné, avait été créée par Gaspard

(1) Tel est le nom que continue à porter en Provence le Convolvulus arvensis L. L'orthographe actuelle est Courrejolo. 
Bauhin. L'auteur du Pinax s'était, d'ailleurs, borné à joindre l'épithète de vulgare au nom de Polypodium que la presque unanimité des botanographes du Xvi ${ }^{\mathrm{e}}$ siècle appliquaient à la même Fougère.

Agaric. - Les anciens auteurs donnaient le nom d'Agaricus au Polyporus officinalis Fries. C'est rraisemblablement de ce Champignon que la Pharmacie provençale disait: «On m'estimera possible avoir oublié ma promesse de [ne] vouloir descrire autres simples purgatifs, en ce traicté, que ceux qui se treuvent en Provence, puisque j'y nombre l'agaric, reputé estranger; mais outre que je le ticns nostre, mesme qu'il croit en plusieurs lieux qui de toute antiquité estoyent de la Provence, comme sont les contrees de Terre neufve (1) et le Gapensois, il est de grande efficace pour nostre intention, et de peu de coust, et suis asseuré que si nous mettions diligénce de le chercher, nous le treuverions presque par tout ce païs : car tous ceux qui en ont escrit nous asseurent qu'il provient non seulement sur les sapins et melezes, en figure d'esponges et de boulets, mais aussi qu'on l'a treuvé croistre sur les vieux chaines, et houssons ou eusses (2) et autres arbres glandiferes, desquels nostre province est partout ornee. Je pense aussi qu'il se trouveroit sur les vieux faux (3) à nostre païs, vers les montagnes du Regeois (4) ).

(1) Voir la note 2 de la page 154

(2) Les deux noms de Housson et Eusse s'appliquent au Ouercus Ilex L. Housson est un dimintitif du mot français Houx. Eusse est provençal. Ce mot, comme nous avons eu plus haut l'occasion de l'indiquer, s'éerit actuellement Éuse (on prononce Eouse).- Nous avons vu Pierre Belon, dans ses Remonstrances, se servir de la forme Eonse.

(3) Faus (lat. Fagus), nom provençal du Hêtre.

(4) Le pays de Riez, Regium. Cette petite ville, qui eut une certaine importance sous la domination romaine et devint ensuite un évêché, est présentement un simple chef-lieu de 
Cabaret ou Asaron, - (Asarum europrum L.) "Le cabaret, que les Latins appellent asarum, comme aussi les Grees, est abondant aux montagnes de nostre Provence, et est un simple de grande utilité pour la purgation. )

Enfin, pour clore la série des plantes dont le deuxième livre s'est occupé, il nous reste à reproduire ce que l'auteur a dit d'une espèce qui n'est point spontanée en Provence, mais que les horticulteurs du xvi siècle multipliaient volontiers, le Carthamus tinctorius $\mathrm{L}$,

Carthame ou Saffran bastard. - (Carthamus tinctorius L.) "Combien que le carthame ne nous soit herbe champestre, je ne l'omettray pourtant en ce catalogue, veu qu'il se peut cultiver et se peupler de soy mesme dans nos jardins : il n'est autre chose que la plante qui produit la graine de laquelle on nourrit les perroquets: elle est ornée d'une fleur semblable au saffran, au lieu duquel les plebees quelquefois en usent. »)

Le troisième livre de la Pharmacie provençale a pour objet, nous l'avons dit, un certain nombre de substances végétales qui sont en réalité des aliments, mais des aliments laxatifs, fruits, légumes et plantes potagères; " medicamens, disait le titre, qui outre ce qu'ils purgent le corps, ont aussi quelque pouvoir de le nourrir n.

Bien que ces divers produits végétaux soient du ressort de l'horticulture plutôt que de la botanique,

canton de l'arrondissement de Digne (Basses-Alpes). Par les mots " nostre païs », employés dans la même phrase, Constantin entendait la Haute-Provence, d'où il était originaire : Senez, son lieu natal, n'est pas très éloigné de Riez. 
nous en mentionnerons quelques-uns : ceux à raison desquels Constantin a donné des détails curieux qui méritent d'être relevés.

En dépit du titre contenant le programme du troisième livre, l'auteur y a introduit un chapitre relatif à la manne qui, si elle est un purgatif, ne saurait être admise parmi les substances alimentaires.

La manne, produit d'exsudation de certains arbres, notamment du mélèze, était, au xvi ${ }^{\mathrm{e}}$ siècle, en très grande faveur. On estimait fort celle qui provenait des Alpes du Dauphiné et de la HauteProvence, et que les droguistes vendaient sous le nom de manne de Briançon (1).

Mais, au dire de Constantin, il était inutile de faire venir de si loin un remède que quelques arbres de la Basse-Provence pouvaient fournir aussi bien que les mélèzes de ces montagnes reculées. Voici comment il s'exprimait au sujet de la manne :

" Je n'ay pas eu crainte de la mettre en mon catalogue, tant pource qu'elle s'engendre aux montagnes du Dauphiné et de Piedmont, voisines de nostre Provence, que pour autant que les montagnes de ce païs n'en sont pas toujours destituees, et cncore la trouve-on assés souvent au bas païs : car on en a veu plusieurs fois les saules chargez au terroir de Pertuis, et moy mesmes les ay veu distiller la manne douce, laquelle la chaleur du soleil ayant liquefiee et fondüe, tumboit goutte à goutte, tellement que l'on en eusse peu remplir plusieurs vases... Les bergers et ceux qui paissent le bestail aux champs, soubs la canicule, tesmoignent qu'à l'aube du jour, ils ont veu plusieurs fois les arbres et herbes chargees de ceste rousee celeste : et encores

(1) Voir, relativement à la manne, ce que nous en avons dit dans Pierre Pena et Mathias de Lobel et aussi dans notre Notice sur le botaniste provençal Jean Saurin. 
affirment avoir tres souvent apperceu leurs habillemens comme oincts et moëttes, et leurs cheveux tous prins de ceste liqueur. "

Et sa conclusion était celle-ci :

( Nous laisserons donc l'usage de la manne Brigantine (1), et de celle de Calabre, et mettrons diligence de faire cueillir la nostre. )

Les fruits laxatifs dont Antoine Constantin prônait l'emploi étaient les prunes, les figues, les cerises, les mûres et les melons.

Il mettait les prunes au premier rang : " Entre les medicamens alimenteux, disait-il, qui ont aussi quelque puissance d'esvacuer le ventre, les prunes sont des plus insignes, tres-familieres et domestiques. ) Et il exaltait les prunes de Brignoles, dont la renommée était alors universelle : "Celles de Brignoles sont en grande estime, non seulement en ce païs, mais aussi par toute la France (2). )

A propos des figues, il entonnait un nouvean dithyrambe en l'honneur de la Provence. « Entre toutes les provinces de l'Europe, la Provence se peut glorifier, ou plustost doit remercier Dieu de ce qu'elle est la plus abondante et fertile en toutes les choses necessaires à la vie des hommes, et remplie de tout ce qui peut servir à la delectation et volupté : car on y admire l'abondance et bonté des oliviers, la bonté des pruniers, pomiers, cerisiers, amandriers, poiriers, et semblables et presque infinies especes d'arbres, desquelles les campagnes de ce païs sont naturellement pleines et rerdoyantes. "

(1) De Briançon .

(2) Nous avons donné de curieux détails au sujet des prunes de Brignoles dans Pierre Pena et Mathias de Lobel. Dans notre étude sur Líonard liannolfi, nous avons reproduit l'éloge que fit de ces prunes le voyageur allemand, lorsqu'il traversa Brignoles pour se rendre à Marseille et de là en Syrie. 
- Parmi toutes les variétés de figues que produil en si grande quantité le territoire provençal, c'est aux figues marseillaises qu'il accorde la prééminence : "Celles de Marseille, qui surmontent toutes les autres en bonté (1) (aussi ont-elles tres-grand bruit aux autres païs), en quelque autre terroir qu'elles soyent transplantees, degenerent de la premiere suavité et douceur. ")

Les cerises lui fournissent un argument en faveur de l'acclimatation de nombreux régétaux exotiques qui pourrait être tentée en Provence avec succès assuré : "Les cerises sont tesmoins, entre plusieurs autres plantes que la culture peut rendre nostres quoy qu'elles soyent estrangeres et esloignees de nostre terroir : car la terre provençale en est maintenant si feconde qu'il n'y a aucune contree en tout ce païs, soit aux montaignes, vallees et plaines, qui ne soit tres fertille en toutes sortes de cerises, et toutesfois nous les avons receües des estrangers. »

Les mûres que Constantin appelle domestiques sont, dit-il, "de deux especes, blanches et noires. " Il désigne ainsi les fruits des Morus alba et nigra; par opposition, il nomme champestres les mùres de Rubus. Il mentionne spécialement " celles qui croissent en une sorte de ronce que Dioscoride appelle Rubus Idxus, laquelle est differente des autres, n'ayant point ou fort peu d'espines. Ces meures-cy sont si plaisantes, et à la veuë (car elles ont la couleur d'escarlate), au goust et à l'odorat, qu'elles surmontent toutes les autres en suavité :

(1) Nous avons eu l'occasion de citer dans Pierre. Pena et Mathias de Lobel le témoignage du célèbre botaniste allemand Valerius Cordus, rapportant que les figues sèches de Provence arrivaient jusquen Allemagne dans de petits cabas de forme conicue en sparterie, in minutis et turbinatis sparleis corbibus, et ajoutant que les plus estimées étaient les figues marseillaises : " hae parve quidem sunt, sed suavitate prestantes, Marsilische feigen dictæ. ") 
c'est la ronce que vulgairement on nomme framboisier et son fruict framboises, desquelles plusieurs ont commencé à embellir leurs jardins. "

Enfin, relativement au melon, le troisième livre de la Pharmacie provençale fournit à l'histoire horticole de cette Cucurbitacée la contribution suivante :

" En ce païs, nous en arons de trois sortes, distinguees selon leurs formes et saveurs :

"L'une est de ceux qui sont fort ventreux et de figure d'ovale, les caneleures et rayes desquels sont continuees d'un bout à l'autre, et sont ceux qui sont entendus par le nom de poupon ;

"L'autre est de ceux qui sont plus longs, ayans leurs rayes eminentes et plus petites, lesquels le vulgaire nomme au genre feminin pouponnes ;

"La troisieme espece est de ceux qui, pour estre de la forme d'un coing, sont appellez en latin melopepones, portans le nom de melon et coing ensemble: ceux-cy sont proprement entendus par le nom de melon. "Et l'auteu: ajoute que chez ces derniers, la chair est "dure, amassee et blanchastre » et le goût " beaucoup plus plaisant et aggreable. "

Parmi les plantes potagères douées de " vertu laxative ", Antoine Constantin a rangé les " oignons domestiques, bettes, arroches et blettes, espinars et chous."

Au sujet des oignons, il prétendait, contrairement à l'opinion de Dioscoride, que ceux de forme ronde, cultivés en Provence, ont plus d' " acrimonie » que les autres :

"Combien que les oignons longs de Dioscoride surmontent en acrimonie les ronds, toutesfois nous experimentons le contraire en ceux de nostre Prorence: car l'experience journaliere nous fait voir que les longs en figure d'ovale, tels que croissent au 
terroir de Bouc et de Gardane (1), cedent en acrimonie aux ronds et aplatis en forme de lentille : il s'en treuve quelquefois de si debiles, qu'on les mange sans appercevoir aucune ingratitude pour raison de l'acrimonie, voire tous crus, n'estant aucunement preparez. )

Il nous apprend, incidemment, que l'ail était beaucoup moins en faveur que l'oignon chez les Provençaux du $\mathrm{xvI}^{\mathrm{e}}$ siècle; c'était le contraire en Gascogne :

“ Bien est vray qu'en nostie Provence l'usage des aulx n'est pas si frequent que celuy des oignons et pourreaux : car nous contentans des deux derniers, sommes contens de quitter la possession du premier aux Gascons. 》)

Pour les arroches, il en distingue deux sortes: " une domestique, qui croit seulement aux jardins par la culture, l'autre sauvage, de laquelle le vulgaire use aussi "; et il ajoute ; "les arroches sauvages, lesquelles le vulgaire en Provence entend soubs le nom de cenissons ou cinisclons (2), sont beaucoup plus laxatives que les domestiques."

Par "arroche domestique», il entendait certainement l'Atriplex hortensis L.; et par a arroches sauvages ", suivant toute probabilité, les espèces spontanées qui abondent en Provence, $A$. rosea L., A. hustata L., A. patula L.

Dans le chapitre consacré aux " espinars ", il se préoccupe d'abord de l'étymologie.

(1) Gardanne est actuellement le chef-lieu d'un canton de l'arrondissement d'Aix; Bouc est une commune de ce même canton.

(2) D'après le Trésor de Frédéric Mistral, le mot seniscle et le diminutif senisclet désignent encore en Languedoc l'arroche sauvage. La forme cenisclon, employée par Constantin, est aussi un diminutif de seniscle. 
“Quelques-uns sont d'opinion que ceste herbe a esté premierement veüe en Espagne, d'où elle semble avoir retenu le nom de spanaceum ou hispanicum olus, combien qu'il est vraysemblable qu'on les appelle espinars, pour raison de leur semence espineuse. "

Ici encore, il constate que " des espinars, les uns sont agrestes, les autres domestiques."

( Des espinars domestiques, nous en avons aussi deux sortes, l'une femelle qui est sans graine, ou si en a, est sterile sans pouvoir d'engendrer son semblable : l'autre masle qui en son temps est toujours chargé de semence espineuse et piquante, propre pour la purgation : de tous les deux on use coustumierement aux repas ordinaires, au printemps et à l'automne, et mesmement en caresme et une bonne partie de l'hiver : en quelque façon qu'on les appreste, ils gardent tousjours leur vertu laxative. "

Quant aux " agrestes ", voici ce qu'il en dit :

" Ils se treuvent seulement aux montagnes du Dauphiné, de Terre neufre, et de la haute Provence, desquels les plebees de ces contrees là usent comme des herbes potageres, les appellans vulgairement sanguaris, ausquels recognoissent quelque pouroir de nourrir et de laxer le ventre. " - Il est hors de doute qu'il s'agit ici du Chenopodium Bonus-Henricus L., auquel les Provençaux continuent à donner les noms de sangari et d'espinar-bastard (1).

Enfin, relativement aux choux, Constantin annonce qu'il ne parlera pas des "sauvages"; et des " domestiques desquels nous arons en ce païs de plusieurs espèces », il se contente de dire :

(1) F. Mistral, Le Trésor du Félibrige. 
( Les uns sont blanes, les autres verds, et quelques rouges; les uns ont les fueilles larges et crasses, les autres minces et crespees; les uns les ont esparses et esgarees, les autres unies et amassees quasi comme en un globe, lesquels on nomme chous cabus ou capus : touies ces espèces de chous semblent avoir mesme force laxative. "

Le chapitre du chou clôt la première partie de la Pharmacie provencale; l'auteur y ajoute seulement cetle déclaration qui contenait une promesse :

"Il y a une infinité d'autres simples en ce païs, de mesme vertu et efficace que ceux que j’ay rangez au premier, second, et en ce troisiesme livre, lesquels j'eusse adjoustez pour la preuve de ma proposition n'estoit que j'arois peur d'estre trop prolixe et de sembler descrire des choses qui sont de soy assés manifestes et probables. Joint aussi que tant de tesmoins inobjectables que j'ay produits doyrent suffire pour la confirmation de ceste verité, laquelle j'espere, arec l'aide de Dieu, d'establir et renforcer encores mieux, tant par le denombrement des remedes particuliers et chirurgicaux, repellens, attirans, suppuratifs, mondificatifs, agglutinatifs et sudorifiques, pour chasser hors de nos boutiques le gaïac, la sarza parille, la racine de cinna, et autres piperies que les estrangers nous ont faites avaller auparavant, que par un dispensaire qui sera dressé non seulement pour la nation provençale, mais aussi pour toutes les autres provinces de ce royaume de France. 》)

Comme on le voit, Antoine Constantin promettait de donner une suite à son ouvrage. Il tint parole, et il écrivit, en effet, le complément dont il avait, dans le passage qui précède, tracé le programme. Mais cette seconde partie n'a jamais été imprimée. Au cours du siècle suivant, et quinze ans après 
la mort de l'auteur, Peiresc, mis en possession du manuscrit, manifesta l'intention de le donner au public.

L'illustre conseiller au Parlement de Provence s'était d'abord proposé de rééditer le premier volume. C'est ce que nous apprend Gassendi, dans sa Vie de Peiresc, où il écrit sous le millésime 1629: " procurare intereà voluit iteratam editionem Pharmaceutices Antonii Constantini Provincialis Medici, qui ante annos circiter triginta in id incubuerat, ut ostenderet nihil esse opus ad plantas exoticas, peregrinaque remedia confugere; cùm, benignitate naturæ, idem patrium solum, quod homines gignit, ipsis nutriendis, curandisque consentanea et alimenta ct medicamenta provideat (1). "

Tant pour cette réimpression que pour la publication de la partie inédite, Peiresc voulut s'assurer le concours d'un médecin de grand renom, le docteur René Moreau, que Gassendi appelle « magnum medicx facultatis Parisiensis lumen (2) 》.

Moreau se montra tout d'abord disposé à faire imprimer lui-même l'œuvre de Constantin. Gassendi, se trouvant à Paris en 1628, écrivait le 2 décembre à son ami Peiresc :

(1) Gassendi, Yita Peireskii, édition de Paris, 1641, p. 226.

(2) "René Moreau, né à Montreuil-Bellay le 6 août 1587, mourut à Paris le 17 octobre 1656 . Ce fut le grand ami de Gui Patin. qui parle si souvent de lui dans sa correspondance et toujours avec de grands éloges. " (Note de Tamizely de Larroque, éditeur des Lettres de Peiresc). Le Dictionnaire hislorique de Maine-et-Loire, cité par Tamizey, disait de René Moreau : "Le succès de son enseignement à la Faculté, non moins que ses publications, le désignèrent au choix du grand Aumônier de France, Alphonse de Richelieu, qui le fit nommer à Paris professeur royal au Collège de Cambrai. ») A sa mort, René Moreau laissa une bibliothéque qui " fut vendue, somme inouie pour le temps, 22.000 livres. Fouquet en racheta pour 10.000 livres le principal fonds de médecine qui passa plus tard dans la Bibliothèque Mazarine. D 
Mr Moreau, ayant veu ce que vous m'escriviez du livre de Mr Constantin, me dit que vous n'aviez qu'à le nous envoyer par la premiere commodité parce qu'il prendroit le soin de le faire imprimer en ceste ville, et en tout cas à Genere, ayant dessein de vous en faire l'addresse par une epistre liminaire. Il adjousta qu'il seroit bon de voir avant toute suvre la partie imprimée parce que s'il faloil adjouster, retrancher ou changer quelque chose à ce manuscrit, on rapporteroit mieux toutes choses à l'intention de l'autheur (1)

Mais ce projet de publication fut abandonné, à la suite de certaines difficultés qui s'élevèrent un peu plus tard entre Peiresc et Moreau, nous ne savons à quel propos. Le fait nous est connu seulement par une lettre que, neuf mois après, le même Gassendi, toujours à Paris, adressait à Peiresc le 4 septembre 1629 :

Je ne me suis point encore souvenu de dire à Mr Moreau ce que vous m'escrivites dernierement du livre de Mr Constantin; pour moy j'en ay esté plus fasché pour la peine que vous y avez prise que pour autre chose. Ce monsieur là croyoit peut estre que ce fust là quelque grand tresor dont on se voulust prevaloir à son desadvantage. Il en tirera luy mesme le fruict qu'il pourra, et pour rous vous devez estre satisfait de n'avoir rien oublié de ce qui pouvoit regarder soit la memoire du defunct, soit l'homneur du païs (2).

Qu'est devenu le manuscrit de Constantin? Il existait encore, à Aix, au temps de Garidel. Celui-ci, dans sa notice relative à l'auteur de la Pharmacie provençale, s'exprimait ainsi à ce sujet : "Ce n'est proprement que des purgatifs que nôtre Auteur a parlé dans cet Ouvrage. Il en a composé un second, qui est la suite du premier, qui traite des diuréti-

(1) Lettres de Peirese publiécs par Tamizey de Larroque, t. Iv.

(2) Ibid., p. 210. 
ques, des apéritils, des diaphorétiques, et des altérants domestiques, qui n'a pas vù le jour, et qui est encore en manuserit entre les mains de ses hériticrs, que Mr Joannis, très habile Medecin, m’a assùré avoir lû. 》)

La même notice complète ainsi qu'il suit la biographie d'Antoine Constantin : "Septans après avoir mis son ouvrage au jour, écrit Garidel, il se retira à Lambesc (1) où il fut gagé par la communauté pour y excreer la Medecine. Il y mourut le 18 novembre 1616 et fùt enseveli dans l'Eglise des RR. PP. de la Sainte Trinité. "

Trois ans avant sa mort, le docieur Consiantin fit paraitre un autre ouvrage. Mais celui-ci n'était point, comme le premier, une pharmacopée. L'auteur avait tenu à faire, celte fois, œurre de médecine pure. Son livre, imprimé à Lyon en 1613, a pour titre :

OPUS MEDICE PROGNOSEOS

in quo omnium qux possunt in xgris animadverli symptomatum in omnibus morbis, cause et eventus copiosè et luculenter exponuntur (2).

Mais dans ce traité des différents symptòmes qui permettront de dianostiquer toules les maladies, nous ne frourons rien qui se rapporte à la botanique; nous n'arons pas, dès lors, à nous en occuper.

Il y a, cependant, une particularité que nous tenons à signaler.

L'ourrage est dédié au gourerneur de la Provence, qui était alors Charles de Lorraine, duc de Guise, le

(1) Sa retraite en ce lieu fut sans doute détcrminée par cetle circonstance quil avait épousé une jeune fille originaire de Lambese. "Il sétait marie, dit encore la notice, le za) novembre 1580 avec Damoiselie Catherine Baroncelly, fille i feu Pierre. et de Marguerite Hemerique, de la ville de Lambesc. n

(2) Lugduni, apud Claudium Norillon Typographum, M. D. C. XIrI. 
même qui rétablit à Marseille l'autorité royale, quand, en 1593, Pierre Libertat iua le consul Charles de Casaulx, le dernier des Ligueurs. Constantin, en son épitre dédicatoire, ne manque pas de faire allusion à ce mémorable érènement; au mot de Provence, qu'il vient d'écrire, il joint cette phrase incidente qui certainement lui assura les bonnes gràces du gouverneur : tu intrepide é tyrannorum faucibus, Maciliae urbi antiquissima et polentissima libertate restituta, habenas Prorex mira providentia moderaris.

Antoine Constantin laisse voir dans cette épître qu'il n'était pas un auteur modeste et qu'il avait conçu de son propre mérite la plus haute idée. Il ne craint pas d'appeler son noureau traité sublime et excellens opus; il insiste sur les efforts et la peine que ce livre lui a coûtés : foxtus quidem est summis vigiliis, períinaci et improbo labore, variisque partus torminibus. Aussi, redoutant, comme jadis pour la Pharmacic provencale, les attaques des envieux, qu'il compare cette fois à des vautours el à des corbeaux, il confie au duc de Guise le soin de protéger cet ouvrage, qui in liberam lucem proditurus, tui altgusti nominis umbra et alis, ut à vulturum rostris et corvorum croticibus tutus avolaret, indigebat (1). Espérait-il que le duc de Guise le protègerait aussi contre l'oubli, d'où nous l'avons tiré pour quelques instants, et dans lequel, hélas! il est, ainsi que sa méthode, destiné à retomber ?

(1) L'épître dédicatoire au duc de Guise est ainsi datée: " Ex nostro museolo Lambisci tuce dominationis, Idib. Augusti, anno 1612. $\nu$ Le fief de Lambesc appartint pendant plusieurs siècles et jusqu'à la Révolution à la maison de Lorraine. Le P. Anselme donne le titre de comte de Lambese et d'Oigon à François de Lorraine tué en $152 \pm$ à la bataille de Pavie. Plus tard Lambese fut érigé en principauté. Les armoiries de cette petite ville sont " d'azur à la croix de Lorraine d'or ». 



\section{INDEX}

DES NOMS DE PERSONNES MENTIONNÉES DANS CE VOLUME

Aetius : 26, 33, 47, $141 . \quad$ Betz : 71 .

Aldrovande : $16 . \quad$ Beys : 131 .

Alpin (Prosper), Alpinus : Boissard : 70.

\section{5.}

Ancelin : 144 .

André de Croatie : 71.

Anguillara (Louis) : 9-34, 40, Burnat : 46 .

$50,162$.

Anselme (le P.) : 181.

Archigène : 26, 27.

Arduino : 154 .

Artefeuil : 56 .

Avenzoar : 149.

Avicenne : 149, 155.

Baroncelly : 180.

Bauhin (Gaspard) : 12, 13, Césalpin : 156.

15, 22, 23, 27, 30-32, 89, Charles IX : 40.

$116,153,154,156,157,169$. Charles-Emmanuel Ier : 144.

Bauhin (Jean) : 23, 26, 59, Charles Quint : 76.

116, 153.

Beaumont (de) : 89 .

Belin : 124.

Bellay (René du) : 37, 38, 46. Belon (Pierre) : 37-66, 87, $102,135,153,154,169$.

Bernardi : 145.

Berry (Marguerite, duchesse

de) $: 14,15$.
Chatillon (le cardinal de) : 62.

Chrysippe : 146.

Claret (F. de) : 103, 105.

Constantin (Antoine) : 137, 139, 141, 143, 144, 146-154, 156, 158-163, 165-168, 170181.

Constantin (Claude) : 141. 
Constantin le Rhodiote : $12 . \quad 106,108-125,129,132,136$

Contarini : 15. $178,179$.

Cordus (Valerius) : 38, 89, Fabri de Valavez (Pala-

$115,153,155,173$.

Costrus : 150 .

Darmesteter : 50, 64 .

Delille : 60 .

Delisle (Léopold) : 80 .

Demoulins de Rochefort : 14.

Dioclès : 146 .

Dioscoride : $16,22,24,51$, $99,100,149,152,158,163$, $173,174$.

Dodoens (Rembert), Dodonæus : $69,76,77,79,91$, $153,155,165$.

Doins : 124 .

Domitien : 27.

Dupetit-Thouars : 15.

Eberwein, V. Cordus.

Elisée : 140.

Erasistrate : 146 .

Escluse (Charles de l'), Clusius : $19,22,30,31,39,41$, 45, 69-83, 85-93, 95-103, 105, $106,108-111,114-121,123$, $125-127,129,132,136,153$, 162.

Escluse (Michel de 1') : 70.

Fabri de Callas (Rainaud) : So.

Fabri de Peiresc (Nicolas- Henri II : 14, 40, 42, 76.

Claude) : 79-86, $93-99$, Henri IV : 145.
Faccioli : 17.

Fontaine : 124, 125 .

Fouque : 157 .

Fouquet : 178.

François $\mathrm{I}^{\mathrm{er}}: 103$.

Fries : 120, 121.

Fuchs : 150.

Fugger : 78 .

Galien : 145, 149, 151.

Gallaup-Chasteuil (Louis de) : 144 .

Garidel : 89, 125, 141, 149, $150,152,155-157,160,162$, 179, 180.

Gassendi : 81, 82, 85, 99, 110, $125,178,179$.

Gesner (Conrad) : 22, 38, 89, $90,115,122,123,153,156$. Goorle (Abraham de), Gorlocus : 131.

Gouan : 27.

Grenier et Godron : 27.

Groot (Hugot de), Grotilus : 131.

Gualandi : 14 .

Gualdo : 81 .

Haller : 18.

Hammes (de) : 40 .

Hatzfeld : 50, 64 .

Hémerique : 180 . 
Herman : 157.

Hérophile : 146 .

Hippocrate : 149, 152.

Huet : 154 .

Imperato (Ferrante) : 109.

Jason : 39, 40 .

Joannis : 180.

Joret : $110,115-118$.

Kentman : 122, 123.

Kieffer : 71 .

Lamarck : 91.

Legré (Ludovic) : 33, 47.

Libertat : 181.

Liebault : 16 .

Linné : 22, 23, 27, 30-32, 43, Nerva : 27. $45,51,87,100,103,115$, $116,153-157,162,165,168$.

Littré : 14, 28-30, 50, 64.

Lobel (Mathias de) : 18, 19, Oribase : 149. $22,46,54,71,75,81,83$, $84,100,101,103,116,126$, 162, 166, 171-173.

Loë : 77 .

Loredano : 15.

Lorraine (Charles de), duc Guise : 180, 181.

Lorraine (François de) : 181.

Louis II : 88.

Odon : 13.

Ollivier : 41.

Patin (Gui) : 178.

Peiresc, V. Fabri.

Perrin : 145, 146.
$30,89,150,152,156,162$, 165.

Maximilien II : 76, 78 .

Mesué : 149, 152, 153, 159.

Michiele : 10.

Mistral (Frédéric) : 45, 53, 111, 115-118, 151, 154, 161, $167,175,176$.

Moïse : 140 .

Molhuysen (le docteur P.C.) : 84,97 .

Mons (de) : 135 .

Moreau : 178, 179.

Morren (Edouard) : 70, 77, 79.

Mortreuil : 60 .

Mundella : 13.

Paul d'Egine : 149.

Pena (Pierre) : 18, 19, 22, $46,54,71,75,80,83,100$, $101,103,114,116,154$, 162, 166, 171-173.

Pinelli : 81, 109, 131, 135.

Magdelaine (sainte) : 83, 84. Planchon : 71, 72, 90.

Maicox : 141.

Plantin : 79.

Marinello : 14-16, 20.

Martins (Ch.) : 88, 89.

Platter : 71, 72, 75, 166.

Pline : 28, 29, 30.

Matthiole : 16, 17, 19, 20, Praxagore : 146. 
Prinster : 13.

Pritzel : 15 .

Prodicus : 146.

Quadramio : 17, 18.

Quiqueran de Beaujeu : 102, Tahernæmontanus : 30.

103, 105, 142.

Rauwolff : 70, 75, 78, 172.

Ravelingen, Raphelengius :

79, 99, 123, 125, 130.

Ray (Jean) : 125.

Raynaudet : 70, 75 .

René (le roi) : 88.

Ribbe (Charles de) : 88.

Richelieu (Alphonse de) :

178.

Robin (Vespasien) : 85.

Rodolphe II : 78 .

Rondelet : 71-73, 90, 100, 101, 122.

Ronsard : 39, 40.

Roux (Honoré) : 45, 89, 90, Trets (le baron de) : 55, 56, $153,154$.

Roze (Ernest) : 108, 120.

Ruel : 150.

Saccardo : 34 .

Saint-Lager : 31,34 .

San Michiele Comasco : 11. Vorst : 71.

Saurin : 155, 171.

Scaliger : 81, 131, $177 . \quad$ Yolande d'Aragon : 88.
Seguier : 13, 15.

Solier (Hugues de) : 33, 47, 48, 141, 152.

Squalermo : 34 . $84,97,108,110-112,119$, $123,178,179$.

Théophraste : 25, 149, 156.

Thevet : 39, 40 .

Thomas : 50, 64 .

Thou (le président de) : 131 .

Tiraboschi : 10, 13, 16-18, 21 ,

Tobie : 140.

Tournefort : 13, 15, 69, 89.

Tournon (le cardinal de) : 38,64 .

Tragus : 116.

Trajan : 27.

65.

Valgrisi : 15, 16.

Vasseur : 122.

Vincent : 130.

Vivien de Saint-Martin : 10.

Schenck : 15 . 


\section{INDEX}

DES NOMS GÉOGRAPHIQUES

Agnis (le Mourre d') : 84 . Bollène : 76, 87.

Aigues-Mortes : 55.

Bologne : 13, 21, 30 .

Aix-en-Provence : 49, 55, 56, Bouc : 175.

$65,80,82,85,89,93-95,98$, Boulogne (le bois de) : 40.

$99,110,122,124,130,140$ - Bracciano : 10, 34.

142, 144, 145, 148, 149, 153, Briançon ; 171, 172.

154, 157, 161, 175, 179. Brignoles : 172.

Albenga : 46.

Bruges : 70 .

Alep : 10, 12.

Alexandrie : 12 .

Cadix : 92.

Angers : 88 .

Angoulême : 39 .

Camargue (la) : 75, 86, 101.

Candie : 12.

Anguillara : 10, 34 .

Carcassone : 73 .

Antibes : 44, 62, 121, 123, Carpentras : 20, 29, 30.

154.

Castellane : 141 .

Anvers : 77, 79.

Castellet (le) : 121, 122.

Arles : 49, 74, 75, 86-90, 99, Céphalonie : 11.

101-103, 105, 106, 141.

Chio : $11,44,162$.

Arras : 70, 108.

Cesena : 13.

Arrone $\left(l^{\prime}\right): 10$.

Chypre : 11 .

Athènes : 51.

Coire : 11.

Augsbourg : $78,85$.

Colmars : 155.

Avignon : 20, 29, 30, 57-59, Constance : 71 .

$62,76,87,96,124,125,129$. Constantinople : 11, 39 .

Corfou : 11.

Bâle : 15,89 .

Bausset (le) : 122 .

Belgencier : $80,83,84,106$,

$108,110,113,120,122$.

Crau (la) : 74, 75, 99, 105, 106.

Berlin : 15.

Damas : 12.

Digne : 141, 170. 
Dresde : 122 .

Entraunes : 155.

Ferrare : 17, 18, 34 .

Fouletourte : 37 .

Francfort-sur-le-Mein : 79, $85,94,95,98,112,130,134$.

Fréjus : 44, 62, 96, 129.

Frontignan : 154.

Gand : 70 .

Gapeau (le) : 108 .

Gardanne : 175 .

Gênes : 46.

Genève : 179 .

Grenoble : 76,87 .

Gule (?) : 55, 56, 60 .

Guzarata : 157.

Hambourg : 15.

Hildesheim : 123.

Hybla (le mont) : 51 .

Hyères : 113.

Hymète (le mont) : 51 .

Isle (l') : 21, 24 .

Jéricho : 140.

Jérusalem : 43.

Lambesc : 159, 160, 180, 181.

Lancon : 21, 23.

Lesina : 11 .

Leyde : 70, 71, 76, 79, 80, 82, 84-86, 93, 94, 97, 108, 110, $111,123,125,132,136,157$.

Livourne : 21, 38.

Louvain : 70 .
Lucques : 19.

Lunel : 75.

Lyon : 31, 98, 129, 130, 131, $133,144,180$.

Maguelone : 73.

Malaga : 90.

Malines : 76, 77 .

Mans (le) : 37, 38, 42, 46 .

Marseille : 12, 15, 20, 23-25, $28,32,33,47,50,54-56$, $59,60,62-64,74,75,78$, $86,87,91-102,106,121$, $129,130,157,172,173,181$.

Mazan : 21, 24, 28.

Menton : 44, 154.

Metz: 40.

Milan : 14 .

Monaco : 44, 154.

Montaiguet (le) : 153, 157 .

Monte-Nero : 21.

Montélimar : 44, 76, 87.

Montmajour : 88, 90, 141.

Montpellier : 18, 27, 69, 71$76,79,86,88-90,96,100$, $101,128,129,131,157,163$.

Montreuil-Bellay : 178 .

Naples : 88, 144.

Napoule (la) : 46 .

Nice : $32,44,61,62,123$,

154.

Nìmes : 76, 157.

Nuremberg : 13.

Oizé : 37.

Ollières : 157 .

Orange : $45,62,76,87$.

Orgon : 49, 57, 181 . 
Padoue : 12, 13, 15, 17, 81, Salamanque : 100. 108. Salins d'Hyères (les) : 108.

Paris : $38,40,64,85,96,97$, Salon : 41, 49, 53, 75. 123, 131, 132, 136, 178, 179. Salto della Cerva : $31,32$.

Pavie : 181. Savone : 32,46 .

Peiresc, Castrum de Petrisco: Sebenico : 11. 80, 109, 110, 136.

Pennes (les) : 21, 23.

Pertuis : 171 .

Pise : 19, 21.

Pont-Saint-Esprit (le) : 48, Sienne : 16 . $50,51$.

Pourrières : 157.

Raguse : 57.

Ramatuelle : 41, 45, 55, 62, 154.

Ravenne : 54,55 .

Rhodes : 12.

Rhône (le): 45, 51, 52, 74, Toulon : 33, 80, 83, 96, 122, $75,86,87,99$.

Rians : $157-160$.

Riez : 169, 170 .

Rognes : 160.

Rome : 10, 27, 38, 44 .

Roquebrune : 44 .

Roussillon : 21, 24, 28, 50 .

Saint-Chamas : 75 .

Saint-Gilles : 75, 81, 99.

Saint-Martin-de-Crau : 75 , 99.

Saint-Maximin : 124.

Saint-Pilon (le) : 165.

Saint-Pons-de-Gémenos : 60, Watènes : 70. 61.

Saint-Tropez : 154.

Sainte-Baume (la): 61, 83, Zara : 11 .

160,165 .
Senez : 103, 141, 142, 170.

Séville : 90.

Seyne : 155.

Siemershausen : 38 .

Signes : 84, 107.

Sirpons (?) : 59, 60.

Soulletière (la) : 37 .

Spezzia (la): 44 .

Strasbourg : 89.

Thionville : 40 .

Tholonet (le) : 153.

129.

Tournon : 52 .

Touvoie : 38,46 .

Uzès : 48 .

Valbonette : 160 .

Valence (Dauphiné) : 76, 87.

Valence (Espagne) : 90.

Valfère : 160.

Venise : $12-17,53$.

Vienne : 15, 78.

Villefranche : 46 .

Zante : 11.

Zurich : 89, 90, 122. 



\section{INDEX ALPHABÉTIQUE}

DES NOMS BOTANIQUES NODERNES DES ESPÈCES CITÉES

Acer campestre L. : 117.

- monspessulanum L. : 117.

Agave americana L. : 124 .

Ajuga Iva Schreb. : 117.

Amygdalus persica L. : 47.

Aphyllanthes monspeliensis L.

117.

Arbutus Unedo L. : 50, 113.

Aristolochia Clematitis L. : 162.

- longa L. : 162.

- Pistolochia L. : 29, 162.

- rotunda L. : 162.

Artemisia Absinthium L. : 167.

- $\quad$ campestris L. : 167.

- camphorata Vill. :

167.

- gallica Willd. : 115, 167.

- glutinosa Gay : 115, 167.

Arum italicum I. : 160, 161.

- maculatum L. : 160, 161. Asarum europæum L. : 170. Asphodelus fistulosus L. : 106. Astragalus massiliensis Lamk :

74, 91.

Atriplex hastata L. : 175.

- hortensis L. : 175.

- patula L. : 175 .

- rosea L. : 175 .
Boletus luteus Fries. : 121.

— pachypus Fries : 121.

Bryonia dioica Jacq. : 159.

Bupleurum fruticosum L. : 24, 33, 49.

Campanula latifolia L. : 118.

- Medium L. : 118.

-- persicifolia L.: 118 .

- Trachelium L. :

118.

Carlina corymbosa L. : 27, 28.

- racemosa L. : 27 .

- sulphurea Desf. : 27.

Carthamus tinctorius L. : 170 .

Cedrus Libani Barr.: 61.

Celtis australis L. : 52.

Ceratonia Siliqua L. : 45.

Chamrerops humilis L. : 89.

Chenopodium Bonus-Henricus L. : 176.

Cistus albidus L. : 22, 33.

- monspeliensis L. : 22, 34.

- salviæfolius L. : 22, 33 .

- villosus L. : 22.

Clathrus cancellatus L.:106,120. Cneorum tricoccum L. : 45, 49, 153, 154.

Cnicus benedictus L.: 24, 26, 34. 
Convolvulus arvensis L. : 168. Juniperus communis L. 58 .

- $\quad$ Sepium L. : 168.
Soldanella L. :
163, 164.
Turpethum L. :
157.

Coronilla juncea L. : 30, 161.

- minima L. : 31 .

- valentina L. : 31 .

Crithmum maritimum L. : 117.

Cuscuta Epithymum L. : 117, 166.

Cytinus Hypocistis L. : 22, 34 .

Cytisus sessilifolius L. : 22,34 .

Daphne Gnidium L. : 116, 152, 153.

- Laureola L. : 160.
- Oxycedrus L. : 56.

- phrenicea L.: 56,57 .

- Sabina L. : 57.

Lavandula Stcechas L. : 118.

Lepidium Draba L. : 86.

Ligustrum vulgare L. : 117 .

Medicago marina L. : 73.

Mercurialis annua L. : 168 .

Morus alba L. : 173.

- nigra L. : 173.

Myrtus communis L. : 48,117 .

Narcissus poeticus L. : 115.

- Tazetta L. : 73, 115 .

Ecballium Elaterium Rich.: Obione portulacoides Moq. : 150. 101.

Euphorbia Characias L. : 102, Odontites rubra Pers. : 30. $116 . \quad-\quad$ serotina Rchb. : 30

- dendroides L. : 32, Olea curopæa L. : 115. 33.

- Helioscopia L. : Paliurus australis Rœm. ct 152.

Sch. : 43, 117.

- Lathyris L. : 151. Pancratium maritimum L. :

Euphrasia Odontites L. : $30 . \quad 163$.

Evonymus curopæus L. : 118. Paronychia argentea Lamk. : 99.

Fagus sylvatica L. : 169.

Fumaria spicata L. : 86.

Passerina annua Spreng. : 116.

- Tarton-raira DC. :

116.

Globularia Alypum L. : 117. Phillyrea angustifolia L. : 48, 115.

Helleborus niger L. : $154 . \quad$ Phlomis fruticosa L. : 24.

- viridis L. : 154,155 . Pinus Cedrus L. : 61.

Hippophae rhamnoides L. : - halepensis Mill.: 54, 65. 116.

Iris germanica L. : 158 ,

- maritima Lamk : 54 .

- Pinea L. : 54, 116.

- sylvestris L. ; 116 . 
Pistacia Lentiscus L. : 44, 115, Ruscus aculeatus L. : 28. 162.

- Terebinthus L. : 116. Sambucus Ebulus L. : 158.

Plumbago europæa L. : 100.

Polypodium vulgare L. : 168 . Santolina Chamæcyparissus L.

Polyporus officinalis Fries: 115, 167.

$169 . \quad$ Satureia capitata L. : 51.

- versicolor Fries : Scilla maritima L. : 163.

120. $\quad$ Senecio Cineraria DC. : 117.

Pterotheca nemausensis Cass.: Seseli tortuosum L.: 24, 99, 118. 117.

Smilax aspera L. : 116.

Quercus coccifera L. : 25, 33, Spartium junceum L. : 23, 161. $49,53,102,115 . \quad$ Styrax officinale L. : 118.

- Ilex L. : 53, 102, 115, 169.

Thapsia villosa L. : 156, 157.

Rhamnus Alatcrnus L. : 44, 48, Thymus vulgaris $L .: 51$. 116.

- alpinus L. : 165.

- Frangula L. : 165.

- Paliurus L. : 43.

Rhus Coriaria L. : 44, 116.

- Cotinus L. : 87.

Ricinus communis L. : 151.

Rubus idicus L. : 173.

Ulex parviflorus Pourr. : 23, 34.

Urginea Scilla Steinh. : 163.

Veratrum album L. : 155 .

Viburnum Lantana L. : 118.

Vitex Agnus castus L. : 52 . 



\section{TABLE}

Pages

LOUIS ANGUILLARA. . . . . . . . . 9

PIERRE BELON. . . . . . . . . . 37

CHARLES DE L'ESCLUSE . . . . . . . . 69

ApPENDice : Lettres (inédites) de N.-C. Fabri de

. Peiresc à Charles de l'Escluse . . . . . . . 129

ANTOINE CONSTANTIN . . . . . . . 139

Index des noms de personnes. . . . . . . . 183

Index des noms géographiques . . . . . . . . 187

Index alphabétique des noms botaniques modernes des espèces citées . . . . . . . . . 191 


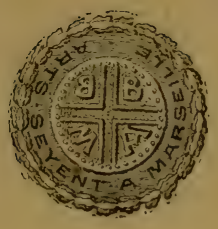

IMPRIMERIE LITHOGRAPHIE BARLATIER

MARSEILLE 



\section{DU MEEME AUTEUR}

\section{ÉTUDES D'HISTOIRE DE LA BOTANIQUE}

La Botanique en Provence au xvi siècle: Pienre Pena ET Mathias DE Lobel (Marseille, 1899, in-80, vili-263 p.).

La Botanique en Provence au xvie siècle : Hugues de Solien (Marseille, 1899 , in- $8^{\circ}, 45$ p.).

(Ces deux ouvrages ont obtenu de l'Académie des Inscriptions et BellesLettres la première mention au concours des Antiquiles de la lirance, en 1899.)

Le vallon du Dragon a Rognes (Boucues-du-Rhône) (Marseille, 1897 , in- $8^{\circ}, 6$ p.).

Notice sur le botaniste provençal Jean Saurin, de ColMARS, 1647-1724 (Paris, 1899, in-80, 15 p.).

La Botanique en Provence au xvi siècle : Félix et Thomas Platter (Marseille, 1900, in-8", vili-93 p.).

Un botaniste flaMand DU Xvi ${ }^{\circ}$ SiÈcle : Valerand Dourez (Lille, 1900, in-8n, 18 p.).

La Botanique en Provence au xvilie siècle : Pierre Forsikal et LE Florula Estaciensis (Marseille, 1900, in-80, 27 p.).

La Botanique en Provence au xvi siècle: Léonard RauwolfF - Jacques Raynaudet (Marseille, 1900, in- 8 . . $\mathrm{X}-149$ p.).

La Botanique en Provence au xvirie siècle: Le Frère Gabiziel, Capucin (Marseille, 1901, in-8`, 8 p.).

L'Indigénat en Provence du Styrax officinal : Pierre Pena et Fabri de PeIresc (Marseille, 1901, in-8o, 23 p.).

\section{EN PRÉPARATION}

La Botanique en Provence au xre siècle:

Jean Bauhin. - Gaspard Bauhin.

Pierre de Quiqueran de Beaujeu.

FLORULA MASSILIOTICA: Histoire des plantes auxquelles la nomenclature botanique a donné une dénomination spécifique dérivée du nom de Marserlle. 
Legre, Ludovic/La botanique en Provence

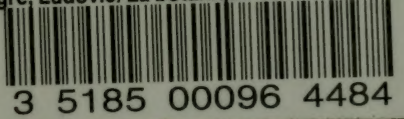


